\title{
International Community Guidelines for Sharing and Reusing Quality Information of Individual Earth Science Datasets
}

\section{International FAIR-DQI Community Guidelines Working Group ${ }^{1}$}

Ge Peng, Carlo Lacagnina, Ivana Ivánová, Robert R. Downs, Hampapuram Ramapriyan, Anette Ganske, Dave Jones, Lucy Bastin, Lesley Wyborn, Irina Bastrakova, Mingfang Wu, Chung-Lin Shie, David Moroni, Gilles Larnicol, Yaxing Wei, Nancy Ritchey, Sarah Champion,

C. Sophie Hou, Ted Habermann, Gary Berg-Cross, Kaylin Bugbee, and Jeanné le Roux

Document ID: FAIR-DQI_Guidelines

Version: v01r02-20220326

Usage License: CC-BY 4.0

\section{Document History}

\begin{tabular}{|l|l|l|}
\hline Version & Contributors & What Is New \\
\hline v0r05-20210417 & $\begin{array}{l}\text { Members of International } \\
\text { FAIR-DQI Community } \\
\text { Guidelines Working Group } \\
\text { (FAIR-DQI WG) }\end{array}$ & $\begin{array}{l}\text { First complete draft of the FAIR dataset } \\
\text { quality information community guidelines } \\
\text { document (FAIR-DQI Guidelines) for } \\
\text { community review. }\end{array}$ \\
\hline v01r00-20211001 & $\begin{array}{l}\text { Members of the FAIR-DQI } \\
\text { WG }\end{array}$ & $\begin{array}{l}\text { First baseline of the FAIR-DQI } \\
\text { Guidelines document. Changes were made } \\
\text { to address edits and comments provided } \\
\text { by reviewers from the community and } \\
\text { working group members. Review } \\
\text { comments and responses are captured in } \\
\text { Appendix I. }\end{array}$ \\
\hline V01r01-20220316; & Ge Peng & $\begin{array}{l}\text { Implemented comments from the FAIR- } \\
\text { DQI WG members including minor } \\
\text { editorial edits and additional examples for } \\
\text { the guidelines 1-5. Detailed FAIR-DQI } \\
\text { WG member contributions. Impacted: } \\
\text { Section 4 and Acknowledgement. }\end{array}$ \\
\hline & & \\
\hline
\end{tabular}

\footnotetext{
${ }^{1}$ A list of author names, affiliations, sectors, roles and/or subject areas, and ORCIDs can be found in Appendix G
} 


\section{Disclaimer}

This document facilitates the development, update, and effective use of the international community guidelines for promoting the representation and sharing of quality information by enabling global access to and harmonization of quality information at the level of individual Earth science datasets. The document is provided without any representations or warranties, express or implied. The views expressed herein are those of the authors and do not necessarily reflect that of the Earth Science Information Partners (ESIP) and the affiliated organizations of the authors. The use cases and examples are provided for references with no endorsement or preference intended. The document is subjected to future evolution without notification as knowledge improves and community requirements expand and/or change.

\section{Feedback and Maintenance of the Document}

This document is a living document. Please provide your comments and suggestions to: Ge Peng at gpeng93@gmail.com; Carlo Lacagnina at carlo.lacagnina@bsc.es, or Ivana Ivánová at ivana.ivanova@curtin.edu.au. The latest version can be downloaded from the Open Science Framework (osf.io) with the following persistent digital object identifier (DOI): https://doi.org/10.31219/osf.io/xsu4p. The document along with additional resources are also maintained at https://wiki.esipfed.org/FAIR_Dataset_Quality_Information

\section{Recommended Citation for This Document}

Peng, G., C. Lacagnina, I. Ivánová, R. R. Downs, H. Ramapriyan, A. Ganske, D. Jones, L. Bastin, L. Wyborn, I. Bastrakova, M. Wu, Chung-Lin Shie, D. Moroni, G. Larnicol, Y. Wei, N. Ritchey, S. Champion, C. Hou, T. Habermann, G. Berg-Cross, K. Bugbee, and J. le Roux, and International FAIR-DQI Community Guidelines Working Group, 2021: International Community Guidelines for Sharing and Reusing Quality Information of Individual Earth Science Datasets. Document ID: FAIR-DQI-Guidelines. Updated: 2022. Version: v01r02 20220326. Open Science Framework. DOI: https://doi.org/10.31219/osf.io/xsu4p 


\section{TABLE OF CONTENTS}

1. EXECUTIVE SUMMARY 4

2. BACKGROUND $\quad 5$

3. SCOPE, RATIONALE, GOALS, AND INTENDED AUDIENCES 6

3a. Scope 6

3b. Rationale $\quad 7$

3c. Goals $\quad 10$

3d. Potential Impacts of the Guidelines 10

3e. Intended Audiences of the guidelines 10

4. FAIR DATASET QUALITY INFORMATION GUIDELINES 11

4a. Basic Elements to Consider When Curating Dataset Quality Information 11

4b. Quality-Attribute Agnostic Guidelines 13

4c. Assessment-Type Agnostic Guidelines 14

4d. Full Dataset Lifecycle Approach 14

4e. Common Terminology 15

4f. Guidelines for Enabling FAIR Dataset Quality Information 15

4h. Additional Examples on Representing Assessment Results in Metadata 21

5. CONCLUSIONS AND DISCUSSION 25

ACKNOWLEDGMENT $\quad 26$

REFERENCES $\quad 28$

$\begin{array}{ll}\text { APPENDICES } & 35\end{array}$

Appendix A. Terms and Definitions $\quad 35$

Appendix B. FAIR Principles and Earth Science Implementation Examples 40

Appendix C. Dataset Quality Attributes, Aspects, and Dimensions 44

Appendix D. Dataset Quality Assessment Types 49

Appendix E. Additional Examples of Quality Assessment Models 52

Appendix F. Community Controlled Vocabularies and Content Standards 53

Appendix G. List of Author Names, Affiliations, Roles and/or Subject Areas and ORCIDs 54

Appendix H. Acronyms 56

Appendix I. Community Comments and Responses 59 


\section{EXECUTIVE SUMMARY}

Under the auspices of the Earth Science Information Partners (ESIP) and with collaboration among members of the ESIP Information Quality Cluster (IQC), the Barcelona Supercomputing Center (BSC) Evaluation and Quality Control (EQC) team, and the Australia/New Zealand Data Quality Interest Group (AU/NZ DQIG), a community effort has been undertaken by international Earth Science domain experts. The objective of this effort is to develop global community guidelines with practical recommendations to promote the representation, sharing and reuse of quality information at the dataset level, leveraging the experiences and expertise of a team of interdisciplinary domain experts and community best practices. The community guidelines are inspired by the guiding principles of findability, accessibility, interoperability, and reusability (FAIR) and aim to help stakeholders such as science data centers, repositories, data producers and publishers, data managers and stewards, etc., i) to capture, describe, and represent quality information of their datasets in a way that is in line with the FAIR guiding principles; ii) to allow for the maximum discovery, trust, sharing, reuse and value of their datasets; and iii) to enable global access to and integration of dataset quality information. The vision of developing these guidelines is to promote the creation and use of freely and openly shared dataset quality information that is consistently described, readily available in community standardized formats, and capable of being integrated across commonly-used Earth science systems and tools for search and access with explicitly expressed usage licenses. 


\section{BACKGROUND}

Knowledge about the quality of data and metadata is important to support informed decisions on the (re)use of individual datasets and is an essential part of the ecosystem that supports open science. Quality assessments reflect the reliability and usability of data and need to be consistently curated, fully traceable, and adequately documented, as these are crucial for sound decision- and policy-making efforts that rely on data. Quality assessments also need to be consistently represented and readily integrated across systems and tools to allow for improved sharing of quality information at the dataset level (Henzen et al. 2021, Wagner et al. 2021; Peng et al. 2021) for individual quality attributes, aspects, or dimensions such as those defined in Wang and Strong (1996) and Ramapriyan et al. (2017). ${ }^{2}$ The need to improve data quality information also extends to crowdsourcing data products such as those from citizen science projects (Downs et al. 2021), which have become increasingly important for augmenting traditional Earth and geospatial science for a wide range of research and applications.

Although the need for assessing the quality of data and associated information at the individual dataset level is well recognized, methodologies for an evaluation framework and presentation of resultant quality information to end users (e.g., Figgemeier et al. 2021) may not have been comprehensively addressed within and across disciplines. Global interdisciplinary domain experts have therefore come together in a workshop to systematically explore needs, challenges and impacts of consistently curating and representing quality information through the entire lifecycle of a dataset. The outcomes of the workshop were reported in Peng et al. (2020). A call-to-action statement paper (Peng et al. 2021) has been published by the Committee on Data of the International Science Council (CODATA) Data Science Journal in response to the CODATA's call for a special open science collection: Open Science for a Global Transformation. ${ }^{3}$

Motivated by the needs and interest from the global Earth science community, a working group was formed as the result of several open calls to the community, especially to the ESIP community, on various occasions. The current members of the working group consist of international domain experts such as data producers, publishers, managers or stewards from national science and/or data centers, domain or institutional repositories, as well as data users from the academic and private sectors. Collectively, they bring together many years of valuable experience in production, management, services, and applications of various types of Earth science data including satellite, in situ, and model data, along with knowledge of the challenges and best practices in their domains.

Since September 2020, the working group members have been working collaboratively to develop practical guidelines to curate, represent, and report dataset quality information in a manner that is consistent with the FAIR guiding principles of being findable, accessible, interoperable, and reusable as defined in Wilkinson et al. (2016). These guidelines build on the success of the FAIR guiding principles on data sharing and the extensive expert knowledge and working experiences of the working group members, leveraging community best practices. This document captures the outcomes of this international community effort.

\footnotetext{
2 Additional information on data quality attributes, aspects, and dimensions can be found in Appendix C.

${ }^{3} \mathrm{http}$ //codata.org/blog/2020/10/28/open-science-for-a-global-transformation-call-for-papers-for-a-specialcollection-in-data-science-journal/
} 
The document is organized as follows. An executive summary has been provided in Section 1. A brief background is provided in this section. The scope, rationale, goals, and intended audiences for the community guidelines are described in Section 3. Guidelines developed are quality-attribute agnostic and assessment-type agnostic. There are needs for a full lifecycle approach and common terminology with controlled vocabulary. Additional information about those points, basic elements to consider, and the guidelines are provided in Section 4. Summary and Discussion are presented in Section 5. Followed by acknowledgement and references. Additional information such as key terms and definitions, the FAIR data guiding principles, explanation, and Earth sciences community implementation examples, quality attributes and dimensions, quality assessment types, and additional examples of quality assessment models, as well as acronyms used in this document are included in Appendices.

\section{SCOPE, RATIONALE, GOALS, AND INTENDED AUDIENCES}

\section{3a. Scope}

A dataset in this document refers to an identifiable collection of data (ISO 19115-1 2014), and it can be published or curated by a single agent (W3C 2020). A dataset can be the digital rendition of a data product of a given version of an algorithm, model, experiment, or observations (descriptions of key terms used in this document can be found in Appendix A). Here we focus on dataset quality, not just on data quality, because we consider information about quality or the state of data (input and output), metadata/documentation, software, procedures, processes, and infrastructure throughout the entire lifecycle of a dataset. A dataset lifecycle in this document starts during the planning and design stage of a data product after data collection (Figure 1). Therefore, it will not touch on sensor algorithms or model development and deployment. However, it is important to note that quality information during these development and implementation stages is important to be captured and described as well, because they are critical to estimating data product uncertainty and error progression to downstream applications (e.g., Matthews et al. 2013).

The dataset lifecycle shown in Figure 1 (the outermost circle) includes three important stages for each one of the four quality aspects defined in Ramapriyan et al. (2017) (the second outermost circle), which are represented by the blue circle. ${ }^{4}$ ) Those dataset lifecycle stages are not necessarily linear or in sequence and may also occur in more than one quality aspect. The feedback and improvement cycle can occur in any one of the stages. One may turn to Peng et al. (2018) for a conceptual framework for managing scientific data stewardship activities, utilizing the Plan-DoCheck-Act (PDCA) cycle (Deming 1986).

\footnotetext{
${ }^{4}$ Additional information on data quality attributes, aspects, and dimensions can be found in Appendix C.
} 


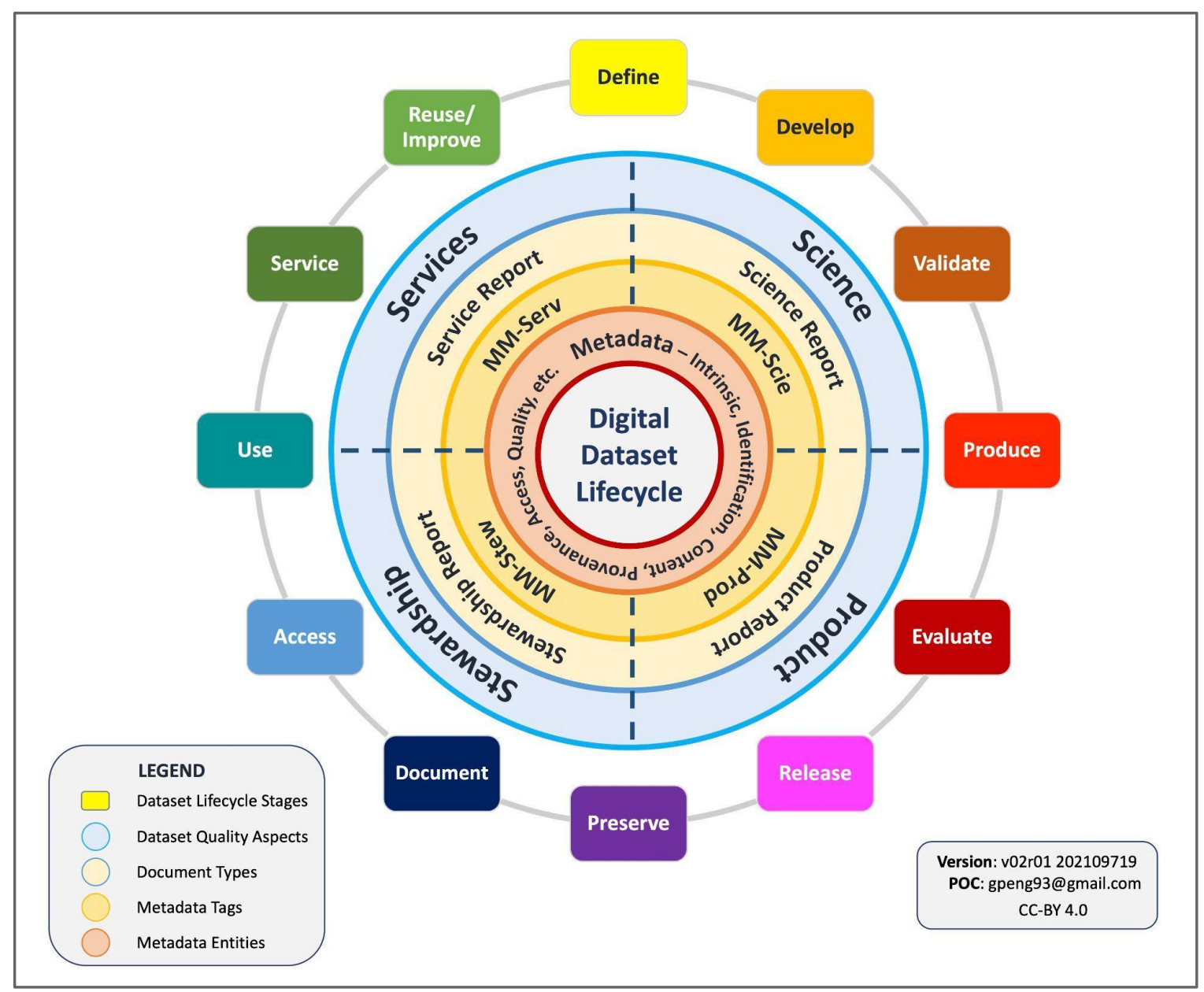

Figure 1: A schematic diagram of dataset lifecycle stages, quality aspects and associated documentation types and metadata tags (MM-*), and metadata entities. See Table C1 for a description of quality aspects and associated documentation types. Creator: Ge Peng; Contributors: Anette Ganske, Lesley Wyborn, and Mingfang Wu.

\section{3b. Rationale}

Quality information at the individual dataset level (hereinafter referred to as dataset quality information) such as accuracy, completeness, timeliness, and provenance, is imperative for establishing trust and enabling accurate use and reuse of data (Digital Science et al. 2019). To support effective decision- and policy-making processes, dataset quality information, such as information about the state of data, metadata, documentation, software, workflows, and tools used for producing and managing the data; and how the data being curated and serviced, should be consistently captured in the metadata and be a part of the ecosystem that supports open science (e.g., WMO 2019; Henzen et al. 2021; RDA Discipline-specific Guidance for Data Management Plans Working Group; ${ }^{5}$ WMO expert team on metadata standards ${ }^{6}$ ).

\footnotetext{
${ }^{5}$ https:/www.rd-alliance.org/groups/discipline-specific-guidance-data-management-plans-wg

${ }^{6}$ https:/community.wmo.int/governance/commission-membership/commission-observation-infrastructures-andinformation-systems-infcom/commission-infrastructure-officers/infcom-management-group/sc-imt/ET-Metadata
} 
Assessment of data quality is key for ensuring that the available data and information are credible and such assessments are essential when establishing trust for reuse of the data (Callahan 2017). Trusted data are perceived as worthy of use in decision making environments where the metadata is sufficient to adequately describe the data, e.g., information about the dataset author and data timeliness. Describing the quality of a data product and providing access to such quality information can support potential users of a particular dataset to determine whether it is appropriate for their planned usage, i.e., fitness for purpose.

Peng et al. (2021) describes a real-life use case of how trusted, timely and readily integrable data and quality information is critical to disaster responses by utility companies with billions of dollars at stake. For disaster response managers, any information needs to be trusted and readily integrated, and understood in layman's terms in a matter of a minute. Accuracy and timeliness of data and information is extremely important. Any data that are selected to be a part of their decision-making processes need to be trusted. Managers will not trust just any available datasets as their decisions can have an impact on the safety and survival of at-risk populations, can cost up to millions of dollars, and influence the reputation of their organizations.

For this use case, datasets are pre-vetted with an operational readiness level (ORL) ranking that is readily available and easily understood by decision makers who are generally non-data experts. An assigned ORL leads such decision makers to rapidly trust datasets. Data and information are integrated into a system to provide an easy-to-understand dashboard to disaster response managers to allow them to make decisions promptly. Thus, providing quality information with the data establishes the trust needed for supporting such potentially life-saving emergency response activities and maximizes the benefit of sharing data.

Pre-vetting datasets and developing the dashboard requires years of work and ongoing effort in addition to cultivated human relationships. Readily available and consistently curated quality information of an individual dataset will help improve the process of establishing trust necessary to support tools and services provided to disaster preparation and response efforts, saving time and money. It will also support effective (re)use of the dataset for other applications, resulting in wide community utilization and therefore maximizing the value of the dataset.

To estimate the annual cost of not sharing data, a systematic analysis was carried out under the European Commission. The cost of not sharing data was found to be a minimum of $€ 10.2 \mathrm{bn}$ per year (European Commission and PwC EU Services 2018). On average, data scientists spent 60$70 \%$ of their effort on dealing with data quality related issues (e.g., Press 2016). Thus, not sharing data quality information will compound that loss, especially productivity loss due to redundancy in assessing data quality or having to reject the data in the absence of quality information.

For dataset quality information to be effectively (re)used, it needs to be consistently curated, fully traceable, adequately documented, updated timely, able to support users to address their specific needs, and where possible, machine readable. This is, however, a daunting objective because it necessitates both a wide range of data quality attributes and heuristic information to ascertain fitness for purpose, while facing challenges in cross-disciplinary (and even in-discipline specific) knowledge integration (Peng et al. 2020). 
It also needs to be considered throughout the whole dataset life cycle, from creation to archiving to servicing, and covering multiple dimensions (e.g., product generation, scientific content curation, data stewardship, services used to access the data) (Peng et al. 2021; see additional discussion in section $4 d$ ).

However, dataset quality information is not routinely curated, albeit some efforts (Figgemeier et al. 2021, Wagner et al. 2021) have been recently made, and much less represented in a human- and machine-readable manner, despite the fact that international standards or vocabularies for describing the quality of geographic data have been in place since 2003 (e.g., ISO 19157: 2013; ISO 19115-1:2014; W3C 2016). The lack of adoption of one or more data quality standards may in part reflect the diversity of approaches, availability of resources, technologies, networks, and research questions of investigators (Leonelli 2017), as well as the context for the planned purpose and use of the data (Canali 2020; Illari 2014). Lack of motivation to document quality can be caused by the lack of prescriptiveness of existing standards - documentation of data quality metadata has always been optional in the ISO 19100 series and as of 2014, the ISO 19115-1 standard for metadata does not define a minimum set of discovery metadata. Several other issues also may contribute to challenges for assessing and reporting data quality, and ultimately for the curation of dataset quality information. A frequently cited barrier against documenting the quality of spatial data is that it mostly requires special domain-expert technical knowledge, while documenting general metadata can be done automatically or by non-specialists (Coetzee 2018, Wagner et al. 2021). Therefore, practical community guidelines on how to curate, report and disseminate dataset quality information in a way that enables sharing and harmonizing the information across Earth science communities are needed and beneficial.

The FAIR data guiding principles defined by Wilkinson et al. (2016) emphasize the importance of data sharing in a machine-friendly environment. Since their inception, the FAIR data guiding principles have been adopted by international entities and have had a major impact in promoting data sharing and reuse globally (e.g., G20 Leaders 2016; Australia FAIR Access Working Group 2017; European Commission 2018; 2020; Mons 2018; U.S. Public Law 115-435 2019; CODATA 2019). See Appendix B for the definition of the FAIR data guiding principles and implementation examples in the Earth science community.

However, the FAIR data guiding principles are somewhat limited in that they call for only meta(data) to be associated with detailed provenance and "richly described with a plurality of accurate and relevant attributes" (Wilkinson et al. 2016). They do not explicitly address the sharing of meta(data) quality information. For example, if the FAIRness of a dataset has been evaluated, what can be done to ensure the method used and assessment results are readily findable, accessible and (re)usable to end users? What can be done to ensure that the information about the method and assessment results can be readily integrated across different tools and systems within and out of individual organizations?

Therefore, building on the direction that the FAIR guiding principles have provided for data sharing, we would like to go one step further and set a stage for all dataset quality information to be FAIR to enable or improve the sharing of quality information of individual datasets. 


\section{3c. Goals}

This effort aims to develop guidelines for the Earth science community, in collaboration with international domain experts on data and information quality. The primary goal of the guidelines is to offer the Earth science community actionable recommendations that can be adopted by a variety of stakeholders to consistently capture and represent dataset quality information. This should be done in a way that is in line with the FAIR guiding principles to improve its sharing and reuse with more targeted practicality. The optimal goal is to allow for global access to and harmonization of quality information of individual datasets as an important step towards open science in both machine- and human-friendly environments.

\section{3d. Potential Impacts of the Guidelines}

Availability of quality information can assist users when deciding whether and how to use a dataset. This is achieved by informing users about the selection of the methodology to be applied, including particular approaches, tools, and techniques for analyzing the data or for using the dataset in conjunction with other datasets, for example.

Improving reuse of data by providing access to quality information about a dataset primarily contributes to the Transparency, Responsibility, and User focus aspects of the TRUST Principles for Data Repositories. It could also contribute to its Sustainability, by enabling future use, and to the application of Technology for using the data (see Lin et al. 2020 for a detailed description of the TRUST Principles). In particular, the disclosure of quality information at the dataset level helps those who developed and curated the data to achieve transparency, which in turn will improve the stewardship maturity of the dataset (Peng et al. 2015). Providing clear guidance facilitates understanding about the quality of data products and their corresponding metadata. Providing such information about a dataset is necessary for its correct use and, therefore, it is a fundamental responsibility of data producers and curators. Describing quality aspects of the data also provides a crucial service to support potential data users when they are deciding whether a particular data product could meet their needs.

FAIR dataset quality information can also help improve the sharing of the data in several ways. When data can be discovered based on information about certain quality attributes, the findability of the data is improved for users who need data that contain such attributes. Accessibility and usability of data is improved by describing issues and conditions that could affect the use of the data. Describing quality information in standardized formats, schemas, and terminology with controlled and even harmonized vocabularies, improves the interoperability of the data. The reusability of data is facilitated by describing limitations on use as well as appropriate and inappropriate uses and usage of the data.

\section{3e. Intended Audiences of the guidelines}

All data stakeholders may benefit from the community guidelines:

- Data producers will find these guidelines useful to ensure that, at the point of acquisition, they are capturing those critical attributes that will later be used to ascertain the quality of the data that they are capturing (e.g., uncertainty of location/measurements, instrument parameters, metadata attributes on the instrument used to acquire the data). The same applies to those producers that generate multiple products from raw measurements. Data 
quality guidelines also will help data producers to clean up their data prior to submission to a repository and to document data quality and share data quality information.

- Data publishers and data curators may find the community guidelines valuable for improving the quality information associated with the data that they publish and manage;

- Journal editors and reviewers may refer to the guidelines when assessing data that are associated with manuscripts under evaluation for potential publication;

- Sponsors and funders may find the guidelines helpful when reviewing data management plans in proposals for support of projects and programs that will be creating, curating, disseminating, and supporting the use of data. They will also find them useful at project closure phase when assessing the quality of the data produced against the initial project aims and data management plans; and

- Data users/consumers also may find that the guidelines improve their understanding of quality issues when determining whether a particular data product or service is appropriate for their intended use and what the limitations may be.

\section{FAIR DATASET QUALITY INFORMATION GUIDELINES}

\section{4a. Basic Elements to Consider When Curating Dataset Quality Information}

Assessing dataset quality is a multi-dimensional problem. Despite the multi-dimensionality of quality, there are aspects that are common when assessing datasets. Knowledge about the common aspects may help to set the direction for the right approach to follow in each specific case. In this section, the basic elements are outlined for developing data quality management processes and curating dataset quality information.

Lee et al. (2002) presented how data quality management (DQM) may be organized into four phases: define, measure, analyze, and improve. Inspired by the quality evaluation procedures defined in ISO 19157 (2013), Six Sigma (e.g., Cordy et al. 2006) and to help organizations and data stewards address the challenge of where to start, we have developed a typical workflow (Figure 2). It highlights the basic ingredients and elements to be considered when curating dataset quality information. We add the dissemination, a.k.a. "reporting" in ISO 19157 (2013), of dataset quality information, which is becoming an increasingly important task to build trust between data providers and end-users and to increase data usability. ${ }^{7}$

As shown in Figure 2, the following two phases are needed prior to carrying out any assessment activity.

- Quality specification - Curating dataset quality information should start with defining what quality attribute(s), aspect, or dimension will be assessed and at which level of granularity (variable, ensemble member, model or algorithm), and which data and quality attribute should be prioritized. This step will need some profiling, i.e., an initial analysis of the available data to understand the challenges and the most critical issues to set priorities and figure out the best strategy forward.

\footnotetext{
7 https://is.enes.org/ (the Infrastructure for the European Network for Earth System Modelling (IS-ENES) programme)
} 
- Evaluation specification - The next step is to identify or develop an approach or method to evaluate the identified quality attribute(s) or assess its maturity, for example, statistical analysis approach (Wu et al. 2017) or scientific maturity matrix (Zhou et al. 2016). This is the step where the framework for the evaluation is defined. It is important to describe in this step the identified quality attribute or dimension, the evaluation method used, and the protocols, standards and workflows applied (e.g., Wu et al. 2017; Zhou et al. 2016; Lemieux et al. 2017; Popp et al. 2020). A well-documented quality evaluation helps to increase transparency, verifiability, reproducibility and resilience of the quality evaluation process.

The next two steps are important to capture and convey the resultant quality information.

- Evaluation execution - At this stage the actual assessments are performed based on the tools, approaches and priorities defined in the previous phases. While doing this, the assessments should be captured in structured, human- and machine-readable, and standard-based formats (e.g., Peng et al. 2019a; Heydebreck et al. 2020).

- Quality dissemination - The results of the assessments represent the core of the dataset quality information and need to be disseminated along with the data for the benefit of the end-users and data providers to enable effective data discovery and use. For reproducibility purposes, the operations performed to produce the quality information also are recommended to be published. In this step, the way that quality information is disseminated (e.g., metadata, web page) is implemented and put into practice.

The feedback from the users should be sought and harvested to improve the assessment provided.

- Monitoring and improvement - The feedback collected in the previous steps and the experience gained during the assessments are rationalized to consider improvements of the protocols, tools, and approaches and to redefine priorities in the assessment process. This step is continuous during the assessment to dissemination steps and helps to improve the curation of quality information, thereby increasing the reliability of the data repository. 


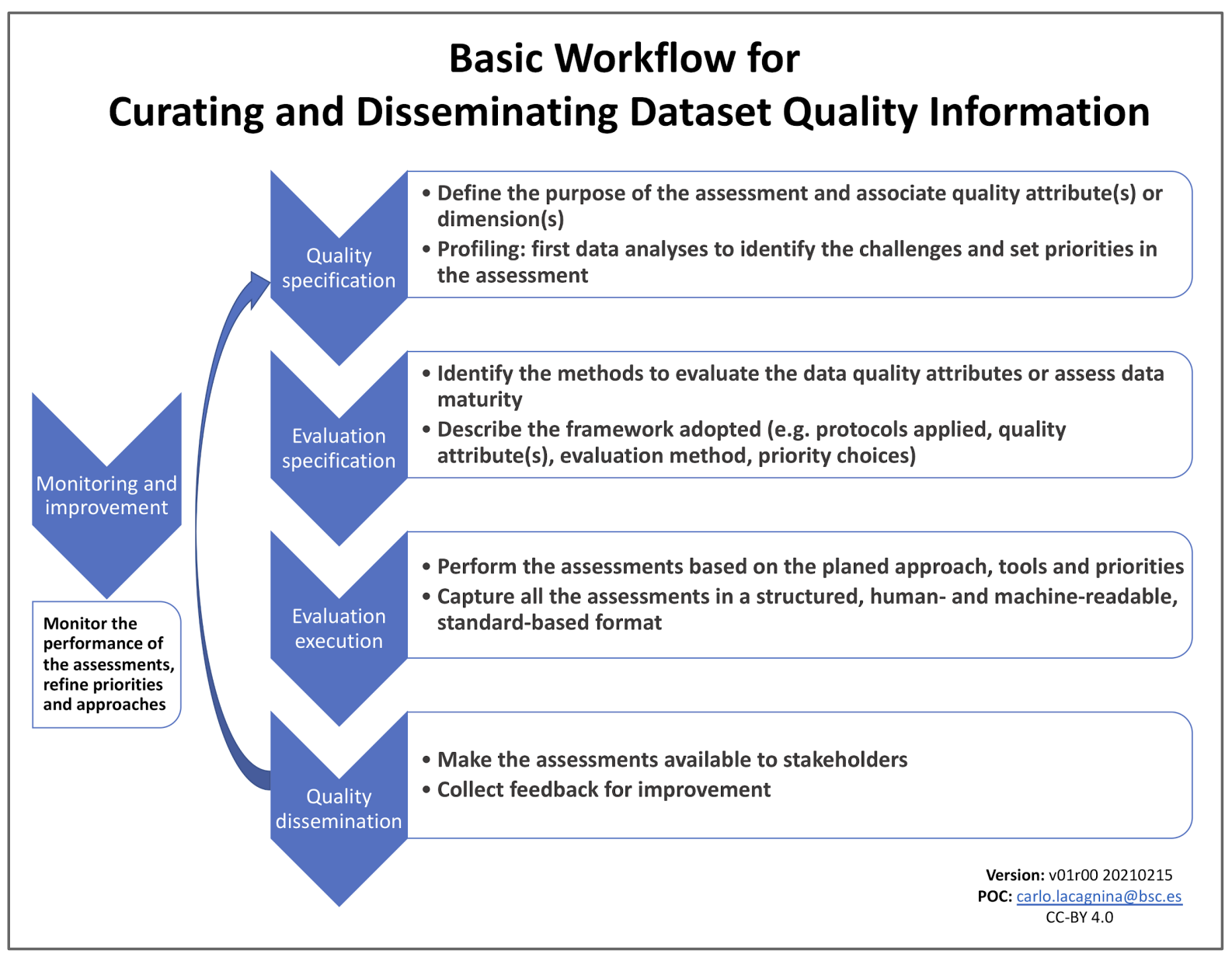

Figure 2: A schematic diagram of workflow and basic ingredients for curating and disseminating dataset quality information. Creator: Carlo Lacagnina; Contributor to conceptual design: Ge Peng.

\section{4b. Quality-Attribute Agnostic Guidelines}

As mentioned previously and in Appendix C, assessing dataset quality is a complex, multidimensional problem. The selection of the relevant attributes is context-dependent and it leads to different categorizations and practical dimensions (Redman 1996) (See Appendix C for an outline of relevant quality attributes, aspects, and dimensions). The complexity exists even for a single quality attribute within one discipline in terms of its definition and how to measure and represent it consistently. An example of this is on data uncertainty as explored by Moroni et al. (2019).

The selection of the relevant attributes is context-dependent because datasets are often crafted for specific designated communities. Traditionally, designated communities of data consumers are domain literate and have some familiarity with the scientific context, data generation, or intended data use. As discussed by Baker et al (2016), designated communities can change over time. With the increasing availability of data today, the existence of interested audiences representing a variety of scientific backgrounds outside the domain of data collection must be considered in order for scientific knowledge to be widely conveyed and understood by broader audiences.

Lessons learned from various data curation initiatives indicate that an alternative approach is to equip data consumers with readily available information that is consistently captured, in a way that can be easily understood by a variety of end-users and integrated across tools and systems, 
regardless of the quality attribute and the assessment approach. How to tailor the dataset quality information to the designated community is left to the specific entities who serve that particular community. To support such a decision process, a description of what quality attribute or dimension is assessed and what assessment approach is utilized, should be captured in machinereadable quality metadata and/or a human-readable quality report in a consistent way for transparency and enhanced interoperability.

\section{4c. Assessment-Type Agnostic Guidelines}

Similar complexity exists for the types of assessments that one can carry out throughout the entire data lifecycle (see Appendix D for a comprehensive description of relevant assessment types). The assessments can be individual checks for different dimensions such as:

- Accuracy checks for data values, variable names, corresponding units of the variables, content of metadata elements, etc.;

- Completeness checks for data values, metadata entities, temporal and spatial coverage, etc.;

- Conformity checks for compliance to community standards for data format or variable standard names, metadata structure or syntax, keywords, etc.;

- Consistency checks for data values, data fixation (integrity), metadata syntax, data and metadata representation, etc.

Accuracy, completeness, conformity and consistency checks for data values are usually performed during the data production process (e.g., Durre et al. 2010). On the other hand, accuracy, completeness, conformity and consistency checks for metadata are usually performed during the data preservation stages, often associated with data management and stewardship (e.g., O'Brien et al. 2016, Stockhause et al. 2012). Automating such checks, when possible, can improve the efficiency of the data quality process.

\section{4d. Full Dataset Lifecycle Approach}

Dataset quality can be affected by activities that are conducted throughout the data lifecycle. For example, lack of a quality assurance and control (QA/QC) procedure when generating the data product may impact the scientific quality of the data, while lack of the information about the QA/QC procedure will influence the quality of metadata and potentially reduce the level of user's confidence in trusting and using the data. In addition, data can be corrupted at any stage of the data lifecycle. In order for users and decision-makers to trust the data and the scientific findings resulting from analysis of this data, it is essential to establish and demonstrate, in a consistent and transparent way, the credibility of not only the data itself, but also the whole process of producing, managing, stewarding, analyzing, and servicing the data (Tilmes et al. 2015a). Therefore, a dataset lifecycle approach to dataset quality assessment is necessary. Furthermore, a dataset lifecycle approach to dataset quality assessment can facilitate effective recording of dataset quality information during various dataset lifecycle activities. The details of such information could be lost during later stages in the dataset lifecycle if they are not recorded in a timely fashion when the dataset quality events or assessments occurred. Moreover, managing quality throughout the entire dataset lifecycle is imperative for ensuring that the information and knowledge gained are not contaminated by inaccurate or corrupt data, as well as for facilitating accurate uncertainty estimates in the derived analyses. The value of lifecycle approaches to data quality has been recognized for various kinds of data, including remote sensing observations (Barsi et al. 2019), 
health services (Kahn et al. 2015), and health and biomedical citizen science (Borda et al. 2020). Data lifecycle approaches to quality assessment also could be informed by lifecycle approaches to software quality (Lenhardt et al. 2014).

\section{4e. Common Terminology}

Consistent terminology is essential for enabling interoperability. The lack of an overarching consistent dataset quality vocabulary is identified as one of the priority gaps in data quality (Nightingale et al. 2019). It is recommended to seek out and adopt existing common and controlled vocabularies and content standards for the Earth science community. Examples can be found in Appendix F.

Being semantically and syntactically consistent is another complex challenge facing various domains during the whole dataset quality information curation and representation workflow that is conducted throughout the entire dataset lifecycle. Semantic and syntactic consistency are critical for enabling interoperability across systems and tools within and across individual organizations. It is beyond the scope of this document to provide exhaustive research in this area and detailed guidance. Nevertheless, an example is given in Figure 1 to demonstrate how dataset lifecycle stages (the outermost circle) can be mapped to the four dataset quality aspects (shaded blue circle) and how each quality aspect can be matched with associated document (light yellow shaded circle) and metadata tags (MM-*, light orange shaded circle). Metadata is developed throughout the entire dataset lifecycle with core metadata entities listed (light red shaded circle). (Descriptions of the terms in Figure 1 can be found in Table $\mathrm{C} 1$ in Appendix C.) Figure 1 is intended to depict an example of a holistic and systematic view to potentially change the culture and the way that quality information evaluation and curation is approached. Taking such an approach can serve as a first step in moving towards community consensus for developing terminology and syntax to describe, report, and disseminate dataset quality information.

\section{4f. Guidelines for Enabling FAIR Dataset Quality Information}

The following guidelines are developed by the International FAIR-DQI Community Guidelines Working Group to enable curated dataset quality information to be FAIR, namely, findable, accessible, interoperable, and reusable, to both human and machine end users. Examples are provided for references with no endorsement or preference intended. Some of the examples are quite preliminary and still maturing as they represent the current state of our awareness. The list is not necessarily exhaustive, but can serve as a starting point to help interested parties to improve the data quality process and optimally lead to community convergence. Additional examples may be added when they are provided by the Earth science community.

Guideline 1: Describe dataset (title, persistent identifier [PID] with a comprehensive landing page, e.g., digital object identifier [DOI], product uniform resource identifier [URI], version, data producer, publication/update date, publisher, date accessed, usage license, e.g., CC-BY 4.0 or $\mathrm{CC} 0)$.

\section{Examples:}

- Ensemble Mean of CMIP5 TOS for the Period 1971 to 2000. http://doi.org/10.5281/zenodo.12843, v1, Bruno Combal. November 24, 2014. Zenodo, CC-BY 4.0 International. 
- Airborne Sea Ice Plus Snow Thickness During the PAMARCMIP 2017 Aircraft Campaign in the Arctic Ocean. https://doi.org/10.1594/PANGAEA.924848, v1, Hendricks et al. 2020. PANGAEA. CC-BY 4.0 International.

- NOAA/NSIDC Climate Data Record of Passive Microwave Sea Ice Concentration, Version 3. Meier et al. 2017. Boulder, Colorado, USA: National Snow and Ice Data Center (NSIDC). doi: https://doi.org/10.7265/N59P2ZTG

Notes: It is recommended to use a consistent title for the dataset throughout the entire workflow, including that in the dataset-level metadata record and quality assessment report document. Sometimes it may be desirable to include a short name or unique identifier which may be used as an internal tag for the dataset and/or a part of naming convention for a quality assessment report document or rating diagrams, especially if they are generated in an automatic fashion.

The square brackets denote elements that are optional because the information may not always be available but it is strongly recommended to include the usage license with the data, if known. Generally speaking, information about the license or permissions associated with the data is necessary to determine whether the intended use of the data would be allowed.

Guideline 2: Utilize a one- (or more) dimensional, structured quality assessment metric that is:

2.1. versioned and publicly available with a globally unique, persistent and resolvable identifier (PID) such as digital object identifier (DOI) and universally unique identifier (UUID);

2.2. registered or indexed in a searchable resource that supports authentication and authorization, such as Figshare, Zenodo, GitHub, and Dryad; and

2.3. retrievable by their identifier using an open, free, standardized and universally implementable communications protocol such as Hypertext Transfer Protocol Secure (HTTPS) or Open Archives Initiative - Protocol for Metadata Harvesting (OAI$\mathrm{PMH})$.

\section{Examples:}

- Data Stewardship Maturity Matrix (DSMM) (Peng et al. 2015) and Self-Evaluation DSMM Template (Peng 2014);

- WMO Stewardship Maturity Matrix for Climate Data (SMM-CD) (Peng et al. 2019b) and Self-Evaluation SMM-CD Template (Lief and Peng 2019);

- RDA FAIR Data Maturity Model Working Group (2020);

- Analysis and Review of NASA Common Metadata Repository (ARC; Bugbee et al. 2021). The ARC metadata curation dashboard tool is publicly available at: https://github.com/nasa/cmr-metadata-review;

- Delayed Mode QA/QC Best Practice Manual (Woo and Gourcuff 2021).

Additional examples of assessment models in a form of metric or matrix are available in Appendix E. Peng (2018) describes maturity assessment models associated with each of four dataset quality aspects defined by Ramapriyan et al. (2017).

Notes: If no suitable assessment model is available, a quality assessment model may need to be developed or adapted. In this case, conditions (2.1-2.3), above, should be satisfied to make the 
model findable and accessible. Individual researchers can utilize the Registry of Research Data Repositories (re3data) at https://doi.org/10.17616/R3D to find appropriate repositories for their assessment models based on their particular requirements. A CoreTrustSeal certified repository demonstrates more matured organizational processes and capabilities in managing its holdings of digital objects (CoreTrust Seal 2019).

A published, peer-reviewed paper, with an associated DOI, that describes the model is preferred to ensure that the model has been assessed by the user community. Also, publishing the assessment model itself, with a DOI, in a community-based repository can facilitate discovery and persistent accessibility. Publishing a quality assessment model on a project website is not recommended, since such locations are not necessarily sustainable and often cannot guarantee persistent access. For example, a broken link can result from a system reorganization or migration, leading to an inaccessible assessment model.

Guideline 3. Capture the quality attribute(s)/aspect(s)/dimension(s), assessment method and results in a dataset-level metadata record using a consistent framework/schema that:

3.1. is semantically and structurally consistent and follows community standards preferably compliant with national or international metadata standards that satisfy the conditions of Guideline 2 (i.e., 2.1-2.3),

3.2. includes a description of the quality attribute(s), aspect(s), or dimension(s) to be assessed,

3.3. includes a description of the assessment method and assessment model structure and version, and access date if applicable,

3.4. includes a description of the assessment results, and

3.5. includes versioning and the history of the assessments.

\section{Examples:}

- DSMM OneStop ISO Quality Metadata Implementation (Peng et al. 2019a);

- AtMoDat Maturity Indicator (Heydebreck et al. 2020);

- Automated metadata and data quality extraction and Geo-dashboard concept (Wagner et al. 2021).

Notes: Adopting or adapting (including information about the adaptation) existing quality metadata frameworks is recommended. If that is not possible, a new quality metadata framework or schema could be developed. In this case, the framework should have the capability to allow for conditions (3.1-3.5), above, to be satisfied.

Furthermore, including a consistent metadata tag is recommended when developing a quality assessment metadata schema, if applicable. For example, Peng et al. (2019a) uses MM-Stew as a metadata tag to denote stewardship maturity assessment (Table 1). Once the new schema is stable, registering it with schema.org or other relevant metadata schema host entities, such as DataCite, is recommended.

Guideline 4. Describe comprehensively the assessment method, workflow, and results in at least a human-readable quality report that: 
4.1. preferably follows a template that is published and satisfies the conditions of Guideline 2 (i.e., 2.1-2.3),

4.2. is published with an explicit open license and history of the report, satisfying the conditions of Guideline 2, and

4.3. links the report PID to the dataset-level metadata record.

\section{Examples:}

- DSMM OneStop - Data Stewardship Maturity Report (DSMR; e.g., Sea Ice CDR (Lemieux et al. 2017));

- Quality Maturity Matrix used at DKRZ (Höck et al. 2020);

- An example of a report on how quality control was applied during the deployment of the IMOS East Australian Current (EAC) Deep Water moorings array (Cowley 2021).

Notes: The National Oceanic Atmospheric Administration (NOAA) National Centers for Environmental Information (NCEI) has developed workflows and tools to automate the processes of i) generating International Standards Organization (ISO) quality metadata to be integrated into the dataset-level metadata record, and ii) creating Data Stewardship Maturity Reports (DSMR) documents to be published by the NOAA Central Library with assigned DOIs (Peng et al. 2019a).

Guideline 5. Report/disseminate the dataset quality information in an organized way via a web interface with a comprehensive description of:

5.1. the dataset according to the Guideline 1,

5.2. assessed quality attribute(s)/aspect(s)/dimension(s),

5.3. the evaluation method and process including the review process, if applicable, and

5.4. how to understand and use the information.

Conveying dataset quality information in a manner that is easily understood and usable by data users is recommended along with providing a mechanism to obtain user feedback.

\section{Examples:}

- JPSS Data Product Algorithm Maturity Portal:

https://www.star.nesdis.noaa.gov/jpss/AlgorithmMaturity.php

(This portal also provides a timeline of algorithm maturity status (Beta, Provisional, Validated) and supporting documents for each data product with a defined and coordinated review process.)

- Copernicus Climate Change Service (C3S) Climate Data Store Dataset Quality Assessment Portal: https://cds.climate.copernicus.eu/cdsapp\#!/dataset/reanalysis-era5single-levels?tab=eqc

- NOAA OneStop Data Discovery Portal: https://data.noaa.gov/onestop/collections/details/ad83c4df-6f2d-447c-8b43-bafa0a91d10d (The average assessment rating is displayed as filled stars at the bottom of the page; click on the question icon next to the stars to see the rating value and a list of nine components of the assessment model along with an embedded link to the reference.)

- Rollingdeck to Repository (R2R) QA Dashboard: https://www.rvdata.us/qa info 
(R2R QA dashboard provides information on the status of quality assessment tests conducted on individual cruise datasets that are readily readable and actionable by machines. Figgemeier et al 2021 propose a Geo-dashboard to visualize quality information and related provenance information.)

- $\quad$ Fourth National Climate Assessment (NCA4) Metadata Viewer:

https://nca2018.globalchange.gov/chapter/1/ (scroll to Figure 1.2, click eye icon for metadata record)

(The NCA4 metadata viewer captures provenance of individual figures, for example, Figure 1.2 in NCA4. It not only has a significant amount of data and information underpinning the figure with 13 individual panels, but this figure also persists with each NCA. The original is traced back to a published version where panels are composed of time series, and where most recent versions are now rooted in the United States Global Change Research Program (USGCRP) Indicators Working Group.)

Notes: Organized reporting of dataset quality information is the most challenging area with diverse practices. The examples shown above demonstrate how different approaches can be applied when disseminating dataset quality information. The challenges for diverse practice also come from the dependencies of the audience for which this information is intended. Data users can provide feedback on which and how disseminated information is most relevant and what can be improved. Therefore, user engagement activities are very relevant at this stage, including prompt response to user requirements. ${ }^{8}$ See Appendix D for additional discussion on user engagement and feedback.

\section{4g. Map the Guidelines to the FAIR Guiding Principles}

To provide an abstractive view of how each guideline is related to the FAIR principles, crosswalks between the guidelines and the FAIR principles are provided in Table 1.

Table 1: Crosswalks between the Guidelines to the FAIR Guiding Principles

(Creator: Anette Ganske; Contributor: Ge Peng.)

\begin{tabular}{|l|l|}
\hline \multicolumn{1}{|c|}{ FAIR Dataset Quality Information Guideline } & $\begin{array}{l}\text { Corresponding } \\
\text { FAIR Principles } \\
\text { (Wilkinson et al. } \\
\text { 2016; also see Table } \\
\text { B1 of Appendix B) }\end{array}$ \\
\hline $\begin{array}{l}\text { Guideline 1. Describe dataset (title, persistent identifier [PID] with a } \\
\text { comprehensive landing page, e.g., digital object identifier [DOI], product } \\
\text { uniform resource identifier [URI], version, data producer, } \\
\text { publication/update date, publisher, date accessed, usage license, e.g., CC- } \\
\text { BY 4.0 or CC0). }\end{array}$ & $\mathrm{F}^{*}, \mathrm{R} 1$ \\
\hline $\begin{array}{l}\text { Guideline 2. Utilize a one- (or more) dimensional, structured quality } \\
\text { assessment metric that is: }\end{array}$ & \\
\hline
\end{tabular}

${ }^{8}$ https://public.wmo.int/en/bulletin/what-do-we-mean-climate-services 


\begin{tabular}{|c|c|}
\hline $\begin{array}{l}\text { 2.1. versioned and publicly available with a globally unique, persistent } \\
\text { and resolvable identifier (PID) such as digital object identifier } \\
\text { (DOI) and universally unique identifier (UUID) }\end{array}$ & F1 \\
\hline $\begin{array}{l}\text { 2.2. registered or indexed in a searchable resource that supports } \\
\text { authentication and authorization, such as Figshare, Zenodo, } \\
\text { GitHub, and Dryad }\end{array}$ & $\mathrm{F} 4, \mathrm{~A} 1.2$ \\
\hline $\begin{array}{l}\text { 2.3. retrievable by their identifier using an open, free, standardized and } \\
\text { universally implementable communications protocol such as } \\
\text { Hypertext Transfer Protocol Secure (HTTPS) or Open Archives } \\
\text { Initiative - Protocol for Metadata Harvesting (OAI-PMH) }\end{array}$ & A1 \\
\hline $\begin{array}{l}\text { Guideline 3. Capture the quality attribute(s)/aspect(s)/dimension(s), } \\
\text { assessment method and results in a dataset-level metadata record using a } \\
\text { consistent framework/schema that: }\end{array}$ & I3, R1 \\
\hline $\begin{array}{l}\text { 3.1. is semantically and structurally consistent and follows community } \\
\text { standards - preferably compliant with national or international } \\
\text { metadata standards that satisfy the conditions of Guideline } 2 \text { (i.e., } \\
2.1-2.3 \text { ) }\end{array}$ & $\mathrm{I} 1, \mathrm{R} 1.3, \mathrm{~F} 1, \mathrm{~F} 4$ \\
\hline $\begin{array}{l}\text { 3.2. includes a description of the quality attribute(s), aspect(s), or } \\
\text { dimension(s) to be assessed }\end{array}$ & $\mathrm{R} 1$ \\
\hline $\begin{array}{l}\text { 3.3. includes a description of the assessment method and assessment } \\
\text { model structure and version, and access date if applicable }\end{array}$ & R1 \\
\hline 3.4. includes a description of the assessment results & R1 \\
\hline 3.5. includes versioning and the history of the assessments & $\mathrm{R} 1.2$ \\
\hline $\begin{array}{l}\text { Guideline } 4 \text {. Describe comprehensively the assessment method, } \\
\text { workflow, and results in at least a human-readable quality report that: }\end{array}$ & R1 \\
\hline $\begin{array}{l}\text { 4.1. preferably follows a template that is published and satisfies the } \\
\text { conditions of Guideline } 2 \text { (i.e., } 2.1-2.3 \text { ) }\end{array}$ & $\mathrm{F} 1, \mathrm{~F} 4, \mathrm{~A} 1, \mathrm{R} 1$ \\
\hline $\begin{array}{l}\text { 4.2. is published with an explicit open license and history of the report, } \\
\text { satisfying the conditions of Guideline } 2\end{array}$ & $\begin{array}{l}\text { F1, F4, A1, R1.1, } \\
\text { R1.2 }\end{array}$ \\
\hline 4.3. links the report PID to the dataset-level metadata record & $\mathrm{I} 3 / \mathrm{F} 3$ \\
\hline $\begin{array}{l}\text { Guideline 5. Report/disseminate the dataset quality information in an } \\
\text { organized way via a web interface with a comprehensive description of: }\end{array}$ & $\mathrm{F} 2, \mathrm{~A} 1, \mathrm{R} 1$ \\
\hline
\end{tabular}




\begin{tabular}{|l|l|}
\hline 5.1. the dataset according to the Guideline 1 & F2, R1 \\
\hline 5.2. assessed quality attribute(s)/aspect(s)/dimension(s) & F2, R1 \\
\hline $\begin{array}{l}\text { 5.3. the evaluation method and process including the review process, if } \\
\text { applicable }\end{array}$ & F2, R1 \\
\hline \begin{tabular}{l} 
5.4. how to understand and use the information \\
\hline
\end{tabular} & F2, R1 \\
\hline
\end{tabular}

* The letter F, A, I or R in the right column denotes that the guideline from the left column can crosswalk to all criteria of being findable, accessible, interoperable, or reproducible, respectively, while the number $(n)$ after the letter of F, A, I, or R refers to the $n$th criterion in that aspect of the FAIR.

\section{4h. Additional Examples on Representing Assessment Results in Metadata}

Here we present two methods for providing quality information in metadata. These are practical examples presented for illustrative purposes, with no specific associated endorsement included.

Adopting ISO 19115-1 (2014) data quality metadata standards, Peng et al. (2019a) has proposed and utilized the implementation practices and framework to curate and represent stewardship maturity of individual datasets assessed with a stewardship maturity matrix, which can be adapted for any quality aspect and potentially other metadata standards (Figure 3 and Table 2). The provenance of the assessment can be captured by using the history of assessments, e.g., original assessment date, modification date, along with a description of major changes associated with each version change if applicable. It is worth noting that Dataset Quality Dimension, DQ Attribute, and DQ Metadata in Figure 3 correspond to Data quality, Data quality element, and Metaquality in ISO 19157 (2013).

Another framework of representing data maturity ratings is also provided based on Heydebreck et al. (2020). This framework has been proposed for inclusion in DataCite's metadata standards (Table 3). The crosswalks between these two frameworks are captured in Table 4.

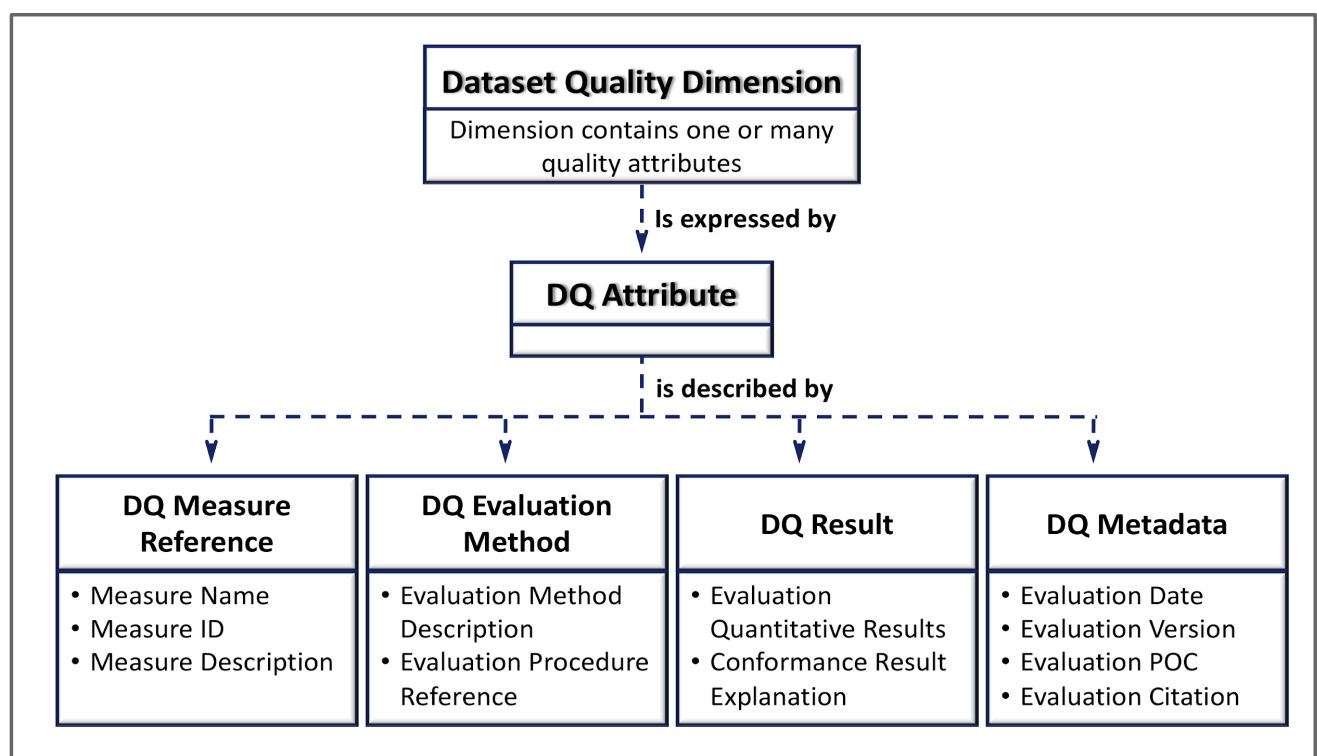


Figure 3: A structural diagram and practices for capturing and representing dataset quality information for a given quality dimension, attribute, evaluation method and results, along with evaluation metadata. Adapted from Figure 6 in Peng et al (2019a).

Table 2: Elements of a conceptual framework for representing dataset quality information in datasetlevel quality metadata. An example is provided based on Peng et al. (2019a), which is associated with the stewardship quality aspect as shown in Figure 1. Please refer to Peng et al. (2015) for a description and scope of the data stewardship maturity matrix utilized.

\begin{tabular}{|c|c|c|}
\hline Element & Description & Example \\
\hline $\begin{array}{l}\text { Dataset Quality } \\
\text { Dimension }{ }^{1}\end{array}$ & $\begin{array}{l}\text { Quality dimension or aspect } \\
\text { of dataset }\end{array}$ & Stewardship \\
\hline $\begin{array}{l}\text { Dataset Quality } \\
\text { Attribute }^{2}\end{array}$ & $\begin{array}{l}\text { Quality attribute under the } \\
\text { dataset quality dimension or } \\
\text { aspect }\end{array}$ & Accessibility \\
\hline Measure Name & Name of assessment & Data Stewardship Maturity Assessment \\
\hline Measure ID & Identifier of assessment & MM-Stew \\
\hline Measure Description & $\begin{array}{l}\text { Description of the measure } \\
\text { utilized to assess the quality } \\
\text { attribute and the rating system } \\
\text { of assessment outcomes if } \\
\text { applicable }\end{array}$ & $\begin{array}{l}\text { The Data Stewardship Maturity Matrix } \\
\text { (DSMM) is a unified framework that } \\
\text { defines criteria for each of nine components } \\
\text { based on measurable practices, which can } \\
\text { be used to apply a progressive, 6-level } \\
\text { rating to an individual dataset, representing } \\
\text { stewardship maturity stages rated as Not } \\
\text { Assessed or Not Available (Level 0), Ad } \\
\text { Hoc (Level 1), Minimum (Level 2), } \\
\text { Intermediate (Level 3), Advanced (Level 4), } \\
\text { and Optimal (Level 5). }\end{array}$ \\
\hline $\begin{array}{l}\text { Evaluation Method } \\
\text { Description }\end{array}$ & $\begin{array}{l}\text { Description of how evaluation } \\
\text { was carried out. }\end{array}$ & $\begin{array}{l}\text { Data Stewardship Maturity Assessment was } \\
\text { evaluated by the metadata content editor for } \\
\text { the NOAA OneStop project using the } \\
\text { Scientific Data Stewardship Maturity } \\
\text { Assessment Model Template v4.0. }\end{array}$ \\
\hline $\begin{array}{l}\text { Evaluation } \\
\text { Procedure Reference }\end{array}$ & $\begin{array}{l}\text { Citation for the evaluation } \\
\text { procedure, template, and } \\
\text { tools. }\end{array}$ & $\begin{array}{l}\text { Peng, Ge. The Scientific Data Stewardship } \\
\text { Maturity Assessment Model Template. } \\
\text { 2015-06-23. } \\
\text { doi:10.6084/m9.figshare. } 1211954\end{array}$ \\
\hline Evaluation Date & $\begin{array}{l}\text { Date of the evaluation being } \\
\text { competed and results being } \\
\text { summarized }\end{array}$ & $2016-12-08$ \\
\hline $\begin{array}{l}\text { Evaluation } \\
\text { Quantitative Results }\end{array}$ & $\begin{array}{l}\text { Quantitative results of } \\
\text { assessment by the measure for }\end{array}$ & Advanced \\
\hline
\end{tabular}




\begin{tabular}{|l|l|l|}
\hline & $\begin{array}{l}\text { the attribute of the quality } \\
\text { dimension or aspect }\end{array}$ & \\
\hline $\begin{array}{l}\text { Conformance } \\
\text { Results Explanation }\end{array}$ & $\begin{array}{l}\text { Explanation of the evaluation } \\
\text { process and the rationale } \\
\text { behind conformance } \\
\text { evaluation result (e.g., } \\
\text { comparison against quality } \\
\text { requirements) }\end{array}$ & $\begin{array}{l}\text { Data stewardship maturity assessment was } \\
\text { carried out by NOAA OneStop metadata } \\
\text { content editor, in collaboration with subject } \\
\text { matter experts of the product and the } \\
\text { maturity matrix. }\end{array}$ \\
\hline Evaluation Version & $\begin{array}{l}\text { Current version of the } \\
\text { evaluation results }\end{array}$ & v03r00 \\
\hline $\begin{array}{l}\text { Evaluation Point-Of- } \\
\text { Contact (POC) }\end{array}$ & $\begin{array}{l}\text { An entity services as a POC } \\
\text { for the evaluation }\end{array}$ & Ge Peng, gpeng@ncsu.edu 4 \\
\hline Evaluation Citation & $\begin{array}{l}\text { Citation of the evaluation } \\
\text { report if applicable }\end{array}$ & $\begin{array}{l}\text { Lemieux, P., G. Peng, and D.J. Scott, 2017: } \\
\text { Data Stewardship Maturity Report for } \\
\text { NOAA Climate Data Record (CDR) of } \\
\text { Passive Microwave Sea Ice Concentration, } \\
\text { Version 2. figshare, } \\
\text { doi:10.6084/m9.figshare.5279932 }\end{array}$ \\
\hline
\end{tabular}

${ }^{1}$ Dataset quality dimension or aspect contains one to many quality attributes.

${ }^{2}$ This element will be repeated for each quality attribute contained in the quality dimension or aspect.

${ }^{3}$ It is recommended to change the evaluation version only when the maturity ratings are modified. For real-time or dynamically changing data, it may be difficult to manually track the versioning.

${ }^{4}$ Now at ge.peng@uah.edu

Table 3: Elements of the suggested schema for representing data maturity ratings, which is proposed to DataCite to be included in the DataCite metadata schema

(Based on Heydebreck et al. 2020).

\begin{tabular}{|l|l|l|}
\hline Element & Definition & Example: NOAA-DSMM* \\
\hline MaturityCheck & & $\begin{array}{l}\text { Data Stewardship Maturity Matrix } \\
\text { (MM-Stew) }\end{array}$ \\
\hline maturityCheckSchemaVersion & Version of this schema & $\begin{array}{l}\text { NCDC-CICS-SMM_0001_Rev.1 } \\
12 / 09 / 2014\end{array}$ \\
\hline maturityCheckName & $\begin{array}{l}\text { Name of the maturity } \\
\text { check }\end{array}$ & Data Stewardship Maturity Assessment \\
\hline maturityCheckDescription & $\begin{array}{l}\text { Description of the } \\
\text { maturity check. }\end{array}$ & $\begin{array}{l}\text { The Data Stewardship Maturity Matrix } \\
\text { (DSMM) is a unified framework that } \\
\text { defines criteria for each of nine } \\
\text { components based on measurable }\end{array}$ \\
\hline
\end{tabular}




\begin{tabular}{|c|c|c|}
\hline & & $\begin{array}{l}\text { practices, which can be used to apply a } \\
\text { progressive, 6-level rating to an } \\
\text { individual dataset, representing } \\
\text { stewardship maturity stages rated as Not } \\
\text { Assessed or Not Available (Level 0), Ad } \\
\text { Hoc (Level 1), Minimum (Level 2), } \\
\text { Intermediate (Level 3), Advanced (Level } \\
\text { 4), and Optimal (Level 5). }\end{array}$ \\
\hline maturityCheckResourceType & Type of the resource & Web Questionnaire; Manual \\
\hline maturityCheckIdentifier & $\begin{array}{l}\text { PID of the metric } \\
\text { definition }\end{array}$ & $\begin{array}{l}\text { https://doi.org/10.6084/m9.figshare.121 } \\
1954\end{array}$ \\
\hline maturityCheckVersion & $\begin{array}{l}\text { Version of the maturity } \\
\text { check }\end{array}$ & v03r00 \\
\hline maturityCheckPerformedBy & $\begin{array}{l}\text { Information on who } \\
\text { performed the maturity } \\
\text { check }\end{array}$ & Ge Peng \\
\hline maturityCheckReport & $\begin{array}{l}\text { Provide result report } \\
\text { for the check }\end{array}$ & $\begin{array}{l}\text { Lemieux, P., G. Peng, and D.J. Scott, } \\
\text { 2017: Data Stewardship Maturity Report } \\
\text { for NOAA Climate Data Record (CDR) } \\
\text { of Passive Microwave Sea Ice } \\
\text { Concentration, Version 2. figshare, } \\
\text { doi:10.6084/m9.figshare.5279932 }\end{array}$ \\
\hline ReportDate & $\begin{array}{l}\text { Date when the result } \\
\text { was produced }\end{array}$ & 2016-12-08 \\
\hline MetricName & MetricName & Usability \\
\hline MetricResult & Results of the metric & Advanced \\
\hline Unit & unit of the result & Level 5 of 6 \\
\hline
\end{tabular}

Table 4: Crosswalks of the Elements in Tables 2 and 3.

\begin{tabular}{|l|l|}
\hline Elements from Heydebreck et al. (2020) & Elements from Peng et al. (2019a) \\
\hline MaturityCheck & Measure ID \\
\hline maturityCheckSchemaVersion & \\
\hline maturityCheckName & Measure Name \\
\hline maturityCheckDescription & Measure Description \\
\hline maturityCheckResourceType & \\
\hline
\end{tabular}




\begin{tabular}{|l|l|}
\hline maturityCheckIdentifier & Evaluation Procedure Reference \\
\hline maturityCheckVersion & Evaluation Version \\
\hline maturityCheckPerformedBy & Evaluation Point-Of-Contact (POC) \\
\hline maturityCheckReport & Evaluation Citation \\
\hline ReportDate & Evaluation Date \\
\hline MetricName & Dataset Quality Attribute \\
\hline MetricResult & Evaluation Quantitative Results \\
\hline Unit & \\
\hline
\end{tabular}

\section{CONCLUSIONS AND DISCUSSION}

The FAIR guiding principles defined by Wilkinson et al. (2016) have provided an effective way to enable data sharing. Inspired by the FAIR guiding principles for curating and reporting dataset quality information, these guidelines are being developed, iteratively, through a community effort by leveraging the experiences and expertise of an international team of interdisciplinary domain experts who are engaged in aspects of data quality and recommended community practices. The guidelines are aimed to improve the availability and sharing of quality information at the individual dataset level.

Prioritizing the collection, representation, and sharing of data quality information is necessary to improve the scientific process. Utilizing a structured quality assessment model helps ensure the consistency of evaluation methods and results, which in turn will make it easier to capture them systematically. Capturing the assessment results in the dataset-level metadata using a consistent framework improves machine interoperability and supports integration across systems and tools. Disseminating the dataset quality information in a transparent and user-friendly way will help end users to understand and effectively use or integrate the information.

The guidelines developed as a result of this international community effort bring the Earth science community one step closer to standardizing the curation and representation of dataset quality information. These guidelines presented here offer opportunities to enable or improve the transparency and interoperability of dataset quality information. Adopting the guidelines can contribute to the evolving ecosystem that supports open science. An excellent byproduct of streamlining the curation and representation of dataset quality information is the improved likelihood of automating the curation and reporting process, leading to global access to and harmonization of quality information of individual digital datasets.

Making dataset quality information FAIR also helps to improve the overall FAIRness of a dataset by providing standard community-based rich metadata with relevant quality attributes and qualified references. Providing such quality information with each dataset will also help establish the trustworthiness of data and ultimately improve the maturity of such datasets in multiple quality 
dimensions or aspects including product, stewardship, and services by improving the completeness and usability of metadata and documentations.

The following two important issues have been raised during the community review:

- uncertainty propagation and,

- how to ensure the data, software, and information are being used correctly and ethically, i.e., the risk of abuse.

Both issues represent big challenges that face most if not all disciplines and are beyond the scope of this document. However, making quality information such as uncertainty estimates available in a consistent way during various stages or aspects of the dataset lifecycle is a first step towards addressing the uncertainty propagation issue. Likewise, improving data quality information can inform the use of data and reduce the potential for misuse.

Some aspects of the following key points, also raised by reviewers, may have been touched on at a high level in this document. However, providing the thorough exploration that these topics deserve is beyond the scope of the current effort. Nevertheless, these topics could serve as excellent candidates for future work:

- the role of technology design in influencing data quality, with specific discussion around different approaches to capturing knowledge;

- an in-depth discussion of intersections between classic geospatial data and citizen science, how they can augment each other, and how information, if provided via FAIR principles, can empower scientists and communities alike;

- a minimum set of reporting requirements for the decision maker.

This international FAIR dataset quality information community guidelines document is a living document and is expected to evolve over time to accommodate user feedback and emerging community best practices. Use cases will be developed to further improve the maturity of the guidelines and to provide implementation examples and lessons learned for the community.

\section{ACKNOWLEDGMENT}

The development and baseline of the community FAIR-DQI guidelines document would not have been possible without the voluntary and dedicated effort of the domain experts of the international FAIR-DQI community guidelines working group. We would like to thank all members of the working group for their interest, participation, and contribution.

\section{The members of the international FAIR-DQI community guidelines working group are:}

Ge Peng, Carlo Lacagnina, Ivana Ivánová, Robert R. Downs, Hampapuram Ramapriyan, Anette Ganske, Dave Jones, Lucy Bastin, Lesley Wyborn, Irina Bastrakova, Mingfang Wu, Chung-Lin Shie, David Moroni, Gilles Larnicol, Yaxing Wei, Nancy Ritchey, Sarah Champion, C. Sophie Hou, Ted Habermann, Gary Berg-Cross, Kaylin Bugbee, and Jeanné le Roux. 
Specifically, G. Peng, C. Lacagnina, and I. Ivánová, as working group co-leads, contributed significantly to strategic planning and oversaw the overall guidelines development and review process.

The following working group members contributed to conceptualization and writing of the guidelines document: G. Peng, C. Lacagnina, R. R. Downs, I. Ivánová, H. Ramapriyan, A. Ganske, D. Jones, and L. Wyborn.

The following working group members contributed content to and reviewed the guidelines document: S. Champion, L. Bastin, C.-L. Shie, I. Bastrakova, G. Berg-Cross, and K. Bugbee.

The following working group members contributed to strategic planning: N. Ritchey, M. Wu, D. Moroni, and Y. Wei. They have also actively reviewed the guidelines document with beneficial edits.

All other working group members have reviewed the guidelines document.

G. Peng, R. R. Downs, H. Ramapriyan, Y. Wei and D. Moroni contributed to planning for and participated in community engagement events that were organized by the ESIP IQC. L. Wyborn, I. Ivánová, M. Wu and I. Bastrakova did so for the events organized by the AU/NZ DQIG. C. Lacagnina and G. Larnicol did so for the events organized by the BSC EQC team. We thank ESIP IQC, AU/NZ DQIG, and BSC EQC team members for their beneficial feedback. In addition, G. Peng, C. Lacagnina, I. Ivánová, R. R. Downs, H. Ramapriyan, and L. Wyborn organized or participated in community engagement events on behalf of the working group.

The community interest and support has helped propel us to the finish line. Contents from Peng et al. $(2020 ; 2021)$ are reused in this document. We thank Janet Fennema for the excellent job in putting together the acronym list.

We thank ESIP for sponsoring the virtual workshop held on July 13, 2020 and all participants of the workshop and the ESIP 2020 Summer Meeting session for helping lay the ground for initiating and developing the guidelines. In particular, we thank the following presenters and attendees who have contributed significantly to the discussions: Mitch Goldberg, Jörg Schulz, Mirko Albani, Christina Lief, Shelley Stall, Lihang Zhou, Iolanda Maggio, Marie Drévillon, Brian Westra, Siri Jodha Khalsa, Kerstin Lehnert, Paul Lemieux, Donald Collins, Gastil Gastil-Buhl, and Danie Kinkade.

We thank participants in the ESIP 2021 Winter Meeting session, especially Chantel Ridsdale, Shawn Smith, Shannon Leslie, Rebecca Hudak, Tyler Christensen, and Venice Bayrd, for beneficial discussions and information, particularly on the top 3 stages that are associated with each quality aspect within the dataset lifecycle shown in Figure 1.

We thank all the reviewers who have taken their time and efforts in reviewing the draft document and provided us with valuable comments and suggestions which have improved the clarity and comprehensiveness of the document. Special thank goes to Siri Jodha Khalsa, Erin Kenna, Stefan Schliebner, Alfred Stein, Peter Strobl, Tyler Christensen, Jasmine Muir, Jessie Oliver, Kenneth 
Casey, and Christin Henzen and her colleagues from the Geoinformatics/TU Dresden and the GeoKur project team.

\section{REFERENCES}

Austin, C, Cousijn, H, Diepenbroek, M, Petters, J, and Soares E Silva, M 2019 WDS/RDA Assessment of Data Fitness for Use WG Outputs and Recommendations. DOI:https://doi.org/10.15497/rda00034

Australia FAIR Access Working Group 2017 Policy Statement on FAIR Access to Australia's Research Outputs. Version: Jan 2017. Available at: https://www.fair-access.net.au/fairstatement

Baker, K S, Duerr, R E, and Parsons, M A 2016 Scientific Knowledge Mobilization: Coevolution of Data Products and Designated Communities. International Journal of Digital Curation, 10(2), 110-135. DOI:https://doi.org/10.2218/ijdc.v10i2.346

Barsi, Á, Kugler, Z, Juhász, A, Szabó, G, Batini, C, Abdulmuttalib, H, Huang, G, and Shen, H 2019 Remote sensing data quality model: from data sources to lifecycle phases. International Journal of Image and Data Fusion, 10(4):280-99. DOI:https://doi.org/10.1080/19479832.2019.1625977

Bates, J J and Privette, J L 2012 A maturity model for assessing the completeness of climate data records. EOS, Trans. American Geophysical Union, 93(44), 441. DOI:https://doi.org/10.1029/2012EO440006

Borda, A, Gray, K, and Fu, Y 2020 Research data management in health and biomedical citizen science: practices and prospects. JAMIA Open, 3(1):113-25. DOI:https://doi.org/10.1093/jamiaopen/ooz052

Bruce, T R and Hillmann, D I 2004 The Continuum of Metadata Quality: Defining, Expressing, Exploiting. In: Metadata in Practice. Cornell University Library: ALA Editions. Available at https://hdl.handle.net/1813/7895

Bugbee, K, le Roux, J, Sisco, A, Kaulfus, A, Staton, P, Woods, C, Dixon, V, Lynnes, C and Ramachandran, R 2021 Improving Discovery and Use of NASA's Earth Observation Data Through Metadata Quality Assessments. Data Science Journal, 20(1), p.17. DOI:http://doi.org/10.5334/dsj-2021-017

Callahan, T, Barnard, J, Helmkamp, L, Maertens, J, and Kahn, M 2017 Reporting data quality assessment results: identifying individual and organizational barriers and solutions. $e G E M s$, 5(1). DOI: https://doi.org/10.5334/egems.214

Canali, S 2020 Towards a Contextual Approach to Data Quality. Data. 5(4):90. DOI:https://doi.org/10.3390/data5040090

CODATA 2019 The Beijing Declaration on Research Data. Version: 7 November 2019. Available at: http://www.codata.org/uploads/Beijing\%20Declaration-19-11-07-FINAL.pdf

Coetzee, S 2018 Implementing Geospatial Data Quality Standards - Motivators and Barriers, 2nd International Workshop on Spatial Data Quality, Valletta, Malta 6-7 February 2018, https://eurogeographics.org/wp-content/uploads/2018/06/4-SDQ2018 Coetzee_V1e.pdf

CoreTrustSeal 2019 Core Trustworthy Data Repository Requirements 2020-2022 - Extended Guidance. Version 2.0 November 2019. Zenodo. https://zenodo.org/record/3638211\#.YCfqv89Ki7M

Cordy, C E and Coryea, L R 2006 Champion's Practical Six Sigma Summary. Version: 27 January 2006. Xlibris Corporation. 65 pp. ISBN 978-1-4134-9681-9. 
Cunningham, J A, Speybroeck, M V, Kalra, D, and Verbeeck, R 2016 Nine Principles of Semantic Harmonization. AMIA Annu Symp Proc. 2016, 451-459. Available at: https://www.ncbi.nlm.nih.gov/pmc/articles/PMC5333211/

Deming, WE 1986 Out of the Crisis. MIT Center for Advanced Engineering Study. The 2010 MIT Press edition, 507 pp. Cambridge, MA, USA.

Digital Science, Fane, B, Ayris, P, Hahnel, M, Hrynaszkiewicz, I, Baynes G and others 2019 The State of Open Data Report 2019. Digital Science. Report. DOI:https://doi.org/10.6084/m9.figshare.9980783

Dretske, F I 1981 Knowledge and the Flow of Information, 273 pp. Basil Blackwell, Oxford. Available at: https://www.amazon.com/Knowledge-Flow-Information-FredDretske/dp/157586195X

Downs, RR, Ramapriyan, HK, Peng, G, and Wei, Y. 2021. Perspectives on Citizen Science Data Quality. Frontiers in Climate. 3. DOI: https://doi.org/10.3389/fclim.2021.615032

EUMETSAT 2013 CORE-CLIMAX Climate Data Record Assessment Instruction Manual. Version 2, 25 November 2013. Available from:

https://www.eumetsat.int/search?text=CORE-CLIMAX

European Commission 2018 Turning FAIR into reality - Final Report and Action Plan from the European Commission Expert Group on FAIR data, EC: Brussels, DOI:https://doi.org/10.2777/1524

European Commission 2020 Recommendations on FAIR Metrics for EOSC, European Commission: Brussels, DOI: https://doi.org/10.2777/70791

European Commission and PwC EU Services 2018 Cost-benefit analysis for FAIR research data: Cost of not having FAIR research data. Version: March 2018. Available at: https://op.europa.eu/en/publication-detail/-/publication/d375368c-1a0a-11e9-8d0401aa75ed71a1/language-en

Evans, B, Druken, K, Wang, J, Yang, R, Richards, C, and Wyborn, L 2017 A data quality strategy to enable fair, programmatic access across large, diverse data collections for high performance data analysis. Informatics, 4(4), 45. DOI:https://doi.org/10.3390/informatics4040045

FGDC (Federal Geographic Data Committee) 2002 Content standard for digital geospatial metadata - extension for remote sensing data. Version: FGDC-STD-012-2002. Federal Geographic Data Committee. Washington, D.C. Available at: https://www.fgdc.gov/standards/projects/csdgm_rs_ex/MetadataRemoteSensingExtens.pdf

Figgemeier, H, Henzen, C, Rümmler, A 2021 A Geo-Dashboard Concept for the Interactively Linked Visualization of Provenance and Data Quality for Geospatial Datasets. AGILE GIScience Ser., 2, 25, DOI:https://doi.org/10.5194/agile-giss-2-25-2021

Ganske, A, Kraft, A, Kaiser, A, Heydebreck, D, Lammert, A, Höck, H, Thiemann, H, Voss, Grawe, V D, Leitl, B, Schlünzen, K H, Kretzschmar, J, and Quaas, J 2020a ATMODAT Standard (v3.0). World Data Center for Climate (WDCC) at DKRZ. Available at: https://cera-www.dkrz.de/WDCC/ui/cerasearch/entry?acronym=atmodat_standard_en_v3_0

Ganske, A, Heydebreck, D, Höck, H, and Kaiser, A 2020b A short guide to increase FAIRness of atmospheric model data. Meteorol. Z. (Contrib. Atm. Sci.), 29, DOI:https://doi.org/10.1127/metz/2020/1042 (supplement includes a JSON example for DOI metadata.)

GCMD 2020 GCMD Keywords, Version 9.1. Greenbelt, MD: Earth Science Data and Information System, Earth Science Projects Division, Goddard Space Flight Center (GSFC) 
National Aeronautics and Space Administration (NASA). Available at:

https://earthdata.nasa.gov/earth-observation-data/find-data/gcmd/gcmd-keywords

G20 Leaders 2016 G20 Leaders' Communique Hangzhou Summit. Version: 5 September 2016.

Available at: https://ec.europa.eu/commission/presscorner/detail/en/STATEMENT 162967

Haiden, T, Janousek, M, Vitart, F, Ferranti, L, Prates, F, and Prates, F 2019. Evaluation of ECMWF forecasts, including the 2019 upgrade. DOI:https://doi.org/10.21957/mlvapkk

Henzen, C, Della Chiesa, S, Bernard, L 2021 Recommendations for Future Data Management Plans in Earth System Sciences. AGILE GIScience Ser., 2, 31,.

DOI:https://doi.org/10.5194/agile-giss-2-31-2021

Hewitt, C D, Stone, R C, and Tait, A B 2017 Improving the use of climate information in decision-making. Nature Climate Change, 7(9), 614-616.

DOI:https://doi.org/10.1038/nclimate3378

Hey, T, Tansley, S, and Tolle, K 2009 The Fourth Paradigm: Data-Intensive Scientific

Discovery. Microsoft Research, USA. 252 pp.

Heydebreck, D, Ganske, A, Kraft, A, Kaiser, A, Thiemann, H, Habermann, T, and Peng, G 2020 Maturity Indicator - potential extension to the DataCite Metadata Schema. GitHub. Version 7.1. Available at: https://github.com/AtMoDat/maturity-indicator

Höck, H and Toussaint, F 2019 Quality Maturity Matrix Checklist for Levels 4 and 5 with Protocols. World Data Center for Climate (WDCC) at DKRZ.

DOI:https://doi.org/10.2312/WDCC/TR QMM_Checkl_Levels 4-5 Prots

Höck, H, Toussaint, F and Thiemann, H 2020 Fitness for Use of Data Objects Described with Quality Maturity Matrix at Different Phases of Data Production. Data Science Journal, 19, DOI:http://doi.org/10.5334/dsj-2020-045

Illari, P 2014 IQ: Purpose and Dimensions. In The Philosophy of Information Quality; Floridi, L, Illari, P, Eds.; Springer: Berlin, Germany pp. 281-302. DOI:https://doi.org/10.1007/978-3319-07121-3 14

ISO 19115-1 2014 Geographic Information-Metadata - Part 1: Fundamentals. Version: 201404. International Organization for Standardization. Geneva, Switzerland. Available at: https://www.iso.org/standard/53798.html

ISO 191312007 Geographic information — Data product specifications. Version: 2007-04. International Organization for Standardization. Geneva, Switzerland. Available at: https://www.iso.org/standard/36760.html

ISO 191572013 Geographic information - Data quality, Geneva, Switzerland, Available at: https://www.iso.org/standard/32575.html

ISO 19165-2:2020 Geographic information - Preservation of digital data and metadata — Part 2: Content specifications for Earth observation data and derived digital products, Geneva, Switzerland, Available at: https://www.iso.org/standard/73810.html

Jones, M and Slaughter, P 2019 Quantifying FAIR: metadata improvement and guidance in the DataONE repository network. DataONE Webinar, May 14, 2019. Slides ae available at: https://www.dataone.org/uploads/dataonewebinar jonesslaughter fairmetadata 190514.pdf

Kahn, M G, Brown, J S, Chun, A T, Davidson, B N, Meeker, D, Ryan, P B, Schilling, L M, Weiskopf, N G, Williams, A E, and Zozus, M N 2015 Transparent reporting of data quality in distributed data networks. Egems, 3(1). DOI:https://doi.org/10.13063/2327-9214.1052

Lawrence, B., Jones, C., Matthews, B., Pepler, S., and Callaghan, S. 2011 Citation and Peer Review of Data: Moving Towards Formal Data Publication, Int. J. Digi. Cur., 2, 4-37. 
Lee, Y W, Strong, D M, Khan, B K and Wang, R Y 2002: AIMQ: a methodology for information quality assessment, Information \& Management, 40, 133-146.

DOI:https://doi.org/10.1016/S0378-7206(02)00043-5

Lenhardt W, Ahalt S, Blanton B, Christopherson L, and Idaszak R 2014 Data management lifecycle and software lifecycle management in the context of conducting science. Journal of Open Research Software, 2(1). DOI:http://doi.org/10.5334/jors.ax

Leonelli, S 2017 Global Data Quality Assessment and the Situated Nature of "Best" Research Practices in Biology. Data Science Journal, 16, p.32. DOI:http://doi.org/10.5334/dsj-2017$\underline{032}$

Lemieux III, P, Peng, G and Scott, DJ 2017 Data Stewardship Maturity Report for NOAA Climate Data Record (CDR) of Passive Microwave Sea Ice Concentration, Version 2. Figshare. DOI:https://doi.org/10.6084/m9.figshare.5279932

Lief, C and Peng, G 2019 The WMO Stewardship Maturity Matrix for Climate Data (SMM-CD) Template. Document ID: WMO-SMM-CD-0003. Updated 2020. Version: v04r01 20200615. Figshare. DOI:https://doi.org/10.6084/m9.figshare.7003709

Lin, D, Crabtree, J, Dillo, I, Downs, R R, Edmunds, R, Giaretta, D, De Giusiti, M, L'Hours, H, Hugo, W, Jenkyns, R, Khodiyar, V, Martone, M, Mokrane, M, Navale, V, Petters, J, Sierman, B, Sokolova, D V, Stockhause, M, Westbrook, J 2020. The TRUST Principles for Digital Repositories. Scientific Data 7, 144. DOI:https://doi.org/10.1038/s41597-020-0486-7

Mankins, J 1995 Technical Readiness Level - A White Paper. Version: April 6, 1995. Available at: http://www.artemisinnovation.com/images/TRL White Paper 2004-Edited.pdf

Mankins, J 2009 Technology readiness assessments: A retrospective. Acta Astronautica. 65. Available at: http://www.onethesis.com/wp-content/uploads/2016/11/1-s2.0S0094576509002008-main.pdf

Matthews, J L, Mannshardt, E, and Gremaud, P 2013 Uncertainty Quantification for Climate Observations, Bulletin of the American Meteorological Society, 94, ES21-ES25. DOI:http://doi.org/10.1175/BAMS-D-12-00042.1

Mislan, K A S, Heer, J M, and White, E P, 2015 Elevating The Status of Code in Ecology. Trends Ecol. Evol., 31(1). DOI:https://doi.org/10.1016/j.tree.2015.11.006

Moe, K, Jones, D, Bermudez, L E, and Fayne, J V 2018 Operational Readiness Levels - A Trust Metric for Operational Data. American Geophysical Union Fall Meeting 2018, abstract \#IN52B-08.

Mons, B, 2018 Data Stewardship for open science: implementing FAIR principles. 1st Edition. Chapman and Hall/CRC Press, Taylor \& Francis, New York. 244 pp. Available at: https://www.taylorfrancis.com/books/9781315380711

Moroni, D F, Ramapriyan, H, Peng, G, Hobbs, J, Goldstein, J C, Downs, R R, Wolfe, R, Shie, CL, Merchant, C J, Bourassa, M, Matthews, J L, Cornillon, P, Bastin, L, Kehoe, K, Smith, B, Privette, J L, Subramanian, A C, Brown, O, and Ivánová, I 2019 Understanding the Various Perspectives of Earth Science Observational Data Uncertainty. Figshare.

DOI:https://doi.org/10.6084/m9.figshare.10271450

Mosely, M, Brackett, M, Early, S and Henderson, D. (eds) 2009 The Data Management Body of Knowledge (DAMA-DMBOK Guide). Bradley Beach, NJ, USA: Technics Publications, LLC. 2nd Print Edition, 406 pp.

NCEI/ESIP-DSC MM-Serv Working Group 2018 NCEI/ESIP-DSC Data Use and Services Maturity Matrix (MM-Serv). Figshare. DOI:https://doi.org/10.6084/m9.figshare.6855020 
Nightingale, J, Mittaz, J P D, Douglas, S, Dee, D, Ryder, J, Taylor, M, Old, C, Dieval, C, Fouron, C, Duveau, G, and Merchant, C 2019 Ten priority science gaps in assessing climate data record quality. Remote Sensing, 11(8), 986. DOI:https://doi.org/10.3390/rs11080986

O'Brien, M, Costa, D, Servilla, M 2016 Ensuring the quality of data packages in the LTER network data management system. Ecological Informatics, 36.

DOI:https://doi.org/10.1016/j.ecoinf.2016.08.001

OGC (Open Geospatial Consortium) 2020 OGC Discussion Paper 2020 On the definition of dataset. Available at:

https://github.com/heidivanparys/discussion_paper_dataset/releases/download/v20200312/Di scussionPaperDataset.pdf

Pearlman, J, Bushnell, M, Coppola, L, Karstensen, J, and others 2019 Evolving and Sustaining Ocean Best Practices and Standards for the Next Decade. Front. Mar. Sci., DOI:https://doi.org/10.3389/fmars.2019.00277

Peng, G 2014 NCDC-CICSNC Scientific Data Stewardship Maturity Assessment Model Template. Figshare. Updated: 2015. Version: v4.0-20150623.

DOI:https://doi.org/10.6084/m9.figshare.1211954.v23

Peng, G 2018 The state of assessing data stewardship maturity - an overview. Data Science Journal, 17, DOI: https://doi.org/10.5334/dsj-2018-007

Peng, G, Privette, J L, Kearns, E J, Ritchey, N A, and Ansari, S 2015 A unified framework for measuring stewardship practices applied to digital environmental datasets. Data Science Journal, 13, 231 - 253. DOI:https://doi.org/10.2481/dsj.14-049

Peng, G, Privette, J L, Tilmes, C, Bristol, S, Maycock, T, Bates, J J, Hausman, S, Brown, O, and Kearns, E J 2018 A Conceptual Enterprise Framework for Managing Scientific Data Stewardship. Data Science Journal, 17. DOI:https://doi.org/10.5334/dsj-2018-015

Peng, G, Milan, A, Ritchey, N, Partee II, R P, Zinn, S, McQuinn, Lemieux III, P E, Ionin, R, Collins, D, Jones, P, Jakositz, A, and Casey, K S 2019a Practical Application of a Stewardship Maturity Matrix for the NOAA OneStop Program. Data Science Journal, 18. DOI:https://doi.org/10.5334/dsj-2019-041

Peng, G, Wright, W, Baddour, O, Lief, C and the SMM-CD Work Group 2019b The guidance booklet on the WMO-Wide Stewardship Maturity Matrix for Climate Data. Figshare. DOI:https://doi.org/10.6084/m9.figshare.7002482

Peng, G, Lacagnina, C, Downs, R R, Ivánová, I, Moroni, D F, Ramapriyan, H, Wei, Y, and Larnicol, G 2020 Laying the Groundwork for Developing International Community Guidelines to Effectively Share and Reuse Digital Data Quality Information - Case Statement, Workshop Summary Report, and Path Forward. Open Science Framework, https://doi.org/10.31219/osf.io/75b92

Peng, G, Downs, R R, Lacagnina, C, Ramapriyan, H, Ivánová, I, and others 2021 Call to Action for Global Access to and Harmonization of Quality Information of Individual Earth Science Datasets. Data Science Journal, 20. DOI: http://doi.org/10.5334/dsj-2021-019

Popp, T, Hegglin, M I, Hollmann, R, Ardhuin, F, Bartsch, A, and others, 2020 Consistency of satellite climate data records for Earth system monitoring. BAMS, DOI:https://doi.org/10.1175/BAMS-D-19-0127.1

Press, G 2016 Cleaning Big Data: Most Time-Consuming, Least Enjoyable Data Science Task, Survey Says. Forbes. Version: March 23, 2016. Available at: https://www.forbes.com/sites/gilpress/2016/03/23/data-preparation-most-time-consumingleast-enjoyable-data-science-task-survey-says/?sh=1 ee368c06f63 
Ramapriyan, H and Moses, J 2012 NASA Earth Science Data Preservation Content Specification. NASA GSFC. Document ID: 423- SPEC- 001. Available at: https://cdn.earthdata.nasa.gov/conduit/upload/10607/NASA_ESD_Preservation_Spec.pdf

Ramapriyan, H, Peng, G, Moroni, D, and Shie, C-L 2017 Ensuring and Improving Information Quality for Earth Science Data and Products. D-Lib Magazine, 23, DOI:https://doi.org/10.1045/july2017-ramapriyan

RDA FAIR Data Maturity Model Working Group 2020 FAIR Data Maturity Model: specification and guidelines. https://doi.org/10.15497/rda00050

Renear, A H, Sacchi, S, and Wickett, K M 2010 Definitions of Dataset in the Scientific and Technical Literature. ASIST 2010. The American Society for Information Science and Technology, Pittsburgh, PA. DOI:https://doi.org/10.1002/meet.14504701240

Redman, C T 1996 Data quality of the information age. Artech House, Boston. 303 pp.

Romain, D, Mabile, L, Mohamed, Y, Cambon-Thomsen, A, Archambeau, A-S, Bezuidenhout, L, and others 2018 How to operationalize and assess the inclusion of the 'FAIR' concept in data sharing: towards a simplified assessment grid for compliance with the FAIR criteria. (Version 1.0). The National Open Science Day (JNSO 2018), Paris France: Zenodo. DOI:http://doi.org/10.5281/zenodo.1995646

Stockhause, M, Höck, H, Toussaint, F, and Lautenschlager, M 2012 Quality assessment concept of the World Data Center for Climate and its application to CMIP5 data. Geoscientific Model Development, 5(4), 1023-1032. DOI:https://doi.org/https://doi.org/10.5194/gmd-5-10232012

Tegmark, M 2013 Everything in the Universe Is Made of Math - Including You. discovermagazine.com. Version: 4 November 2013. Accessed 2/25/2017 at: http://discovermagazine.com/2013/dec/13-math-made-flesh

Tilmes, C, Privette, A P, Chen, J, Ramachandran, R, Bugbee, K M, and Wolfe, R E 2015a Linking from observations to data to actionable science in the climate data initiative. Proc. 2015 IEEE Geosci. and Remote Sensing Symposium, 26 - 31 July 2015, Milan, Italy.

Tilmes, C, Wolfe, R E, Duggan, B, Aulenbach, S, Goldstein, J C, Ma, X, and Zednik, S 2015b Supporting trust with provenance of the findings of the national climate assessment. METHOD 2015: The 4th Intl. Workshop on Methods for Establishing Trust of (Open) Data. 11 Oct. 2015, Bethlehem, PA, USA. Available at: http://www.few.vu.nl/ dceolin/method2015/papers/METHOD 2015 paper_2.pdf

U.S. Public Law 115-435 2019 Foundations for Evidence-Based Policymaking Act of 2018. Title II OPEN Government Data Act. Version: 14 January 2019. Available at: https://www.congress.gov/115/plaws/pub1435/PLAW-115publ435.pdf

W3C 2016 Data on the Web Best Practices: Data Quality Vocabulary. Version: 15 December 2016. Available at: https://www.w3.org/TR/vocab-dqv/

Wagner, M, Henzen, C, Müller-Pfefferkorn, R 2021 A Research Data Infrastructure Component for the Automated Metadata and Data Quality Extraction to Foster the Provision of FAIR Data in Earth System Sciences. AGILE GIScience Ser., 2, 41, DOI:https://doi.org/10.5194/agile-giss-2-41-2021

Wang, R Y and Strong, D M 1996 Beyond Accuracy: What Data Quality Means to Consumers. Journal of Management Information Systems, 12(4):5, DOI:https://doi.org/10.1080/07421222.1996.11518099 
Wilkinson, M D, Dumontier, M, Aalbersberg, I J, Appleton, G, Axton, M, Baak, A, and others 2016 The FAIR Guiding Principles for scientific data management and stewardship.

Scientific Data, 3, 160018 (2016). https://doi.org/10.1038/sdata.2016.18

WMO (World Meteorological Organization) 1992 International meteorological vocabulary. Document ID: WMO-No. 182. Available at:

https://library.wmo.int/?lvl=notice display\&id=220\#.YEjM5ndKiqc

WMO 2019 Manual on the High-quality Global Data Management Framework for Climate.

Document ID: WMO-No. 1238. World Meteorological Organization. Available at:

https://library.wmo.int/index.php?lvl=notice display\&id=21686

Woo, L M and Gourcuff, C 2021) Delayed Mode QA/QC Best Practice Manual Version 3.0

Integrated Marine Observing System. DOI:https://doi.org/10.26198/5c997b5fdc9bd

Wu, F, Cornillon, P, Boussidi, B, \& Guan L 2017 Determining the Pixel-to-Pixel Uncertainty in Satellite-Derived SST Fields. Journal of Remote Sensing, 9(9),

DOI:https://doi.org/10.3390/rs9090877

W3C (World Wide Web Consortium) 2020 Data Catalog Vocabulary (DCAT), Version 2.

Available at: https://www.w3.org/TR/vocab-dcat-2/\#Class:Dataset

Zhou, L, Divakarla, M, and Liu, X 2016 An Overview of the Joint Polar Satellite System (JPSS)

Science Data Product Calibration and Validation. Remote Sensing, 8,

DOI:https://doi.org/10.3390/rs8020139 


\section{APPENDICES}

\section{Appendix A. Terms and Definitions}

There is a fair amount of work on terms and definitions related to data and information management. Many organizations, if not all, including domain and national data centers or repositories, maintain a glossary or a list of vocabulary, i.e., an alphabetical list of terms and brief explanations. ${ }^{9}$ It often relates to a particular subject or domain. For example, the World Meteorological Organization (WMO) maintains an international meteorological vocabulary (WMO 1992), which has been continuously updated and is searchable online. ${ }^{10}$ Some glossaries have been developed for the research data management community, such as the one maintained by the Committee on Data of the International Science Council (CODATA) ${ }^{11}$, the Data Foundation and Terminology (DFT) Interest Group of Research Data Alliance (RDA) ${ }^{12}$, and Consortia Advancing Standards in Research (CASRAI). ${ }^{13}$ One can also obtain definitions of terms from online dictionaries such as Merriam-Webster ${ }^{14}$ or wikipedia ${ }^{15}$ as well as from community and international standards such as Mosely et al. (2009) and ISO/TC 211. ${ }^{16} 17$

It is beyond the scope of this document to provide a comprehensive list of vocabulary pertaining to data and information quality management. It is, however, beneficial to our stakeholders to provide a list of key terms used in this document and their definitions and/or explanations. It is also helpful to better limit the scope of those terms as they may be used in various contexts in different disciplines.

Currently, there are no formal or unique definitions for many of those key terms. Definitions may be different within specific domains and disciplines. For example, Renear et al. (2010) examined the literature and found large variation among the definitions of dataset. Additional discussion on the definition of dataset can be found in OGC (2020).

In some instances, there appears to be a visible gap between a scholarly definition that tends to be highly abstract and that described with layman's terms which is more practical to follow. For example, definitions of dataset collected by the RDA DFT Interest Group include "a type of managed data aggregation from multiple data elements which are considered as an aggregated unit for processing purposes" as well as "A collection of data, published or curated by a single agent, and available for access or download in one or more formats." Again, it is beyond the scope of this document to discuss the variety of existing definitions of those key terms. We, therefore, have aimed to collect and integrate existing definitions from various sources to retain the generality of these definitions, but to adopt the ones that are easy to understand and also to align them with that of the Earth science community (Table A1). The goal is to provide a good starting point for

\footnotetext{
${ }^{9}$ https://science.nasa.gov/glossary

$10 \mathrm{https}$ //public.wmo.int/en/resources/meteoterm

11 https://codata.org/rdm-glossary/

12 https://smw-rda.esc.rzg.mpg.de/dft-2.0.html

13 https://casrai.org/rdm-glossary/

14 https:/www.merriam-webster.com/dictionary/data

15 https://en.wikipedia.org/wiki/Data

16 https://isotc211.geolexica.org/

${ }^{17}$ https://www.iso.org/obp/ui
} 
reaching a community consensus. It is expected that definitions may evolve with feedback from the Earth science community.

Table A1: Definitions/description, Examples/Notes of Key Terms

\begin{tabular}{|c|c|}
\hline $\begin{array}{l}\text { Term } \\
\text { Examples/Notes }\end{array}$ & Definition/Description \\
\hline Data & $\begin{array}{l}\text { Data are representations of observations, objects, or other phenomena and can refer } \\
\text { to anything that is collected, observed, generated or derived, and used as a basis for } \\
\text { reasoning, discussion, or calculation. Data can be either structured or unstructured, } \\
\text { analog or digital, and can be represented in quantitative, qualitative, or physical } \\
\text { forms. }\end{array}$ \\
\hline Examples/Notes & $\begin{array}{l}\text { Quantitative data can be either discrete or continuous numbers, such as in } \\
\text { situ/ground, suborbital or satellite measurements. Qualitative data is descriptive } \\
\text { text, such as description of weather stations and sensors used in meteorological } \\
\text { observations. Tegmark (2013) has argued that the data in qualitative form can also } \\
\text { be represented digitally. Data in a physical form can be deduced or interpreted } \\
\text { from physical samples such as air, water, fish, or ice core samples. Physical data } \\
\text { can also be represented in analog by images, hand-drawn nautical charts or } \\
\text { physical meteorological records. Unless it is digitally described, a collection of } \\
\text { data in physical form is not easy to share and is not machine interoperable. } \\
\text { However, nowadays, almost all the images, nautical charts, or physical } \\
\text { meteorological records are digital or digitized. Generated data can be results from a } \\
\text { numerical model, e.g., a climate model, or a statistical model, e.g., a linear } \\
\text { regression model. Derived data can be a data product with a well-thought out } \\
\text { algorithm or approach that facilitates an end goal through the use of observations. } \\
\text { Data products tend to be structured and can be raw measurements or scientific } \\
\text { products derived from raw measurements or other products. Products can also be } \\
\text { statistical or numerical model outputs, including analyses, reanalyses, predictions, } \\
\text { or projections. Earth Science data products may be further categorized based on } \\
\text { their processing levels (e.g., FGDC 2002). }\end{array}$ \\
\hline Dataset & $\begin{array}{l}\text { Dataset refers to an identifiable collection of data (e.g., ISO 19115-1 2014). A } \\
\text { dataset can be processed, curated or published by a single agent (e.g., W3C 2020). }\end{array}$ \\
\hline Examples/Notes & $\begin{array}{l}\text { A dataset is a type of managed data aggregation from multiple data elements which } \\
\text { are considered as an aggregated unit for processing purposes. The general notion of } \\
\text { datasets found in the literature currently is characterized by an interrelated family } \\
\text { of more specific concepts: grouping, content, relatedness, and purpose (Renear et al } \\
\text { 2010). Time series are good examples of a dataset. The 1790-1960 Decennial } \\
\text { Censuses are described as Datasets by such repositories as the CISER Data } \\
\text { Archive: Online Catalog. An overview of existing definitions of a dataset can be } \\
\text { found in OGC (2020). }\end{array}$ \\
\hline Data Collection & $\begin{array}{l}\text { Data Collection refers to a grouping of digital data or products that share common } \\
\text { characteristics, is represented by a single metadata record, and consists of one or } \\
\text { more granules. A collection is often identified by a PID. }\end{array}$ \\
\hline
\end{tabular}




\begin{tabular}{|c|c|}
\hline Examples/Notes & $\begin{array}{l}\text { In this document, a data collection refers to a minimum citable unit of data, which } \\
\text { oftentimes refers to a dataset. What consists of data collection can be very } \\
\text { subjective. Contents in a data collection may be static or change over time. For } \\
\text { example, a query issued to a database can be invariant, but the result may change } \\
\text { each time. A sensor data stream always has new data from the most recent } \\
\text { observation. The stream itself may be identified, but the contents are not static. }\end{array}$ \\
\hline Data Granule & $\begin{array}{l}\text { Data Granule refers to the smallest aggregation of data that can be independently } \\
\text { managed (described, inventoried, and retrieved) in an archival and/or dissemination } \\
\text { system. }\end{array}$ \\
\hline Examples/Notes & $\begin{array}{l}\text { Common examples of a granule can be an individual sample in a sample collection } \\
\text { or an individual data file of a dataset. Like the concept of data collection, data } \\
\text { granule can be quite subjective. }\end{array}$ \\
\hline Data Quality & $\begin{array}{l}\text { Data quality is a degree to which a set of inherent characteristics of data fulfills } \\
\text { requirements (e.g., ISO 8000-2 2018) }\end{array}$ \\
\hline Examples/Notes & $\begin{array}{l}\text { Data quality can be expressed as a conformance with product specification (e.g., } \\
95 \% \text { conformant), or as detailed report including specifics of quality evaluation per } \\
\text { each data characteristic (e.g., for 'positional accuracy': } 25 \% \text { of the nodes within } \\
\text { data quality scope have an error distance greater than } 1 \mathrm{~m} \text { ). }\end{array}$ \\
\hline Dataset Quality & $\begin{array}{l}\text { Dataset quality includes quality of both data and associated information, examples } \\
\text { of which are metadata, software, algorithms, and practices or procedures applied to } \\
\text { the dataset throughout its entire life cycle. } \\
\text { Dataset quality is a multi-dimensional construct perception and/or a judgment of } \\
\text { data's fitness or trustworthiness to serve intended research uses in a given context. }\end{array}$ \\
\hline Examples/Notes & $\begin{array}{l}\text { The scope of quality of a dataset goes beyond that of data. See Figure } \mathrm{C} 1 \text { and Table } \\
\mathrm{C} 1 \text { for lists of dataset quality aspects and attributes such as Completeness (no gaps } \\
\text { in coverage) and standards (data and metadata). Not included is consistency } \\
\text { (internal and external). }\end{array}$ \\
\hline $\begin{array}{l}\text { Dataset Quality } \\
\text { Information }\end{array}$ & $\begin{array}{l}\text { Dataset quality information includes both data quality descriptive information such } \\
\text { as that captured in documents, e.g., papers, reports or user guides, and quality } \\
\text { metadata that is captured in a metadata record, throughout the entire life cycle of a } \\
\text { dataset. }\end{array}$ \\
\hline Examples/Notes & \\
\hline Information & $\begin{array}{l}\text { Information is considered as data being processed, organized, structured, } \\
\text { communicated or presented so as to be meaningful to the recipient in a given } \\
\text { context. }\end{array}$ \\
\hline Examples/Notes & $\begin{array}{l}\text { "Information is data in context." Mosely et al. (2009). Examples include spatial } \\
\text { distribution maps of topographic or bathymetric measurements. }\end{array}$ \\
\hline Knowledge & Knowledge is an abstract concept, defined as a familiarity, awareness, or \\
\hline
\end{tabular}




\begin{tabular}{|c|c|}
\hline & $\begin{array}{l}\text { understanding of someone or something, gained through education, experience, or } \\
\text { association. It can refer to a theoretical or practical understanding of a subject. }\end{array}$ \\
\hline Examples/Notes & $\begin{array}{l}\text { Knowledge is gained from an understanding of the significance of information } \\
\text { (Mosely et al. 2009). Knowledge represents the internalized or understood } \\
\text { information that can be used to make decisions. }{ }^{18} \text { The relationship between } \\
\text { information and knowledge includes prior knowledge about a specific information } \\
\text { source and additional knowledge is added by the interpreted content of information } \\
\text { which may be conveyed by data representing that information. One then says that } \\
\text { data bears information (Dretske 1981). }\end{array}$ \\
\hline Metadata & $\begin{array}{l}\text { Metadata is literally data about data and provides information about the data. } \\
\text { Metadata plays a role of documenting data and may be categorized into many types } \\
\text { including: descriptive, structural, administrative, reference, and statistical metadata. } \\
\text { Metadata entities may also be categorized as search and discovery, usability, } \\
\text { access, usage, provenance, and quality metadata. Furthermore, metadata may be } \\
\text { categorized as business and technical metadata. }{ }^{19}\end{array}$ \\
\hline Examples/Notes & $\begin{array}{l}\text { Examples include data about related datasets (including provenance metadata), } \\
\text { software, publications, organisations, persons (such as producer of the data). } \\
\text { Typically, descriptive metadata includes such things as source \& time of creation. } \\
\text { For data and report publication it may include administrative metadata such as } \\
\text { authors \& date of submission. A PID is an example of metadata used to reference } \\
\text { data. An example is retention period metadata which defines the date when } \\
\text { retention of the data object should be evaluated. A metadata record may be curated } \\
\text { at dataset level (i.e., collection-level) or at file-level (i.e., granule-level). Metadata } \\
\text { contained in a NetCDF data file is considered as a granule-level metadata. }\end{array}$ \\
\hline Provenance & $\begin{array}{l}\text { Provenance is a type of historical information or metadata about the origin and } \\
\text { history of entities, locations, activities, and people involved in producing, } \\
\text { modifying, and preserving a piece of data or object. }\end{array}$ \\
\hline Examples/Notes & Examples include creation, attribution, or version history of managed data. \\
\hline $\begin{array}{l}\text { Quality } \\
\text { Assessment }\end{array}$ & $\begin{array}{l}\text { Quality Assessment is a totality of measures carried out consistently and } \\
\text { systematically in order to assure that a product conforms with the requirements of a } \\
\text { stated specification (ISO/IEC 2382-36 2019) }\end{array}$ \\
\hline Examples/Notes & $\begin{array}{l}\text { Assessment may be in the form of checks for evaluating accuracy or completeness } \\
\text { of data values, variable names and units, content of metadata elements. Assessment } \\
\text { is often guided by policy. These may include periodic data files integrity } \\
\text { validation. }\end{array}$ \\
\hline $\begin{array}{l}\text { Quality } \\
\text { Assurance }\end{array}$ & $\begin{array}{l}\text { Quality Assurance is part of quality management focused on providing confidence } \\
\text { that quality requirements will be fulfilled (ISO 9000: 2005) }\end{array}$ \\
\hline
\end{tabular}

\footnotetext{
18 https://codata.org/rdm-glossary/knowledge/

${ }^{19} \mathrm{https}$ //codata.org/rdm-glossary/metadata/
} 


\begin{tabular}{|c|c|}
\hline Examples/Notes & $\begin{array}{l}\text { Data quality assurance example: A quality assurance framework for Earth } \\
\text { observations (QA4EO) has been developed with a set of guidelines to provide } \\
\text { guidance on EO quality assurance (Yang 2013). Additional documentation can be } \\
\text { found at: http://qa4eo.org/documentation/. } \\
\text { Metadata quality assurance example: A metadata quality assessment framework } \\
\text { has been developed by the NASA the Analysis and Review of the Common } \\
\text { Metadata Repository (ARC) team, focusing on the metadata quality dimensions of } \\
\text { correctness, completeness, and consistency (Bugbee et al. 2021). }\end{array}$ \\
\hline $\begin{array}{l}\text { Data[set] } \\
\text { Quality } \\
\text { Attribute }\end{array}$ & $\begin{array}{l}\text { Data[set] Quality Attribute is a characteristic describing a certain aspect of } \\
\text { data[set]. }\end{array}$ \\
\hline Examples/Notes & $\begin{array}{l}\text { Examples of quality attributes include (positional, thematic or temporal) accuracy, } \\
\text { completeness, consistency, resolution, quality of service, homogeneity, } \\
\text { provenance. }\end{array}$ \\
\hline Quality Control & $\begin{array}{l}\text { Quality Control is part of quality management focused on fulfilling quality } \\
\text { requirements (ISO 9000:2005). }\end{array}$ \\
\hline \multicolumn{2}{|l|}{ Examples/Notes } \\
\hline $\begin{array}{l}\text { Data[set] } \\
\text { Quality } \\
\text { Dimensions }\end{array}$ & $\begin{array}{l}\text { Quality Dimensions represent the degree to which to which a set of inherent } \\
\text { characteristics of data[set] fulfill requirements (ISO 8000-2:2020) }\end{array}$ \\
\hline Examples/Notes & \\
\hline
\end{tabular}




\section{Appendix B. FAIR Principles and Earth Science Implementation Examples}

Table B1: Definitions of the FAIR Data Principles from Wilkinson et al. (2016), explanation based on the Swiss National Science Foundation, along with implementation examples of practices from the Earth sciences community.

\begin{tabular}{|c|c|c|c|}
\hline & $\begin{array}{l}\text { Definitions } \\
\text { (From Wilkinson et } \\
\text { al. 2016) }\end{array}$ & $\begin{array}{l}\text { Explanation } \\
\text { (Based on Swiss National Science } \\
\text { Foundation) }\end{array}$ & $\begin{array}{l}\text { Implementation Examples for } \\
\text { Earth Sciences Datasets }\end{array}$ \\
\hline \multirow{4}{*}{$\mathbf{F}$} & $\begin{array}{l}\text { F1. (meta)data are } \\
\text { assigned a globally } \\
\text { unique and eternally } \\
\text { persistent identifier. }\end{array}$ & $\begin{array}{l}\text { Each dataset is assigned a globally } \\
\text { unique and persistent identifier (PID), } \\
\text { for example a DOI, ARK, RRID... } \\
\text { These identifiers allow users to find, cite } \\
\text { and track (meta)data. }\end{array}$ & \multirow{6}{*}{$\begin{array}{l}\text { Dataset is assigned a DOI (a } \\
\text { globally unique and persistent } \\
\text { digital object identifier), that is } \\
\text { minted by DataCite (well- } \\
\text { established minting service } \\
\text { provider) with a defined } \\
\text { metadata schema, resolved to a } \\
\text { standardized layout dataset } \\
\text { landing web page (e.g., NOAA } \\
\text { OISST; NOAA/NSIDC Sea Ice } \\
\text { Concentration), driven by a } \\
\text { comprehensive dataset-level } \\
\text { metadata record that conforms to } \\
\text { ISO 19115-1 or WMO } \\
\text { Integrated Global Observing } \\
\text { System (WIGOS) metadata } \\
\text { standard (domain, national, or } \\
\text { international standards) and is } \\
\text { integrated into geoportal or } \\
\text { indexed in Google Data Search } \\
\text { or catalog.data.gov (US); } \\
\text { europeandataportal.eu (EU); } \\
\text { ecat.ga.gov.au (GA); } \\
\text { https://researchdata.edu.au/(AU) } \\
\text { (a data registry and discovery } \\
\text { platform with standard-based } \\
\text { protocols of metadata and APIs.) } \\
\text { The data can be accessed by } \\
\text { direct download or via data } \\
\text { servers such as Thematic Real- } \\
\text { time Environmental Distributed } \\
\text { Data Services (THREDDS), and } \\
\text { Environmental Research } \\
\text { Division's Data Access Program } \\
\text { (ERDDAP) server (e.g., NCEI } \\
\text { OISST; open, free data access } \\
\text { protocol that allows for }\end{array}$} \\
\hline & $\begin{array}{l}\text { F2. data are } \\
\text { described with rich } \\
\text { metadata (defined by } \\
\text { R1 below). }\end{array}$ & $\begin{array}{l}\text { Each dataset is thoroughly (see below, } \\
\text { in R1) described: the metadata } \\
\text { document how the data was generated, } \\
\text { under what terms (license) and how it } \\
\text { can be (re)used, and provides the } \\
\text { necessary context for proper } \\
\text { interpretation. This information needs to } \\
\text { be machine-readable. }\end{array}$ & \\
\hline & $\begin{array}{l}\text { F3. metadata clearly } \\
\text { and explicitly } \\
\text { include the identifier } \\
\text { of the data it } \\
\text { describes. }\end{array}$ & $\begin{array}{l}\text { The metadata and the dataset they } \\
\text { describe can be stored in separate files. } \\
\text { The association between a metadata file } \\
\text { and the dataset is obvious thanks to the } \\
\text { mention of the dataset's PID in the } \\
\text { metadata. }\end{array}$ & \\
\hline & $\begin{array}{l}\text { F4. (meta)data are } \\
\text { registered or indexed } \\
\text { in a searchable } \\
\text { resource. }\end{array}$ & $\begin{array}{l}\text { Metadata are used to build easily } \\
\text { searchable indexes of datasets. These } \\
\text { resources will allow us to search for } \\
\text { existing datasets similar to searching for } \\
\text { a book in a library. }\end{array}$ & \\
\hline \multirow[t]{2}{*}{$\mathbf{A}$} & $\begin{array}{l}\text { A1. (meta)data are } \\
\text { retrievable by their } \\
\text { identifier using a } \\
\text { standardised } \\
\text { communications } \\
\text { protocol. }\end{array}$ & $\begin{array}{l}\text { If one knows a dataset's identifier and } \\
\text { the location of where it is archived, one } \\
\text { can at least access the metadata. } \\
\text { Furthermore, the user knows how to } \\
\text { proceed to get access to the data. }^{2}\end{array}$ & \\
\hline & $\begin{array}{l}\text { A1.1. the protocol is } \\
\text { open, free, and } \\
\text { universally } \\
\text { implementable. }\end{array}$ & $\begin{array}{l}\text { Anyone with a computer and an internet } \\
\text { connection can access at least the } \\
\text { metadata. }\end{array}$ & \\
\hline
\end{tabular}




\begin{tabular}{|c|c|c|c|}
\hline & $\begin{array}{l}\text { A1.2. the protocol } \\
\text { allows for an } \\
\text { authentication and } \\
\text { authorization } \\
\text { procedure, where } \\
\text { necessary. }\end{array}$ & $\begin{array}{l}\text { It often makes sense to request users to } \\
\text { create a user account on a repository. }{ }^{3} \\
\text { This allows authentication of the owner } \\
\text { (or contributor) of each dataset, and to } \\
\text { potentially set user specific rights. }\end{array}$ & \multirow{2}{*}{$\begin{array}{l}\text { authentication and authorization } \\
\text { if needed.) } \\
\text { ISO 19115-1 collection-level } \\
\text { (dataset) metadata record } \\
\text { explicitly includes dataset PID, } \\
\text { the data access protocol, the data } \\
\text { usage and access license, and } \\
\text { provenance elements. It also } \\
\text { includes vocabulary terms and } \\
\text { their URI(s). }\end{array}$} \\
\hline & $\begin{array}{l}\text { A2. metadata are } \\
\text { accessible, even } \\
\text { when the data are no } \\
\text { longer available. }\end{array}$ & $\begin{array}{l}\text { Maintaining all datasets in a readily } \\
\text { usable state eternally would require an } \\
\text { enormous amount of curation work } \\
\text { (adapting to new standards for formats, } \\
\text { converting to different formats if } \\
\text { specifically needed software is } \\
\text { discontinued, etc.). Keeping the } \\
\text { metadata describing each dataset } \\
\text { accessible, however, can be done with } \\
\text { much less resources. This allows } \\
\text { building of comprehensive data indexes } \\
\text { including all current, past and } \\
\text { potentially arising datasets. }\end{array}$ & \\
\hline I & $\begin{array}{l}\text { I1. (meta)data use a } \\
\text { formal, accessible, } \\
\text { shared, and broadly } \\
\text { applicable language } \\
\text { for knowledge } \\
\text { representation. }\end{array}$ & $\begin{array}{l}\text { Interoperability typically means that } \\
\text { each computer system has at least } \\
\text { knowledge of the other system's formats } \\
\text { in which data is exchanged. If } \\
\text { (meta)data are to be searchable and if } \\
\text { compatible data sources should be } \\
\text { combinable in a (semi)automatic way, } \\
\text { computer systems need to be able to } \\
\text { decide if the content of datasets are } \\
\text { comparable. Ontologies help with } \\
\text { constraining the meaning of terms } \\
\text { (Cunningham et al. 2016). Obvious } \\
\text { issues arise when different languages } \\
\text { are used to describe the data or when } \\
\text { spelling errors make the comparison of } \\
\text { descriptions and variable names more } \\
\text { difficult. It is critical to use controlled } \\
\text { vocabularies and a well-defined } \\
\text { framework to describe and structure } \\
\text { (meta)data in order to ensure findability } \\
\text { and interoperability of datasets. }\end{array}$ & $\begin{array}{l}\text { Data in NetCDF (Network } \\
\text { Common Data Format - } \\
\text { interoperable; community } \\
\text { standard) with global attributes } \\
\text { for provenance and relevant data } \\
\text { sources; compliant with NetCDF } \\
\text { Climate and Forecast (CF) } \\
\text { Metadata Conventions }{ }^{4} \text { (e.g., } \\
\text { standard variable names, } \\
\text { units, ...), utilizing Global } \\
\text { Change Master Directory } \\
\text { (GCMD) keywords }{ }^{5} \text { or other } \\
\text { domain specific vocabularies. } \\
\text { (All GCMD keywords are } \\
\text { publicly available and GCMD } \\
\text { assigns a UUID (universally } \\
\text { unique identifier) for each of the } \\
\text { keywords.) }\end{array}$ \\
\hline & $\begin{array}{l}\text { I2. (meta)data use } \\
\text { vocabularies that } \\
\text { follow FAIR } \\
\text { principles. }\end{array}$ & $\begin{array}{l}\text { The controlled vocabulary used to } \\
\text { describe datasets needs to be } \\
\text { documented. This documentation } \\
\text { needs to be easily findable and } \\
\text { accessible by anyone who uses the } \\
\text { dataset. }\end{array}$ & $\begin{array}{l}\text { schema as they go so they are } \\
\text { self-defining (Hey et al. 2009). } \\
\text { So are HDF (Hierarchical Data } \\
\text { Format) files and their } \\
\text { variations. }\end{array}$ \\
\hline
\end{tabular}




\begin{tabular}{|c|c|c|c|}
\hline & $\begin{array}{l}\text { I3. (meta)data } \\
\text { include qualified } \\
\text { references to other } \\
\text { (meta)data. }\end{array}$ & $\begin{array}{l}\text { If the dataset builds on another dataset, } \\
\text { if additional datasets are needed to } \\
\text { complete the data, or if complementary } \\
\text { information is stored in a different } \\
\text { dataset, this needs to be specified. In } \\
\text { particular, the scientific link between the } \\
\text { datasets needs to be described. } \\
\text { Furthermore, all datasets need to be } \\
\text { properly cited (i.e., including their } \\
\text { persistent identifiers). For provenance, it } \\
\text { is essential that each derivative dataset } \\
\text { links to the version of the source dataset. } \\
\text { Through identifiers it should be possible } \\
\text { to link back to the original source } \\
\text { version of the data and enhance } \\
\text { reproducibility of the higher level data } \\
\text { products (Klump et al. 2021). }\end{array}$ & $\begin{array}{l}\text { Standards for capturing the data } \\
\text { provenance: W3C PROV, } \\
\text { DCAT2 or ISO 19115-1 } \\
\text { Metadata is also given with a } \\
\text { knowledge representation data } \\
\text { model such as RDFS or OWL. } \\
\text { Links to other related datasets } \\
\text { are given, e.g., in the case of } \\
\text { simulation results of a regional } \\
\text { atmospheric model, the dataset } \\
\text { with the boundary conditions of } \\
\text { the simulation is mentioned in } \\
\text { the metadata. } \\
\text { Related publications to the } \\
\text { dataset are cited with their } \\
\text { respective PIDs, such as the } \\
\text { publication for which the data } \\
\text { was used, about data sources, } \\
\text { error estimates, validation } \\
\text { results, and/or auxiliary data } \\
\text { (e.g., published boundary/initial } \\
\text { conditions and forcing datasets } \\
\text { for model data.) }\end{array}$ \\
\hline \multirow{3}{*}{$\mathbf{R}$} & $\begin{array}{l}\mathrm{R} 1 . \text { meta(data) are } \\
\text { richly described with } \\
\text { a plurality of } \\
\text { accurate and relevant } \\
\text { attributes, }\end{array}$ & $\begin{array}{l}\text { Description of a dataset is required at } \\
\text { two different levels: (1) metadata } \\
\text { describing the dataset (intrinsic): } \\
\text { what does the dataset contain, how was } \\
\text { the data generated, how has it been } \\
\text { processed, how can it be reused ... (2) } \\
\text { metadata describing the data submitter- } \\
\text { defined: any needed information to } \\
\text { properly use the data, such as definitions } \\
\text { of the variable names. }\end{array}$ & \multirow{3}{*}{$\begin{array}{l}\text { See examples in F \& A - may } \\
\text { repeat relevant examples in this } \\
\text { aspect if deemed necessary. } \\
\text { Metadata management is core to } \\
\text { support discovery and reuse of } \\
\text { data products. Wagner et al. } \\
2021 \text { proposed a tool for } \\
\text { automated metadata and data } \\
\text { quality extraction to foster the } \\
\text { provision of FAIR data by } \\
\text { generating (complementing) } \\
\text { metadata for collected data, and } \\
\text { by providing structured } \\
\text { machine-readable quality } \\
\text { information }\end{array}$} \\
\hline & $\begin{array}{l}\text { R1.1. (meta)data are } \\
\text { released with a clear } \\
\text { and accessible data } \\
\text { usage licence. }\end{array}$ & $\begin{array}{l}\text { The conditions under which the data can } \\
\text { be used should be clear to machines and } \\
\text { humans. This has to be specified in the } \\
\text { metadata describing a dataset. }\end{array}$ & \\
\hline & $\begin{array}{l}\mathrm{R} 1.2 . \text { (meta)data are } \\
\text { associated with } \\
\text { detailed provenance. }\end{array}$ & $\begin{array}{l}\text { Detailed information about the } \\
\text { provenance of data is necessary for } \\
\text { reuse: this will, for example, allow } \\
\text { researchers to understand how the data } \\
\text { was generated, in which context it can } \\
\text { be reused, and how reliable it is. } \\
\text { Provenance is a central component in }\end{array}$ & \\
\hline
\end{tabular}




\begin{tabular}{|c|c|}
\hline & scientific databases to validate data. \\
\hline $\begin{array}{l}\text { R1.3. (meta)data } \\
\text { meet domain- } \\
\text { relevant community } \\
\text { standards. }\end{array}$ & $\begin{array}{l}\text { It is easier to reuse datasets if they are } \\
\text { similar: same type of data, data } \\
\text { organized in a standardized way, well- } \\
\text { established and sustainable file formats, } \\
\text { documentation (metadata) following a } \\
\text { common template and using common } \\
\text { vocabulary. If community standards or } \\
\text { best practices for data archiving and } \\
\text { sharing exist, they should be followed. } \\
\text { Note that quality issues are not } \\
\text { addressed by the FAIR principles. How } \\
\text { reliable data is lies in the eye of the } \\
\text { beholder and depends on the foreseen } \\
\text { application. }\end{array}$ \\
\hline
\end{tabular}

${ }^{1}$ Swiss National Science Foundation: Explanation of the FAIR data principles. Available at: http://www.snf.ch/SiteCollectionDocuments/FAIR principles translation SNSF logo.pdf

${ }^{2}$ This is not given - Additional information needs to be documented to inform users how to proceed to get access to data. For novice users who do not know anything about data access, but want to use the data for decision making, they will languish as frustration builds.

${ }^{3}$ This requirement may actually hinder data sharing when anonymity needs to be protected - should not be used widely and only for data that requires access constraints which can be specified in metadata along with information on the type of authentication and/or authorization. For machine access, authentication can be achieved via an access key in many APIs.

${ }^{4}$ Additional information on the NetCDF Climate and Forecast (CF) Metadata Conventions:

http://cfconventions.org/cf-conventions/cf-conventions.html

${ }^{5}$ Additional information on the Global Change Master Directory (GCMD) keywords: https://earthdata.nasa.gov/earth-observation-data/find-data/gcmd/gcmd-keywords 


\section{Appendix C. Dataset Quality Attributes, Aspects, and Dimensions}

A good number of distinctive quality attributes or characteristics may be associated with a dataset. For example, from a data consumer perspective, over 179 individual data quality attributes were identified by a survey highlighted in Wang and Strong (1996). Many of these quality attributes may be overlapping to a certain extent, for example, accuracy, correctness, free from bias, etc.

Multiple quality attributes of a dataset may be grouped together to emphasize a certain aspect of data and information quality such as findability, accessibility, interoperability, and reusability as FAIR for data sharing (Wilkinson et al. 2016) or accuracy, precision, and uncertainty for scientific quality aspect as defined by Ramapriyan et al. (2017).

Data quality attributes can be categorized into different dimensions and aspects. For instance, Wang and Strong (1996) prioritized 179 quality attributes down to 15 and categorized them into four dimensions that are important to data consumers:

- Intrinsic (accuracy, objectivity, believability, reputation);

- Contextual (relevance, value-added, timeliness, completeness, appropriate amount of data);

- Representational (interpretability, ease of understanding, concise representation and representational consistency);

- Accessibility (accessibility, access security).

Redman (1996) defined accuracy, completeness, consistency, and currency as four quality dimensions of data values. Garvin (1987) proposed eight dimensions of product quality management that can be used to analyze product quality characteristics for a company to deliver reliable products: performance, features, reliability, conformance, durability, serviceability, aesthetics, and perceived quality. Bruce and Hillmann (2004) identified completeness, correctness, provenance, consistency, timeliness and accessibility as common metadata quality dimensions.

ISO/IEC 25010 (2011) refers to dimension and attribute as "characteristic" and "subcharacteristic" and defines eight quality characteristics in its software product quality model: functional suitability, performance efficiency, compatibility, usability, reliability, security, maintainability, and portability. ISO 19157 (2013) defines quality along following dimensions: accuracy (spatial, thematic and temporal), completeness, consistency and metaquality.

Ramapriyan et al. (2017) categorized quality attributes into four aspects based on the full dataset life cycle outlined by the ring of circles in Figure 1; also shown in Figure $\mathrm{C} 1$. 


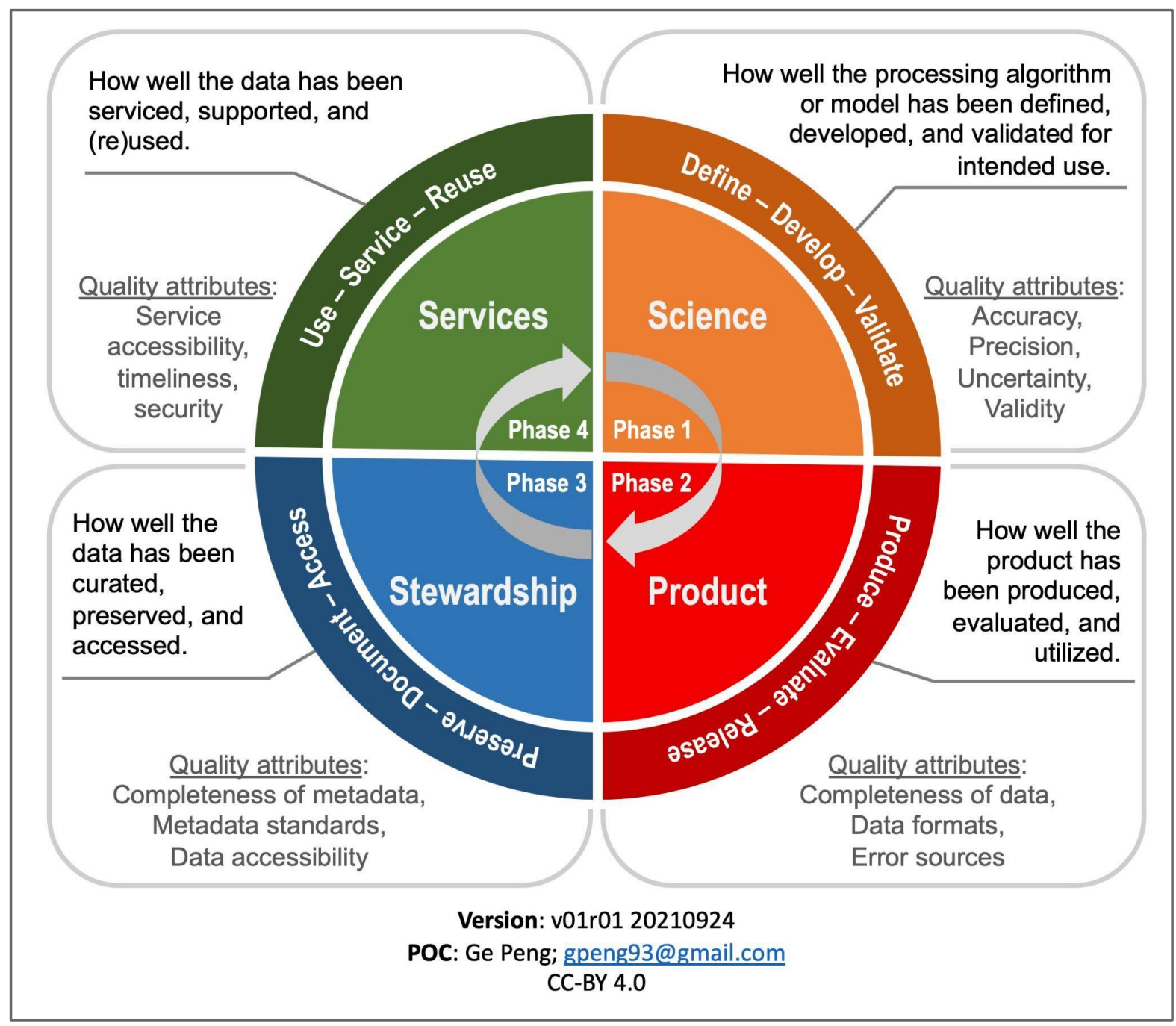

Figure C1: Description of quality aspects throughout a dataset lifecycle, three key stages and a few quality attributes associated with each quality aspect. The quality aspects and associated phases are based on Ramapriyan et al. (2017) with the following changes, based on feedback from the ESIP community and the International FAIR DQI Working Group: i) Replaced "Assess" by "Evaluate" in the Product aspect; ii) Replaced "Deliver" by "Release" in the Product aspect; and iii) Replaced "Maintain" by "Document" in the Stewardship aspect. Additionally, completeness of metadata is moved from the Product to Stewardship aspect. Creator: Ge Peng; Contributors to conceptual design: Lesley Wyborn and Robert Downs.

For each quality aspect, three key stages are identified. A description of these stages and associated document types is provided below in Table $\mathrm{C} 1$. The descriptions of the stages and document types are preliminary and tend to lean towards practices associated with managing satellite data, especially climate data, and may be modified according to feedback from other domains. 
Table C1: Key stages of dataset lifecycle and associated quality aspect and document types

\begin{tabular}{|c|c|c|}
\hline Key Stage & Description & $\begin{array}{l}\text { Quality Aspect } \\
\text { /Document Type }\end{array}$ \\
\hline Define & $\begin{array}{l}\text { Planning/designing/defining data accuracy and } \\
\text { precision requirements for the intended use. }\end{array}$ & \multirow{3}{*}{$\begin{array}{l}\text { Science Quality } \\
\text { Aspect/Science Report }\end{array}$} \\
\hline Develop & $\begin{array}{l}\text { Developing or implementing the software for the } \\
\text { processing algorithm, quality assurance procedure } \\
\text { for input data, quality control procedure for data } \\
\text { generation, and data management plan. }\end{array}$ & \\
\hline Validate & $\begin{array}{l}\text { Assessing/validating the processing algorithm to } \\
\text { ensure that the data product meets defined } \\
\text { requirements. Generating the Science Report } \\
\text { document including the data accuracy and } \\
\text { precision requirements, intended purpose, and the } \\
\text { timeline for data availability. }\end{array}$ & \\
\hline Produce & $\begin{array}{l}\text { Generating the data product according to the } \\
\text { defined production working flow. }\end{array}$ & \multirow{3}{*}{$\begin{array}{l}\text { Product Quality } \\
\text { Aspect/Product Report }\end{array}$} \\
\hline Evaluate & $\begin{array}{l}\text { Evaluating the quality of the data product against } \\
\text { other similar data products; Initial analysis often } \\
\text { carried out by scientist(s) who developed and } \\
\text { produced the data product. The maturity of the } \\
\text { software may also be evaluated. Generating } \\
\text { Product Report document including description of } \\
\text { actual production workflow, data processing } \\
\text { flowchart, QA/QC procedures, data error sources } \\
\text { and uncertainty. }\end{array}$ & \\
\hline Release & $\begin{array}{l}\text { Initial release to research community or delivery } \\
\text { to a data center or repository; often limited in data } \\
\text { access with minimum metadata and } \\
\text { documentation. Users are required to have } \\
\text { extensive knowledge about the data product and } \\
\text { the subject the product was designed for. }\end{array}$ & \\
\hline Preserve & $\begin{array}{l}\text { Ingesting and archiving data; curating rich } \\
\text { dataset-level metadata. }\end{array}$ & \multirow{3}{*}{$\begin{array}{l}\text { Stewardship Quality } \\
\text { Aspect/Stewardship Report }\end{array}$} \\
\hline Document & $\begin{array}{l}\text { Maintaining and documenting: Ensuring data } \\
\text { fixation; evaluating the stewardship maturity of } \\
\text { the dataset and generating the Stewardship Report } \\
\text { document. }\end{array}$ & \\
\hline Access & Enabling data discovery and access & \\
\hline
\end{tabular}




\begin{tabular}{|c|c|c|}
\hline Use & $\begin{array}{l}\text { Enabling data utilization and application by the } \\
\text { wide user community. }\end{array}$ & \multirow{3}{*}{$\begin{array}{l}\text { Use \& Service Quality } \\
\text { Aspect/Service Report }\end{array}$} \\
\hline Service & $\begin{array}{l}\text { Providing i) the secure and stable infrastructure } \\
\text { for data users to find, obtain, and effectively use } \\
\text { the data; ii) User support and engagement; and iii) } \\
\text { venue for collecting user feedback. }\end{array}$ & \\
\hline Reuse/Improve & $\begin{array}{l}\text { Reused in purposes rather than initially designed } \\
\text { for; Data users may not have in-depth knowledge } \\
\text { of the dataset and science domain it was designed } \\
\text { for. Improvement in data, metadata or service } \\
\text { capability may be made in responding to users } \\
\text { feedback. It may need to go to the planning phase } \\
\text { for a new version of the data product. }\end{array}$ & \\
\hline Document Type & Description & Examples/Notes \\
\hline Science Report & $\begin{array}{l}\text { Document that: i) describes the data product } \\
\text { requirements or specifications including sensor or } \\
\text { instrument characteristics if applicable, accuracy } \\
\text { and precision and intended use, ii) describes the } \\
\text { processing algorithm, how the algorithm is } \\
\text { assessed and validated, iii) defines the process for } \\
\text { developing and producing the data product, and } \\
\text { iv) may include a data management plan for it to } \\
\text { be accessed, stewarded and serviced. }\end{array}$ & $\begin{array}{l}\text { NASA Mission/Program } \\
\text { Document: Operation } \\
\text { IceBridge Level-1 Science } \\
\frac{\text { Requirements and }}{\text { Scientific Basis }} \\
\text { ISO } 19131 \text { compliant data } \\
\text { product specification }\end{array}$ \\
\hline Product Report & $\begin{array}{l}\text { Document that describes: i) how the data product } \\
\text { was generated (algorithm and process flow), ii) } \\
\text { what input data (source and ancillary) were used } \\
\text { including description of sensor or instrument } \\
\text { characteristics if applicable, as well as iii) how } \\
\text { the data product was evaluated and estimated } \\
\text { product error sources or uncertainty. }\end{array}$ & $\begin{array}{l}\text { One can simply view the } \\
\text { Product Report as a } \\
\text { description of the state of } \\
\text { the product quality of the } \\
\text { dataset that has been } \\
\text { produced. } \\
\text { An example of a product }\end{array}$ \\
\hline
\end{tabular}




\begin{tabular}{|c|c|c|}
\hline & & $\begin{array}{l}\text { document is algorithm } \\
\text { theoretical basis document } \\
\text { (ATBD) that originated } \\
\text { from NASA, commonly } \\
\text { used for satellite data } \\
\text { products. } \\
\text { NOAA climate data record } \\
\text { (CDR) program has } \\
\text { adapted it and developed a } \\
\text { template: } \\
\text { NOAA C-ATBD Template; } \\
\text { C-ATBD for OISST }\end{array}$ \\
\hline $\begin{array}{l}\text { Stewardship } \\
\text { Report }\end{array}$ & $\begin{array}{l}\text { Report documents the stewardship practices } \\
\text { applied to the dataset and summarizes the current } \\
\text { stage of stewardship maturity of those practices, } \\
\text { including those for ensuring the scientific and } \\
\text { product quality of the dataset and enabling data } \\
\text { access and re(use). }\end{array}$ & $\begin{array}{l}\text { One can simply view the } \\
\text { stewardship maturity report } \\
\text { as a description of the } \\
\text { current state of the quality } \\
\text { of stewardship practices } \\
\text { applied to the dataset to } \\
\text { enable data access and use. } \\
\text { Data Stewardship Maturity } \\
\text { Report }\end{array}$ \\
\hline Service Report & $\begin{array}{l}\text { Report summarizes a dataset use metric such as } \\
\text { data download and citations, and impact metric. } \\
\text { such as if the data has been used in national or } \\
\text { international climate monitoring and assessment } \\
\text { reports or by private sectors. User feedback for } \\
\text { further improvement should also be described. }\end{array}$ & $\begin{array}{l}\text { One can simply view the } \\
\text { Service Report as a } \\
\text { description of the current } \\
\text { state of the quality of use } \\
\text { and impact of the dataset. } \\
\text { Website with dataset } \\
\text { download metrics - to be } \\
\text { added. } \\
\text { NOAA Data Impact } \\
\text { Reports: Retail and } \\
\text { Manufacturing; Logistics } \\
\text { and Transport; } \\
\underline{\text { Reinsurance }} \\
\text { Or something similar to } \\
\underline{\text { NASA EOSDIS annual }} \\
\text { data metrics report but for } \\
\text { individual datasets. }\end{array}$ \\
\hline
\end{tabular}

* ISO 19131 can be used to describe specifications of the product, to benchmark the finished product, to potentially identify where the product did not meet specifications. In some areas this can be seen as a measure of 'quality' of the final product. 


\section{Appendix D. Dataset Quality Assessment Types}

As outlined in section $4 \mathrm{c}$, quality attributes and dimensions commonly assessed include accuracy, completeness, currency, relevancy, conformity, and consistency (e.g., Redman 1996; Austin et al. 2019). There are different ways to assess them through the entire data lifecycle and may be grouped as technical, scientific and stewardship assessments. The technical assessment regards the data and metadata files checks, while the scientific assessment consists of data content and cross-data content checks (Stockhause et al. 2012). As an example, when the evaluator looks for the metadata standard compliance such as compliance against the Attribute Convention for Data Discovery (ACDD) ${ }^{20}$ here the evaluator is checking that the attributes describing the files are according to a set of community-recognized metadata characteristics (e.g., specific date-time format). There is no check of the file content, no scientific evaluation in this case, but a metadata conformity check, it is a purely technical assessment (Stockhause et al. 2012, Evans et al. 2017). One the other hand, when the evaluator plots the dataset variable and checks for reproducibility of El Niño events against skill metrics, here the scientific soundness of the data content is considered (e.g., Haiden et al. 2019).

In general, the technical assessment checks data files consistency among the distributed data and metadata repositories and conformance to formal standards. Checks can be as different as the specific needs of the service and may include compliance against community standards (conformity), temporal and spatial checks for unexpected gaps (completeness), identification of corrupted values (integrity). Lawrence et al. (2011) postulates a generic checklist for technical and scientific assessments. As far as the scientific assessment is concerned, this refers to scientific analyses of the physical content described by the dataset to check for its scientific soundness. Given the nature of this assessment, it is typically carried out by domain experts. Analyses may include uncertainty characterization, validation against reference datasets, reproducibility of temporal/spatial patterns. These are typical quality attributes that may be grouped as scientific (Ramapriyan et al. 2017) and are addressed in the scientific assessments. The two concepts overlap to some extent, but are distinct because the former refers to which quality dimension is considered, whereas the latter refers to how the quality attributes in the quality dimension can be evaluated. The technical and scientific assessments are often accompanied by the stewardship assessment to guarantee accessibility and understandability of the dataset distributed. Here we refer to stewardship as anything of relevance in dataset quality that is not associated with the data and metadata file content, e.g., documents accompanying the dataset describing how to use it. Typical examples regard the description of the algorithms or models used to produce and process the data, provision of the DOI and license of use, verified network address to access the data, and information about the archiving procedures. The goal is to ensure that the dataset is well documented, the processing chain is visible, the data readily obtainable and usable.

At times, the assessments described above are accompanied by maturity assessment models. These are formal approaches to support compliance verification, usually defined in discrete stages to evaluate practices applied in organizations, services or products. Maturity is meant as a desired or anticipated evolution from a more ad hoc approach to a more managed process (Peng 2018). Datasets associated with high maturity are produced following best practices of the community and in a more managed fashion, increasing user trust in the data record provided. It should be noted

${ }^{20} \mathrm{https}$ ://wiki.esipfed.org/Attribute_Convention_for_Data_Discovery_1-3 
that a low maturity rating does not necessarily imply low scientific value for a dataset. It can happen especially for datasets managed by a single investigator that may be flagged to have low maturity due to poor quality in metadata, documentation and accessibility.

The types of assessments explained above indicate that there is considerable scope for subjective reviewer expertise, but some of the assessments are rather mechanical and amenable to automated checking. Automated checking is important for a number of reasons, the quality assessments need to be consistent (subjective variability in the analyses and human errors are minimized) and sustainable, especially when done on a routine basis and for a large number of datasets. This calls for efficiency and scalability, which can be supported by considering automated processes for evaluation. Furthermore, the quality information produced should be frequently updated to contain the most current details, which again requires automated processes in place. Automatization is possible if the assessments are machine-readable. A key element to produce dataset quality information that is both machine- and human-readable is to capture this information in standardized forms and distribute it digitized. To wrap up, given the need for scalability and machine readability, dataset quality assessments are recommended to be as much as possible automated, particularly in an operational environment. Operational environments are characterized by routine assessments that have to be "timely", "frequently updated" and "scalable" (Leadbetter et al. 2020). Therefore, it is essential to evaluate quality attributes and represent the quality information in a systematic and consistent way. This implies that the data quality management (DQM) has to develop and maintain capabilities to assess and describe data quality.

Following the TRUST Principles for Data Repositories (Lin et al. 2020), the dataset quality assessment activities need to be supported by software, hardware, and technical services by implementing the relevant and appropriate standards, tools (e.g., Henzen et al. 2021), and technologies for data management and curation. The technical developments underlying the automatization solution should not be underrated when budgeting the work for DQM. Pain is inefficiency and frustration of the domain experts who can better dedicate their knowledge in scientific added value analyses rather than in repetitive manual work. DQM should adopt clear definitions of the competencies, roles and responsibilities required for staff involved in the assessments, as well as develop plans for capacity building and training to ensure availability of the people with the competencies required (Leadbetter et al. 2020). Capacity building refers to human skills, organization tools and resources in general. It paves the way to an operational DQM function optimized in terms of cost-effective infrastructure and maintenance of tools.

All the above indicates that the production of comprehensive quality information requires crossdisciplinary expert knowledge and needs to be curated by domain experts ranging from science, data management, to computer engineering. This is extremely challenging for any single individual. Therefore, dataset quality practitioners are usually organized in well-established functions inside data dissemination services. Depending on the resources and maturity of the established function, the scope can extend from quality control only to comprehensive quality management activities. What guarantees that data is not corrupted and is accurate are the quality control procedures plus a series of protocols to avoid new quality issues in the system (e.g., database). This latter element is part of the quality assurance, which is a proactive process focused on "preventing defects" aiming at maintaining the desired level of quality in a data collection. In contrast, the quality control is a reactive process focused on "detecting defects" and encompasses 
a set of procedures applied to identify and flag the errors to ensure that data available to users are sufficiently reliable to be used with confidence (ISO 9000 2005; WMO 2019).

Both quality control and quality assurance can consider documentation, scientific (e.g., uncertainty) and technical (e.g., temporal completeness) aspects. The information acquired during the quality control/assurance processes has to be disseminated to improve "usability" of the data and "verifiability" of the quality procedures applied, with the ultimate goal of increasing trustworthiness in data and information disseminated by the operational services. How to disseminate this quality-related information to end-users is an additional aspect of quality management. Dissemination is becoming increasingly important to guide users to understand the datasets and to promote data uptake. However, conveying dataset quality information in a manner that is understandable and usable to data users is often a challenge (Ramapriyan et al. 2017). At the current status, there is no consensus about a standardized way to disseminate this information and it also depends on the audience towards which this information is intended (Baker et al. 2016). The audience, i.e., the data users, may feedback which of the disseminated information is most relevant and what can be improved. User engagement activities are thus an additional component that may (or may not) be included in DQM.

The dataset quality information should evolve according to the user needs. Understanding "user satisfaction" or "meeting or exceeding user expectation" (Evans and Lindsay 2005) could prove helpful in characterizing data quality in a specific context. The user engagement has to establish several channels to collect the user requirements from the audience identified, which will benefit from the quality information disseminated. The requirements collected can be then analysed to reveal weaknesses, new needs and data issues.

Having a user engagement component in the DQM, including evaluating the understandability of the quality information with the users, may improve guidance in the strategic decisions for better dissemination of the dataset quality information and may help to identify issues with the data that might have escaped the quality control procedures, which in turn leads to improvement of the procedures applied. An additional benefit relates to the fact that involving users increases transparency in the DQM procedures and, more in general, increases trust about the data served. Co-designing with the users creates a strong sense of ownership of the product development process by the user (Hewitt et al. 2017). These aspects are well-aligned with the TRUST Principles for Data Repositories (Lin et al. 2020). Indeed, the TRUST principles highlight the need to make data quality assessed and disseminated for prospective users. This endeavour has to ensure that the expectations of target user communities are met in order to foster usability by enabling users to understand and assess dataset quality. 


\section{Appendix E. Additional Examples of Quality Assessment Models}

This appendix provides additional examples of assessment models for the Earth science community:

- ATMODAT metadata assessment checklists (Ganske et al. 2020a; 2020b);

- Consistency of Satellite Climate Data Records for Earth System Monitoring (Popp et al. 2020);

- CORE-CLIMAX Product System Maturity Matrix (EUMETSAT 2013);

- Data Operational Readiness Levels (Moe et al. 2018; https://www.esipfed.org/orl);

- JPSS Data Product Maturity Matrix (Zhou et al. 2016);

- Metadata checklist by LTER (O’Brien et al. 2016);

- NASA IMPACT ARC Metadata Quality Framework (Bugbee et al. 2021);

- NASA Technical Readiness Level (Mankins 1995; 2009);

- NCEI/ESIP-DSC Data Use and Services Maturity Matrix (Serv-MM Working Group 2018);

- NOAA CDR Product Maturity Matrix (Bates and Privette 2012; Self-evaluation template available at: https://www.ncdc.noaa.gov/cdr/development-guidelines);

- Operational Readiness Levels (Moe et al. 2018; https://www.esipfed.org/orl); (ORL Ranking Tool - limited availability: https://survey123.arcgis.com/share/23ada947ba014cf19f651543c2ee8fb3)

- Quality assessment concept of the World Data Center for Climate and its application to CMIP5 data (Stockhause et al. 2012);

- Quality Assurance Templates (Nightingale et al. 2019);

- Quality Maturity Matrix used at DKRZ (Höck and Toussaint, 2019);

- RDA FAIR Data Maturity Indicators (RDA FAIR Data Maturity Model Working Group, 2020);

- RDA-SHARC Evaluation (Romain et al. 2018);

- WDS/RDA Assessment of Data Fitness for Use WG Checklist for Evaluation of Dataset Fitness for Use (Austin et al. 2019);

- Ocean Best Practices System (Pearlman et al. 2019). ${ }^{21}$

${ }^{21} \mathrm{https}: / /$ www.oceanbestpractices.org/ 


\section{Appendix F. Community Controlled Vocabularies and Content Standards}

This Appendix provides some examples of controlled vocabularies and content standards in the Earth science community.

Climate and Forecast (CF) Metadata Convention (https://cfconventions.org) maintains and onboards standard variable names, standardized regional names and area types at the data file level. It is developed for the NetCDF data format but can be adopted by others.

Global Change Master Directory (GCMD) maintains and expands keywords for Earth science, services, data providers, projects, instruments/sensors, platforms/sources, locations, horizontal, vertical, and temporal data resolutions, URL content types, granule data formats, measurement types, and chronostratigraphic units - a total of thirteen sets of keywords currently (GCMD 2020). Each GCMD keyword is publicly available and assigned a universally unique identifier (UUID).

The British Oceanographic Data Centre (BODC) maintains a collection of controlled vocabularies developed by the marine science communities:

https://vocab.nerc.ac.uk/collection/

The United States Geological Survey maintains a Landsat glossary at:

https://www.usgs.gov/core-science-systems/nli/landsat/landsat-glossary

Global Climate Observing System (GCOS) maintains a list of essential climate variables that are critical to the characterization of Earth's climate (https://public.wmo.int/en/programmes/globalclimate-observing-system/essential-climate-variables). The definitions can be found at:

https://www.ncdc.noaa.gov/gosic/gcos-essential-climate-variable-ecv-data-access-matrix.

Content specifications for preserving Earth sciences data products can be found in (Ramapriyan and Moses 2012), which is now a part of ISO standards (ISO 19165-2 2020).

The World Wide Web Consortium (W3C) maintains a controlled data catalog vocabulary (DCAT) and the current version can be found at:

https://www.w3.org/TR/vocab-dcat-2/

ESIP Attribute Convention for Data Discovery (ACDD) is maintained at: https://wiki.esipfed.org/Attribute_Convention_for_Data_Discovery_1-3 
Appendix G. List of Author Names, Affiliations, Roles and/or Subject Areas and ORCIDs

\begin{tabular}{|c|c|c|c|}
\hline Name (1st Last) & Affiliation(s), Country & $\begin{array}{c}\text { Sector(s), Roles and/or } \\
\text { Subject Areas }\end{array}$ & ORCID \\
\hline Ge Peng & $\begin{array}{l}\text { The University of Alabama in } \\
\text { Huntsville (UAH)/NASA } \\
\text { MSFC IMPACT (Previously } \\
\text { NCSU/NOAA NCEI), USA }\end{array}$ & $\begin{array}{l}\text { Academic, Science Center; } \\
\text { Data Producer, Data User, } \\
\text { Scientific Steward, } \\
\text { Scientific Data Stewardship }\end{array}$ & 0000-0002-1986-9115 \\
\hline Carlo Lacagnina & $\begin{array}{l}\text { Barcelona Supercomputing } \\
\text { Center (BSC), Spain }\end{array}$ & $\begin{array}{l}\text { Service Provider, Data } \\
\text { Quality Management }\end{array}$ & 0000-0001-9434-9809 \\
\hline Robert R. Downs & Columbia University, USA & $\begin{array}{l}\text { Academic, Domain Data } \\
\text { Center, Digital Archivist }\end{array}$ & $0000-0002-8595-5134$ \\
\hline $\begin{array}{l}\text { Hampapuram } \\
\text { Ramapriyan }\end{array}$ & $\begin{array}{c}\text { Science Systems and } \\
\text { Applications, Inc./NASA } \\
\text { GSFC, USA }\end{array}$ & $\begin{array}{l}\text { Government Contractor, } \\
\text { Data Systems (Data } \\
\text { Stewardship, Information } \\
\text { Quality, Provenance) }\end{array}$ & $0000-0002-8425-8943$ \\
\hline Ivana Ivánová & Curtin University, AUS & $\begin{array}{l}\text { Academic, Spatial Data } \\
\text { Quality Research, } \\
\text { Standardisation Expert }\end{array}$ & $0000-0001-6836-3463$ \\
\hline Anette Ganske & $\begin{array}{c}\text { Technische } \\
\text { Informationsbibliothek (TIB), } \\
\text { Germany }\end{array}$ & $\begin{array}{c}\text { Infrastructure Provider, } \\
\text { Data Publication and } \\
\text { Metadata Standards, } \\
\text { Scientist }\end{array}$ & 0000-0003-1043-4964 \\
\hline Dave Jones & $\begin{array}{c}\text { StormCenter Communications } \\
\text { GeoCollaborate, USA }\end{array}$ & $\begin{array}{c}\text { Private Sector, Data } \\
\text { User/Applications, Service } \\
\text { Provider }\end{array}$ & $0000-0003-4573-2400$ \\
\hline Lucy Bastin & Aston University, UK & Data Scientist & 0000-0003-1321-0800 \\
\hline Lesley Wyborn & $\begin{array}{c}\text { Australian National University, } \\
\text { AUS }\end{array}$ & $\begin{array}{l}\text { Academic, Domain Expert } \\
\text { (geoinformatics) }\end{array}$ & 0000-0001-5976-4943 \\
\hline Irina Bastrakova & Geoscience Australia, AUS & Spatial Data Architect & 0000-0002-4643-7289 \\
\hline Mingfang Wu & $\begin{array}{l}\text { Australian Research Data } \\
\text { Commons (ARDC), AUS }\end{array}$ & $\begin{array}{c}\text { Research Data Specialist, } \\
\text { Information Retrieval, } \\
\text { Metadata }\end{array}$ & $0000-0003-1206-3431$ \\
\hline Chung-Lin Shie & $\begin{array}{c}\text { University of Maryland at } \\
\text { Baltimore County/NASA } \\
\text { GSFC }\end{array}$ & $\begin{array}{l}\text { Academic, Scientist, Data } \\
\text { Provider, Domain Expert }\end{array}$ & 0000-0002-1115-1029 \\
\hline David Moroni & $\begin{array}{c}\text { NASA Jet Propulsion } \\
\text { Laboratory/California Institute } \\
\text { of Technology, USA }\end{array}$ & $\begin{array}{l}\text { NASA PO.DAAC Data } \\
\text { Center, Data Manager }\end{array}$ & 0000-0003-2994-557X \\
\hline Gilles Larnicol & BSC/Magellium, Spain/France & & \\
\hline
\end{tabular}




\begin{tabular}{|c|c|c|c|}
\hline Yaxing Wei & $\begin{array}{l}\text { NASA Oak Ridge National } \\
\text { Laboratory (ORNL), USA }\end{array}$ & $\begin{array}{l}\text { NASA ORNL DAAC Data } \\
\text { Center, Center Scientist }\end{array}$ & 0000-0001-6924-0078 \\
\hline Nancy Ritchey & $\begin{array}{l}\text { NOAA's National Centers for } \\
\text { Environmental Information } \\
\text { (NCEI), USA }\end{array}$ & $\begin{array}{l}\text { NOAA NCEI Data Center, } \\
\text { Archive Manager, Domain } \\
\text { Expert (Data Management } \\
\text { and Stewardship) }\end{array}$ & 0000-0003-3939-6287 \\
\hline C. Sophie Hou & $\begin{array}{l}\text { Apogee Engineering/USGS; } \\
\text { Ronin Institute, USA }\end{array}$ & $\begin{array}{l}\text { Governmental Contractor, } \\
\text { Data Usability Specialist }\end{array}$ & 0000-0002-8087-1775 \\
\hline Ted Habermann & $\begin{array}{c}\text { Metadata Game Changers, } \\
\text { USA }\end{array}$ & $\begin{array}{l}\text { Domain Expert (Metadata, } \\
\text { Metadata standards) }\end{array}$ & 0000-0003-3585-6733 \\
\hline Sarah Champion & $\begin{array}{l}\text { North Carolina State } \\
\text { University, USA }\end{array}$ & $\begin{array}{l}\text { Data Architect, Information } \\
\text { Quality Management and } \\
\text { Metadata Specialist }\end{array}$ & 0000-0002-5080-6286 \\
\hline Gary Berg-Cross & Ontolog Forum, USA & $\begin{array}{l}\text { Knowledge Engineer, } \\
\text { Domain Expert } \\
\text { (Ontology/Semantics) }\end{array}$ & \\
\hline Kaylin Bugbee & $\begin{array}{l}\text { NASA Marshall Space Flight } \\
\text { Center (MSFC), USA }\end{array}$ & Informatics & 0000-0001-6733-5698 \\
\hline Jeanné le Roux & UAH/NASA MSFC, USA & Informatics & 0000-0002-8274-987X \\
\hline
\end{tabular}




\section{Appendix H. Acronyms}

\begin{tabular}{|c|c|}
\hline ACDD & Attribute Convention for Data Discovery, ESIP \\
\hline $\mathrm{AHC}$ & All Hazards Consortium \\
\hline APT & Algorithm Publication Tool, NASA IMPACT \\
\hline ARC & Analysis and Review of the Common Metadata Repository (CMR), NASA IMPACT \\
\hline ARDC & Australian Research Data Commons \\
\hline ATBD & Algorithm Theoretical Basis Document \\
\hline ATMODAT & Atmospheric Model Data \\
\hline AU/NZ DQIG & Australia/New Zealand Data Quality Interest Group \\
\hline BSC & Barcelona Supercomputing Center \\
\hline CASRAI & Consortia Advancing Standards in Research \\
\hline CC BY & Creative Commons Attribution License \\
\hline $\mathrm{CCO}$ & Creative Commons Public Domain Dedication \\
\hline CDR & NOAA Climate Data Record \\
\hline CEOS & Committee on Earth Observation Satellites \\
\hline $\mathrm{CF}$ & NetCDF Climate and Forecast \\
\hline CICS & Cooperative Institute for Climate and Satellites, NOAA \\
\hline CODATA & Committee on Data of the International Science Council (ISC) \\
\hline \multicolumn{2}{|c|}{$\begin{array}{l}\text { CORE-CLIMAX COordinating Earth observation data validation for RE-analysis for CLIMAte } \\
\text { ServiceS }\end{array}$} \\
\hline CREWS & Consortium for Research on Environmental Water Systems \\
\hline DAAC & Distributed Active Archive Centers, NASA \\
\hline DataONE & Data Observation Network for Earth, NSF \\
\hline DCAT & Data Catalog Vocabulary \\
\hline DFT & RDA Data Foundation and Terminology \\
\hline DHS & US Department of Homeland Security \\
\hline DKRZ & German Climate Computing Center \\
\hline DMS MM & WGISS Data Management and Stewardship Maturity Matrix \\
\hline DOI & Digital Object Identifier \\
\hline DQM & Data Quality Management \\
\hline \multicolumn{2}{|c|}{ DSMM Data Stewardship Maturity Matrix } \\
\hline DSMR & Data Stewardship Maturity Report \\
\hline ECMWF & European Center for Medium-Range Weather Forecasts \\
\hline EEI & Edison Electric Institute \\
\hline EOSDIS & Earth Observing System Data and Information System, NASA \\
\hline EPSCoR & Established Program to Stimulate Competitive Research, NSF \\
\hline ERDDAP & Environmental Research Division's Data Access Program, NOAA \\
\hline ESA & European Space Agency \\
\hline ESIP & Earth Science Information Partners \\
\hline ESRI & Environmental Systems Research Institute \\
\hline ET-DRC & Expert Team on Data Requirements for Climate, WMO \\
\hline EUMETSAT & European Organisation for the Exploitation of Meteorological Satellites \\
\hline FAIR & Guiding principles for Findable, Accessible, Interoperable, and Reusable \\
\hline FEMA & US Federal Emergency Management Agency \\
\hline FGDC & Federal Geographic Data Committee \\
\hline GCMD & Global Change Master Directory, NASA \\
\hline GSFC & Goddard Space Flight Center, NASA \\
\hline HTTPS & Hypertext Transfer Protocol Secure \\
\hline IMOS & Integrated Marine Observing System \\
\hline IMPACT & Interagency Implementation and Advanced Concepts Team, NASA MSFC \\
\hline
\end{tabular}




\begin{tabular}{|c|c|}
\hline IQC & Information Quality Cluster, ESIP \\
\hline IS-ENES & Infrastructure for the European Network for Earth System Modelling \\
\hline ISO & International Standards Organization \\
\hline JPSS & $\begin{array}{l}\text { Joint Polar Satellite System, a collaborative program between NOAA and its acquisition } \\
\text { agent, NASA }\end{array}$ \\
\hline LTER & Long-Term Ecological Research, NSF \\
\hline MSFC & Marshall Space Flight Center, NASA \\
\hline NASA & National Aeronautics and Space Administration \\
\hline NCA & US National Climate Assessment \\
\hline NCDC & National Climatic Data Center, NOAA \\
\hline NCEI & National Centers for Environmental Information, NOAA \\
\hline NCSU & North Carolina State University \\
\hline NESDIS & National Environmental Satellite, Data, and Information Service, NOAA \\
\hline NetCDF & Network Common Data Form \\
\hline NICC & DHS National Infrastructure Coordinating Center \\
\hline NOAA & National Oceanic and Atmospheric Administration \\
\hline NREs & National Response Events \\
\hline NSF & National Science Foundation \\
\hline NSIDC & National Snow and Ice Data Center, NASA \\
\hline OAI-PMH & Open Archives Initiative - Protocol for Media Harvesting \\
\hline OGC & Open Geospatial Consortium \\
\hline OISST & NOAA daily Optimum Interpolation Sea Surface Temperature \\
\hline ORCID & Open Researcher and Contributor ID \\
\hline ORL & ESIP Operational Readiness Levels \\
\hline ORNL & NASA Oak Ridge National Laboratory \\
\hline OWL & Ontology Web Language \\
\hline PAMARCMIP & Pan-Arctic Measurements and Arctic Regional climate model simulations \\
\hline PDCA & Plan-Do-Check-Act \\
\hline PID & Persistent Identifier \\
\hline $\mathrm{QA} / \mathrm{QC}$ & Quality Assurance and Control \\
\hline QMM & Quality Maturity Matrix \\
\hline R2R QA & Rollingdeck to Repository Quality Assessment dashboard \\
\hline RDA & Research Data Alliance \\
\hline RDFS & Resource Description Framework Schema \\
\hline RMAGs & EEI Regional Management Assistance Groups \\
\hline SHARC & RDA-Sharing Rewards and Credit (SHARC) interest group \\
\hline SISE & Sensitive Information Sharing Environment \\
\hline SMM & Stewardship Maturity Matrix \\
\hline SMM-CD & WMO Stewardship Maturity Matrix for Climate Data \\
\hline SNSF & Swiss National Science Foundation \\
\hline THREDDS & Thematic Real-time Environmental Distributed Data Services \\
\hline TIB & Technische Informationsbibliothek, Germany \\
\hline TRUST & $\begin{array}{l}\text { Principles for Digital Repositories: Transparency, Responsibility, User Focus, } \\
\text { Sustainability, Technology }\end{array}$ \\
\hline UAH & University of Alabama in Huntsville \\
\hline URI & Uniform Resource Identifier \\
\hline USGCRP & US Global Change Research Program \\
\hline USGS & US Geological Survey \\
\hline UUID & Universally Unique Identifier \\
\hline W3C & World Wide Web Consortium \\
\hline
\end{tabular}


WDCC World Data Center for Climate

WDS World Data System

WGISS Working Group on Information Systems and Services, CEOS

WIGOS Integrated Global Observing System, WMO

WMO World Meteorological Organization 
Appendix I. Community Comments and Responses

\begin{tabular}{|c|c|c|c|c|c|}
\hline $\begin{array}{c}\text { Starting } \\
\text { Line } \\
\text { \#No }\end{array}$ & $\begin{array}{c}\text { Content } \\
\text { Type } \\
\text { (phase/ } \\
\text { Paragraph/ } \\
\text { Figure/Table) }\end{array}$ & $\begin{array}{l}\text { Comme } \\
\text { nt Type }\end{array}$ & Comments & Proposed Change & Observations of Project leaders \\
\hline
\end{tabular}

\begin{tabular}{|c|c|c|c|c|c|}
\hline 464 & Phase & ge & $\begin{array}{l}\text { "Appendix C" } \\
\text { Text highlighted in red. }\end{array}$ & Change " $\mathrm{C}$ " to " $\mathrm{C}$ ". & $\begin{array}{l}\text { As a demo. Agreed. Implemented in the } \\
\text { revised version. }\end{array}$ \\
\hline 716 & Sentence & ed & $\begin{array}{l}\text { "We thanks .." } \\
\text { Grammar error. }\end{array}$ & Replace "thanks" by "thank". & $\begin{array}{l}\text { As a demo. Agreed. Implemented in the } \\
\text { revised version. }\end{array}$ \\
\hline 0 & Filename & ed & "FARI_": Туро & Change it to "FAIR_". & $\begin{array}{l}\text { Agreed. Filename modified and uploaded } \\
\text { to OSF }(4 / 22 / 2021)\end{array}$ \\
\hline 53 & TOC & te & $\begin{array}{l}\text { Missing subsections } 4 \mathrm{f}-\mathrm{h} \text { in the table of } \\
\text { contents }\end{array}$ & Include subsections $4 \mathrm{f}-\mathrm{h}$ in $\mathrm{TOC}$ & Agreed. Implemented. \\
\hline 294 & $\begin{array}{l}\text { Subsection } \\
\text { Title }\end{array}$ & ge & Subsection title indent not consistent & $\begin{array}{l}\text { Adjust indent of subsection title } \\
3 \mathrm{e} \text {. }\end{array}$ & Agreed. Implemented. \\
\hline 630 & $\begin{array}{l}\text { Subsection } \\
\text { Title }\end{array}$ & ge & Inconsistent subsection title & Bold subsection title $4 \mathrm{~g}$. & Agreed. Implemented. \\
\hline All & $\begin{array}{l}\text { Whole } \\
\text { document }\end{array}$ & ge & & $\begin{array}{l}\text { file size can be compressed a lot, } \\
\text { as it seems without loss of } \\
\text { information. }\end{array}$ & $\begin{array}{l}\text { Yes, the document contains a lot of } \\
\text { information for background and } \\
\text { examples for practical purposes. We did, } \\
\text { however, removed Appendix G as it is } \\
\text { already included in Peng et al. (2021) }\end{array}$ \\
\hline 0 & & ge & $\begin{array}{l}\text { Are you recommending people should } \\
\text { use ISO 19157, or ISO 19115-1, as the } \\
\text { structure for documenting the data } \\
\text { quality? }\end{array}$ & & $\begin{array}{l}\text { ISO } 19157 \text { or } 19115-1 \text { is one of the } \\
\text { methods that people can use to report } \\
\text { quality assessment reports but we are not } \\
\text { endorsing any particular method. }\end{array}$ \\
\hline 0 & & ge & $\begin{array}{l}\text { Are the guidelines only pertaining to } \\
\text { Earth science datasets? }\end{array}$ & & $\begin{array}{l}\text { The guidelines are primarily developed } \\
\text { for the Earth science community. } \\
\text { However, they are general enough to be } \\
\text { readily adopted to other disciplines. }\end{array}$ \\
\hline All & $\begin{array}{l}\text { Whole } \\
\text { document }\end{array}$ & ed & Both "dataset" and "data set" are used & Consistent use of either one. & $\begin{array}{l}\text { Agreed. All "data set" are replaced by } \\
\text { "dataset" in the revised version. }\end{array}$ \\
\hline 399 & Sentence & ed & possible typo? & $\begin{array}{l}\text { Replace "document" with } \\
\text { "documented". }\end{array}$ & $\begin{array}{l}\text { "document" is the object of "captured". } \\
\text { Added " } a \text { " in front of "document" to be } \\
\text { clear }\end{array}$ \\
\hline 453 & Phase & ed & $\begin{array}{l}\text { should this be referring to } \\
\text { Appendix F (rather than Appendix } \\
\text { E)? }\end{array}$ & $\begin{array}{l}\text { Replace "Appendix E" by } \\
\text { "Appendix F" }\end{array}$ & $\begin{array}{l}\text { Agreed. Implemented in the revised } \\
\text { version. }\end{array}$ \\
\hline
\end{tabular}

22 ge-general, te-technical, ed-editorial 


\begin{tabular}{|c|c|c|c|c|c|}
\hline $459 ; 475$ & Word & ed & & $\begin{array}{l}\text { replace "exhausted" with } \\
\text { "exhaustive" }\end{array}$ & $\begin{array}{l}\text { Agreed. Implemented in the revised } \\
\text { version. }\end{array}$ \\
\hline 562 & & te & $\begin{array}{l}\text { reference to "schema.com". Looks like } \\
\text { the wrong link? Or this domain has } \\
\text { been taken over at least because this } \\
\text { redirects to a private company. I } \\
\text { wondered if this was supposed to } \\
\text { reference schema.org but that doesn't } \\
\text { seem right within this context since you } \\
\text { can't mint PIDs with them. }\end{array}$ & & $\begin{array}{l}\text { Good catch. It should be "schema.org". } \\
\text { Implemented in the revised version. }\end{array}$ \\
\hline 1258 & Appendix F & ge & $\begin{array}{l}\text { NVS would be a worthy mention. It is a } \\
\text { large collection of vocabularies that we } \\
\text { use for marine science and other } \\
\text { applications. } \\
\text { http://vocab.nerc.ac.uk/collection/ (side } \\
\text { note: many of these vocabularies are } \\
\text { related and combined to for complex } \\
\text { descriptions: https://github.com/nvs- } \\
\text { vocabs/P01/blob/master/P01_wheel.pdf } \\
\text { ) }\end{array}$ & & $\begin{array}{l}\text { Thanks for the suggestion. It is included } \\
\text { in the revised version. }\end{array}$ \\
\hline 715 & Sentence & ed & "helping laying ...": grammar error & Replace "laying" by "lay" & $\begin{array}{l}\text { Agreed. Implemented in the revised } \\
\text { version. }\end{array}$ \\
\hline \multirow[t]{2}{*}{681} & Sentence & ed & "which in turns": grammar error & Replace "turns" by "turn" & $\begin{array}{l}\text { Agreed. Implemented in the revised } \\
\text { version. }\end{array}$ \\
\hline & & ge & $\begin{array}{l}\text { What I highly appreciate is an increased } \\
\text { emphasis on open science: it is } \\
\text { regularly referenced, and extends as } \\
\text { well to software and methodology. In } \\
\text { that sense, a good step forward is being } \\
\text { made. Scientists and applications of } \\
\text { spatial data will need more tools and } \\
\text { information to explore the quality of the } \\
\text { data. I further notice that you use the } \\
\text { terms accuracy, precision and fitness for } \\
\text { use. But I am missing the error (or } \\
\text { uncertainty) propagation. That is for me } \\
\text { always the key issue of SDQ: how to } \\
\text { quantify the quality of the product that } \\
\text { is obtained with publicly available data, } \\
\text { modeling and software, that possibly } \\
\text { was collected/created with other } \\
\text { intentions than those for which it will } \\
\text { be used. I could imagine that here open } \\
\text { science can make a huge step. An } \\
\text { interesting and somewhat unexplored } \\
\text { component in open science are its } \\
\text { dangers and restrictions - maybe that } \\
\text { leads to a nice and interesting new } \\
\text { quality criterion: the risk of abuse, i.e. } \\
\text { second use or unethical use, of data } \\
\text { (and models and software). }\end{array}$ & & $\begin{array}{l}\text { Appreciate the positive comments and } \\
\text { the great points on i) uncertainty } \\
\text { propagation and ii) how to ensure the } \\
\text { data, software, and information are being } \\
\text { used correctly and ethically, i.e., the risk } \\
\text { of abuse. Both are big challenges for the } \\
\text { community to address, which is beyond } \\
\text { the scope of this document. However, } \\
\text { providing quality information including } \\
\text { uncertainty in various stages/aspects } \\
\text { should support efforts aiming to address } \\
\text { either one of those challenges - whether } \\
\text { and how useful will be a great use case } \\
\text { for the community to develop. A } \\
\text { discussion has been included in the } \\
\text { revised document. }\end{array}$ \\
\hline 80 & Word/Phase & ge & $\begin{array}{l}\text { It would be good to see FAIR described } \\
\text { briefly when it is first introduced in the } \\
\text { exec summary and further in the } \\
\text { background section }\end{array}$ & & $\begin{array}{l}\text { Agreed partly - the FAIR guiding } \\
\text { principles were already described in the } \\
\text { background session, hence left } \\
\text { unchanged. 'FAIR' abbreviation } \\
\text { expanded in the Executive Summary. }\end{array}$ \\
\hline 1 & ge & ge & $\begin{array}{l}\text { General comment that further } \\
\text { information on communication of } \\
\text { results to non specialists would be }\end{array}$ & & $\begin{array}{l}\text { It is an excellent point but it may be } \\
\text { better considered in an implementation } \\
\text { guidance document. }\end{array}$ \\
\hline
\end{tabular}




\begin{tabular}{|c|c|c|c|c|c|}
\hline & & & $\begin{array}{l}\text { useful i.e. what is a minimum set of } \\
\text { reporting requirements for the decision } \\
\text { maker and how does one arrive at this } \\
\text { set of requirements }\end{array}$ & & \\
\hline $\begin{array}{l}\text { Not a } \\
\text { specific } \\
\text { location } \\
\text { set. }\end{array}$ & $\begin{array}{l}\text { Paragraph - } \\
\text { Technical } \\
\text { and Citizen } \\
\text { Science }\end{array}$ & te & $\begin{array}{l}\text { I note two key things I would } \\
\text { value seeing added: 1) that the } \\
\text { role of technology design in } \\
\text { influencing data quality, which } \\
\text { specific discussion around } \\
\text { different approaches to capturing } \\
\text { knowledge; and } 2 \text { ) the discussion } \\
\text { of intersections between classic } \\
\text { geospatial data and citizen science } \\
\text { can augment each other, } \\
\text { empowering scientists and } \\
\text { communities alike, if information } \\
\text { is provided via FAIR principles. }\end{array}$ & & $\begin{array}{l}\text { These are great points, however, at this } \\
\text { version of the guidelines they are out of } \\
\text { the scope. We revised the introduction } \\
\text { and conclusion by highlighting that these } \\
\text { should be considered long-term. }\end{array}$ \\
\hline $92-93$ & Sentence & ge & $\begin{array}{l}\text { We fully agree on the statement } \\
\text { about quality assessment regarding } \\
\text { representation and integration across } \\
\text { systems and tools and kindly suggest } \\
\text { to reference our paper about } \\
\text { recommendations for data } \\
\text { management plans (DMP) (section } \\
2.2 \text { recommends to include } \\
\text { structured quality information in } \\
\text { DMPs; section 3, in particular } 3.1 \\
\text { discusses linking and sharing across } \\
\text { tools, in our case data management } \\
\text { system, DMP tool, and knowledge } \\
\text { hub). } \\
\text { Further, we suggest to reference our } \\
\text { paper about a research data } \\
\text { infrastructure component to extract } \\
\text { quality information (section } \\
\text { 3.1/figure } 1 \text { indicate that } \\
\text { (automatically generated) quality } \\
\text { information can be used in several } \\
\text { phases of the research data lifecycle, } \\
\text { section } 3.4 / \text { figure } 2 \text { stresses the } \\
\text { importance linking of tools). }\end{array}$ & $\begin{array}{l}\text { Quality assessments also need } \\
\text { to be consistently represented } \\
\text { and readily integrated across } \\
\text { systems and tools to allow for } \\
\text { improved sharing of quality } \\
\text { information at the dataset } \\
\text { level (cp. Henzen et al. 2021, } \\
\text { Wagner et al. 2021) for } \\
\text { individual quality attributes } \\
\text { or dimensions such as those } \\
\text { defined in Wang and Strong } \\
\text { (1996) or Ramapriyan et al. } \\
\text { (2017). }\end{array}$ & Content integrated as suggested. \\
\hline $98-99$ & Sentence & ge & $\begin{array}{l}\text { We agree on that and suggest to } \\
\text { reference our paper about the Geo- } \\
\text { Dashboard concept, which includes } \\
\text { findings on current data quality } \\
\text { challenges (see for instance section } \\
\text { 2.2; examples in table 1), e.g. } \\
\text { lacking guidance; several sources for } \\
\text { quality information; quality } \\
\text { information on different levels of } \\
\text { details; requirements for user- } \\
\text { friendly presentations. }\end{array}$ & $\begin{array}{l}\text { Although the need for } \\
\text { assessing the quality of data } \\
\text { and associated information at } \\
\text { the individual dataset level is } \\
\text { well recognized, } \\
\text { methodologies for an } \\
\text { evaluation framework and } \\
\text { presentation of resultant } \\
\text { quality information to end } \\
\text { users (cp. Figgemeier et al. } \\
\text { 2021) may not have been } \\
\text { comprehensively addressed } \\
\text { within and across disciplines. }\end{array}$ & Content integrated as suggested. \\
\hline
\end{tabular}




\begin{tabular}{|c|c|c|c|c|c|}
\hline 138 & Heading & ge & $\begin{array}{l}\text { We use the term scope slightly } \\
\text { different. In this section, some } \\
\text { framing concepts like dataset, data } \\
\text { life cycle are presented. Thus, we } \\
\text { would recommend to clarify what is } \\
\text { meant with scope at the beginning of } \\
\text { the paragraph or change the heading } \\
\text { to (conceptual) framework. }\end{array}$ & & $\begin{array}{l}\text { The "scope" is a standard term to use } \\
\text { in the literature for the extent of the } \\
\text { area or subject matter that something } \\
\text { deals with or to which it is relevant. } \\
\text { Therefore, scope seems more } \\
\text { appropriate to identify the target of a } \\
\text { document. No change is made. }\end{array}$ \\
\hline $154 \mathrm{ff}$ & & ge & $\begin{array}{l}\text { Considering the term quality } \\
\text { dimension, we'd like to remark: In } \\
\text { some specifications, the term } \\
\text { dimension is used differently. In the } \\
\text { Data Quality Vocabulary, for } \\
\text { instance, quality dimension covers } \\
\text { criteria for assessing quality } \\
\text { (https://www.w3.org/TR/vocab- } \\
\text { dqv/\#dqv:Dimension) and links to } \\
\text { ISO/IEC 25012 dimensions } \\
\text { (https://www.w3.org/TR/vocab- } \\
\text { dqv/\#DimensionsOfISOIEC25012) }\end{array}$ & & $\begin{array}{l}\text { We agree that the term dimension was } \\
\text { lacking consistency particularly } \\
\text { regarding figure } 1 \text { compared to the use of } \\
\text { this term in the other parts of the } \\
\text { document, thus we changed the term } \\
\text { "dimension" inside figure } 1 \text { in favour of } \\
\text { "aspect". }\end{array}$ \\
\hline $\begin{array}{l}159- \\
160\end{array}$ & Sentence & ge & $\begin{array}{l}\text { Dataset quality information and } \\
\text { quality elements seems to be used } \\
\text { synonymously? QE is used only two } \\
\text { times in the text. }\end{array}$ & $\begin{array}{l}\text { We suggest harmonizing } \\
\text { terminology eventually. } \\
\text { Change quality element to } \\
\text { dataset quality information }\end{array}$ & $\begin{array}{l}\text { ISO } 19115-1 \text { and } 19157 \text { use quality } \\
\text { elements. The two occurrences } \\
\text { mentioned: One occurrence was to } \\
\text { describe ISO standards and another } \\
\text { was to state that quality elements used } \\
\text { in ISO standards are equivalent to } \\
\text { "quality attributes". We have } \\
\text { modified the sentence for the first } \\
\text { occurrence but kept the second. } \\
\text { Aiming to use common terminology } \\
\text { was one of our main goals but } \\
\text { unfortunately we have realized } \\
\text { quickly that this issue is bigger than } \\
\text { us - even ISO standards may use the } \\
\text { same term differently and we have } \\
\text { tried to use consistent } \\
\text { terminology/concepts for our } \\
\text { examples as a way forward. }\end{array}$ \\
\hline $\begin{array}{l}163- \\
166\end{array}$ & Sentence & ge & $\begin{array}{l}\text { Such a statement would fit as well } \\
\text { the rationale of data management } \\
\text { plans or at least the rationale of how } \\
\text { a data management plan should be. } \\
\text { Several communities/working } \\
\text { groups (like the RDA WG } \\
\text { Discipline-specific Guidance DMP) } \\
\text { are currently discussing data } \\
\text { management plans, e.g. how to } \\
\text { provide discipline-specific } \\
\text { information or how to guide } \\
\text { researchers to provide useful } \\
\text { information about data quality, etc.. }\end{array}$ & $\begin{array}{l}\text { There should be a link to } \\
\text { modern living data } \\
\text { management plan, which aim } \\
\text { exactly at fulfilling such a } \\
\text { statement. }\end{array}$ & $\begin{array}{l}\text { The references to the community } \\
\text { activities have been added, including } \\
\text { those associated with data management } \\
\text { plans such as the recommended RDA } \\
\text { WG on Discipline-specific Guidance } \\
\text { DMP. }\end{array}$ \\
\hline
\end{tabular}




\begin{tabular}{|c|c|c|c|c|c|}
\hline 172 & & & $\begin{array}{l}\text { This is an important statement and } \\
\text { includes several aspects: (1) quality } \\
\text { information should be } \\
\text { gathered/tracked on a suitable level } \\
\text { of detail and (2) should be presented } \\
\text { in user-friendly visualizations (e.g. a } \\
\text { quality dashboard) to support } \\
\text { evaluating fitness for purpose/use. } \\
\text { Therefore, we suggest to use our } \\
\text { Geo-Dashboard concept as an } \\
\text { example and to stress the relevance } \\
\text { of linked provenance information (as } \\
\text { mentioned in the FAIR principles). }\end{array}$ & $\begin{array}{l}\text { Describing the quality of a } \\
\text { data product and providing } \\
\text { access to such quality } \\
\text { information can support } \\
\text { potential users of a particular } \\
\text { dataset to determine whether } \\
\text { it is appropriate for their } \\
\text { planned usage, i.e., fitness for } \\
\text { purpose. Figgemeier et al } \\
2021 \text { propose a Geo- } \\
\text { dashboard to visualize quality } \\
\text { information and related } \\
\text { provenance information. }\end{array}$ & $\begin{array}{l}\text { Instead of the place mentioned, reference } \\
\text { to this work has been included in } 4 \mathrm{f} \\
\text { guideline } 5 \text {. }\end{array}$ \\
\hline 176 & Sentence & ge & $\begin{array}{l}\text { In our opinion, in appendix G, there } \\
\text { is a real-life example of why quality } \\
\text { information is critical. However, in } \\
\text { we don't see any particular detailed } \\
\text { description or practical example of } \\
\text { what was improved in terms of } \\
\text { quality. Which quality aspect were } \\
\text { improved? Quality assurance? } \\
\text { Quality controls? Quality } \\
\text { information? }\end{array}$ & $\begin{array}{l}\text { We suggest to remove } \\
\text { "detailed" or, even better, add } \\
\text { much more practical details } \\
\text { of what was done in term of } \\
\text { improved data quality. }\end{array}$ & Word "detail" removed. \\
\hline $\begin{array}{l}209- \\
211\end{array}$ & Sentence & ge & $\begin{array}{l}\text { This sentences includes lots of } \\
\text { highly relevant aspects. However, } \\
\text { we would add the availability / } \\
\text { providing quality information via } \\
\text { human- and machine-readable } \\
\text { interfaces. } \\
\text { Within our project GeoKur, we do } \\
\text { not only see cross-discipline } \\
\text { challenges, but even within a } \\
\text { discipline certain quality information } \\
\text { are reported differently, e.g. } \\
\text { uncertainty/thematic accuracy for } \\
\text { remote sensing data are described } \\
\text { with different metrics, using } \\
\text { different ground truth, etc.. Thus, we } \\
\text { suggest to add challenges in } \\
\text { sharing/using quality information } \\
\text { within a discipline. } \\
\text { Does "fully traceable" include the } \\
\text { automatic extraction of quality } \\
\text { information? We addressed some } \\
\text { aspects related to the automatic } \\
\text { extraction of quality information for } \\
\text { earth system science data in our } \\
\text { paper, which could be of interest for } \\
\text { your guidance document. We } \\
\text { suggest to revew Wagner et al. } 2021 \text {, } \\
\text { which also covers technical aspects }\end{array}$ & $\begin{array}{l}\text { For dataset quality } \\
\text { information to be effectively } \\
\text { (re)used, it needs to be } \\
\text { consistently curated, fully } \\
\text { traceable, made available via } \\
\text { adequately human- and } \\
\text { machine-readable interfaces, } \\
\text { adequately documented, } \\
\text { updated timely, able to } \\
\text { support users to address their } \\
\text { specific needs. This is, } \\
\text { however, a daunting objective } \\
\text { because it necessitates both a } \\
\text { wide range of data quality } \\
\text { attributes and heuristic } \\
\text { information to ascertain } \\
\text { fitness for purpose, while } \\
\text { facing challenges in cross- } \\
\text { disciplinary and even in } \\
\text { discipline-specific knowledge } \\
\text { integration (Peng et al. 2020). }\end{array}$ & $\begin{array}{l}\text { Part of the text was added, not the first } \\
\text { part because this is an outcome of the } \\
\text { guidelines not introduction. The paper } \\
\text { Wagner et al. } 2021 \text { has been added in } \\
\text { other parts of the document to refer the } \\
\text { reader to the details mentioned here. }\end{array}$ \\
\hline
\end{tabular}




\begin{tabular}{|c|c|c|c|c|c|}
\hline & & & $\begin{array}{l}\text { on how to include extraction tools in } \\
\text { research data management } \\
\text { infrastructures - sharing quality } \\
\text { information across tools (Data } \\
\text { Management tools, DMP tools, etc. }\end{array}$ & & \\
\hline $219 \mathrm{f}$ & Sentence & ge & $\begin{array}{l}\text { What is about vocabularies, such as } \\
\text { the data quality vocabulary (DQV) } \\
\text { (https://www.w3.org/TR/vocab- } \\
\text { dqv/)? GeoDCAT, a well-known and } \\
\text { well-used metadata schema for } \\
\text { geodata similar to ISO19115, } \\
\text { includes extension points (via } \\
\text { DCAT) to use the DQV. Thus, we } \\
\text { recommend to add DQV. }\end{array}$ & $\begin{array}{l}\text { despite the fact that } \\
\text { international standards or } \\
\text { vocabularies for describing } \\
\text { the quality of geographic data } \\
\text { have been in place since } 2003 \\
\text { (e.g., ISO 19157: 2013; ISO } \\
\text { 19115-1:2014, DQV). }\end{array}$ & Text changed accordingly as W3C 2016 . \\
\hline $\begin{array}{l}219- \\
220\end{array}$ & Sentence & ge & $\begin{array}{l}\text { We fully agree on that statement. } \\
\text { However, we would appreciate, if } \\
\text { you review our papers on automated } \\
\text { quality information extraction } \\
\text { (Wagner et al. 2021) and our Geo- } \\
\text { Dashboard concept for visualizing } \\
\text { quality and provenance information } \\
\text { (Figgemeier et al. 2021) to be linked } \\
\text { here. }\end{array}$ & $\begin{array}{l}\text { Add on Line 219: "Despite } \\
\text { some efforts (Figgemeier et } \\
\text { al. 2021, Wagner et al. 2021), } \\
\text { dataset quality information is } \\
\text { not routinely..." }\end{array}$ & Text added accordingly. \\
\hline 229 & & & $\begin{array}{l}\text { We do not fully understand this. Do } \\
\text { you include provenance in quality } \\
\text { information? We see a strong } \\
\text { linkage and recommend to visualize } \\
\text { provenance and quality, but we } \\
\text { would not use the term provenance } \\
\text { as part of quality. }\end{array}$ & & $\begin{array}{l}\text { We agree that the statement sounds } \\
\text { ambiguous, reference to provenance was } \\
\text { removed. }\end{array}$ \\
\hline $\begin{array}{l}231- \\
233\end{array}$ & Sentence & ge & $\begin{array}{l}\text { We agree on that, but we would add } \\
\text { that at least some quality information } \\
\text { can be extracted automatically from } \\
\text { geospatial files, e.g. } \\
\text { comission/omission. Our metadata } \\
\text { extraction tool, for instance, can be } \\
\text { used to automatically extract quality } \\
\text { information from geodata files } \\
\text { (Geopackage, GeoTiff, CSV, Shp). } \\
\text { Users just need to run the tool, } \\
\text { expert knowledge on quality } \\
\text { information is not needed for that. } \\
\text { However, the set of extracted } \\
\text { measures is still limited. }\end{array}$ & $\begin{array}{l}\text { A frequently cited barrier } \\
\text { against documenting the } \\
\text { quality of spatial data is that it } \\
\text { mostly requires special } \\
\text { domain-expert technical } \\
\text { knowledge, while } \\
\text { documenting general } \\
\text { metadata can be done } \\
\text { automatically or by non- } \\
\text { specialists (Coetzee 2018, } \\
\text { Wagner et al. 2021). } \\
\text { Or you could add: } \\
\text { However, a limited set of } \\
\text { quality information can be } \\
\text { automatically extracted from } \\
\text { files (Wagner et al. 2021). }\end{array}$ & $\begin{array}{l}\text { The first option has been integrated in } \\
\text { the document. }\end{array}$ \\
\hline 245 & & & $\begin{array}{l}\text { As stated before, FAIR principles } \\
\text { address provenance and we } \\
\text { recommend linking provenance and } \\
\text { quality information, getting insights }\end{array}$ & & $\begin{array}{l}\text { It is a good point to take into account in a } \\
\text { later version of these guidelines. For the } \\
\text { general purpose of this first version of the } \\
\text { guidelines, we consider that highlighting }\end{array}$ \\
\hline
\end{tabular}




\begin{tabular}{|c|c|c|c|c|c|}
\hline & & & $\begin{array}{l}\text { for quality changes based on } \\
\text { provenance information. } \\
\text { Thus, starting with quality } \\
\text { information on dataset level is fine. } \\
\text { However, we suggest indicating the } \\
\text { importance of quality information } \\
\text { for data series or parts of datasets } \\
\text { (e.g. quality for certain regions } \\
\text { differs). }\end{array}$ & & $\begin{array}{l}\text { quality information at dataset level is } \\
\text { already a good starting point. }\end{array}$ \\
\hline 243 & Sentence & ge & $\begin{array}{l}\text { it is not strictly necessary, but the } \\
\text { FAIR work "didn't end" in } 2016 . \\
\text { You might add some more up-to- } \\
\text { date references to highlight that the } \\
\text { FAIR work is in constant progress. }\end{array}$ & $\begin{array}{l}\text { Add eventually a short } \\
\text { paragraph highlighting the } \\
\text { FAIR work in progress and } \\
\text { cite some more up-to-date } \\
\text { references } \\
\text { https://doi.org/10.15497/RDA } \\
00035 \text { (2019). } \\
\text { https://doi.org/10.3233/ISU- } \\
\text { 170824 (2017) } \\
\text { https://doi.org/10.1038/sdata. } \\
2018.118(2018)\end{array}$ & $\begin{array}{l}\text { Original text is already full of other } \\
\text { references for years after } 2016 \text {. No more } \\
\text { added. }\end{array}$ \\
\hline 326 & & te & $\begin{array}{l}\text { We are wondering, if Coryea et al } \\
2006 \text { is a relevant reference? In any } \\
\text { case, it has the wrong citation key. }\end{array}$ & $\begin{array}{l}\text { We suggest removing or } \\
\text { fixing the citation key (Cordy } \\
\text { et al...). }\end{array}$ & Citation fixed. \\
\hline $\begin{array}{l}371- \\
372\end{array}$ & figure & ge & $\begin{array}{l}\text { The workflow can be simplified and } \\
\text { improved in its design. }\end{array}$ & $\begin{array}{l}\text { We suggest a circular flow } \\
\text { with a central iterative } \\
\text { concept (monitoring and } \\
\text { improvement). The } \\
\text { specification might be an } \\
\text { overarching title/concept } \\
\text { having underneath quality } \\
\text { and evaluation. The same for } \\
\text { the subsequent two phases } \\
\text { can have an overarching } \\
\text { title/concept (assessment) } \\
\text { with underneath execution } \\
\text { and dissemination. }\end{array}$ & $\begin{array}{l}\text { We prefer to keep the current workflow } \\
\text { picture. Indeed, a circular flow would } \\
\text { imply that quality dissemination feeds } \\
\text { quality specification, which is not true. } \\
\text { What feeds quality specification is the } \\
\text { monitoring/improvement, which is } \\
\text { partially input by the last step but it is } \\
\text { also input from all the other steps. } \\
\text { Moreover, quality specification is input } \\
\text { from steps that are not in the figure, such } \\
\text { as vision management and user } \\
\text { requirements. The input is not specified } \\
\text { on purpose, while a circular plot would } \\
\text { indicate that all inputs are considered by } \\
\text { quality dissemination. }\end{array}$ \\
\hline $\begin{array}{l}418- \\
419\end{array}$ & & te & $\begin{array}{l}\text { We suggest keeping the terminology } \\
\text { simple and avoiding some complex } \\
\text { terms, which were never used and } \\
\text { defined in the text, e.g. "preservation } \\
\text { process" or "stewardship workflow". } \\
\text { This would help the reader to focus } \\
\text { on the content. }\end{array}$ & $\begin{array}{l}\text { Adopt terms defined in figure } \\
1 \text { (Dataset lifecycle). For } \\
\text { instance: The preservation it } \\
\text { is defined as a stage within } \\
\text { the stewardship quality } \\
\text { dimension, not as a process. } \\
\text { Instead of stewardship } \\
\text { workflows, could be used the } \\
\text { stewardship dimension?. }\end{array}$ & Fixed with having just "stewardship". \\
\hline $\begin{array}{l}421- \\
423\end{array}$ & sentence & ge & $\begin{array}{l}\text { The same concept was stated on } \\
\text { lines } 398-400\end{array}$ & $\begin{array}{l}\text { You might remove } \\
\text { redundancies }\end{array}$ & Removed. \\
\hline $479 \mathrm{ff}$ & sentence & ge & $\begin{array}{l}\text { It might be useful to include some } \\
\text { examples for proper metadata } \\
\text { schemas or at least to address that }\end{array}$ & & $\begin{array}{l}\text { Examples are already provided below the } \\
\text { text referenced. }\end{array}$ \\
\hline
\end{tabular}




\begin{tabular}{|c|c|c|c|c|c|}
\hline & & & $\begin{array}{l}\text { metadata schemas already include } \\
\text { (some of) the listed elements as } \\
\text { mandatory fields }\end{array}$ & & \\
\hline 453 & & te & Typo/incorrect appendix reference & $\begin{array}{l}\text { Change Appendix E with } \\
\text { Appendix F }\end{array}$ & $\begin{array}{l}\text { Already fixed because of another similar } \\
\text { comment. }\end{array}$ \\
\hline $\begin{array}{l}500- \\
501\end{array}$ & sentence & ge & Is license optional? & $\begin{array}{l}\text { If the license is optional, it } \\
\text { should be clarified that } \\
\text { without license usage of } \\
\text { public available data is } \\
\text { critical. Basic rule of thumb is } \\
\text { that without license you are } \\
\text { not allowed to do anything } \\
\text { without risking copyright } \\
\text { infringement. }\end{array}$ & $\begin{array}{l}\text { In Guideline } 4 \text { we encourage data quality } \\
\text { information providers to state the license } \\
\text { related to quality information. The } \\
\text { information about the license indicates its } \\
\text { obligation, limitations and repercussions }\end{array}$ \\
\hline $\begin{array}{l}527- \\
539\end{array}$ & sentence & ge & $\begin{array}{l}\text { We consider the sentence from line } \\
525 \text { ("if no suitable...") to } 527 \\
\text { ("... and accessible.") to be sufficient } \\
\text { in the case no assessment model } \\
\text { exists. The rest of the text from line } \\
527 \text { to } 539 \text { is an somehow a } \\
\text { repetition of what is already stated in } \\
\text { guideline } 2 . \\
\text { However, if you like to keep the } \\
\text { sentences, adding GitHub as an } \\
\text { example for publishing the model } \\
\text { might makes sense. It could be used } \\
\text { to share implementation solution for } \\
\text { the quality model or for community } \\
\text { support (issue tracking for further } \\
\text { developments, etc.). Moreover, a } \\
\text { GitHub repo is typically still } \\
\text { available, when projects are finished. }\end{array}$ & $\begin{array}{l}\text { Remove/Shorten the } \\
\text { paragraph from } 527 \text { to } 539 .\end{array}$ & $\begin{array}{l}\text { Removed } 527 \text { to } 529 \text {, the rest is not a } \\
\text { repetition. }\end{array}$ \\
\hline 530 & & te & Two links land on the same page. & Remove one web link. & One link removed. \\
\hline 543 & sentence & ge & $\begin{array}{l}\text { We recommend to make more } \\
\text { explicit suggestions here, e.g. for } \\
\text { comparing quality attributes / } \\
\text { assessment results for several } \\
\text { datasets and for the visualization of } \\
\text { quality assessment results (e.g. as } \\
\text { chart; or along a provenance graph), } \\
\text { we need (named/meaningful) links. } \\
\text { In earth system science (e.g. in } \\
\text { remote sensing), analysing the } \\
\text { results and evaluating the fitness for } \\
\text { use based on quality information is } \\
\text { somehow related to ground } \\
\text { truth/training data. Therefore, we } \\
\text { suggest to add "include } \\
\text { descriptions/links to training data." }\end{array}$ & & $\begin{array}{l}\text { Not sure it is wise to be more explicit, it } \\
\text { is easier to be biased by prescribed } \\
\text { quality dimensions and it is what we } \\
\text { want to avoid. Indeed, even the comment } \\
\text { is biased, "quality information is } \\
\text { somehow related to ground truth", this is } \\
\text { specific to satellite data and specific to } \\
\text { scientific quality validation, not even all } \\
\text { the scientific quality range. }\end{array}$ \\
\hline
\end{tabular}




\begin{tabular}{|c|c|c|c|c|c|}
\hline 555 & sentence & ge & $\begin{array}{l}\text { We recommend to suggest adapting } \\
\text { an existing framework and if not } \\
\text { possible to develop a new quality } \\
\text { framework. Adapting an existing } \\
\text { schema or model includes providing } \\
\text { information on the adaption to } \\
\text { enable linking to the original schema } \\
\text { or model. }\end{array}$ & & Sentence has been rephrased. \\
\hline $\begin{array}{l}541- \\
562\end{array}$ & sentence & & $\begin{array}{l}\text { We developed a metadata profile to } \\
\text { include detailed quality information } \\
\text { including further project } \\
\text { requirements. We suggest to review } \\
\text { our best practice document } \\
\text { (describing the profile; and the } \\
\text { process how to develop such a } \\
\text { profile) and probably include it as a } \\
\text { reference }\end{array}$ & & $\begin{array}{l}\text { Reference to their work is included as } \\
\text { additional examples in the guideline. }\end{array}$ \\
\hline 630 & heading & ed & Heading should be written in bold & Add bold formatting & $\begin{array}{l}\text { Already fixed because of another similar } \\
\text { comment. }\end{array}$ \\
\hline 634 & table & te & $\begin{array}{l}\text { Table 1, second row "guideline } 1 \text { " F, } \\
\text { R1 - Isn't missing a number beside } \\
\text { the F? }\end{array}$ & $\begin{array}{l}\text { Add the proper number } \\
\text { corresponding to the Findable } \\
\text { principle F (F1? F2?) }\end{array}$ & $\begin{array}{l}\text { The letter F, A, I or R in the right column } \\
\text { denotes that the guideline from the left } \\
\text { column can crosswalk to all criteria of } \\
\text { being findable, accessible, interoperable, } \\
\text { or reproducible, respectively, while the } \\
\text { number }(n) \text { after the letter of } \mathrm{F}, \mathrm{A}, \mathrm{I} \text {, or } \mathrm{R} \\
\text { refers to the } n \text {th criterion in that aspect of } \\
\text { the FAIR. } \\
\text { A footnote has been added to the } \\
\text { table improve the clarity }\end{array}$ \\
\hline 654 & table & ge & $\begin{array}{l}\text { As presented in the latest working } \\
\text { group meeting, the usability element } \\
\text { will be removed from the ISO19157 } \\
\text { in the new version. }\end{array}$ & $\begin{array}{l}\text { If available, you might } \\
\text { choose another example not } \\
\text { referring to the usability } \\
\text { element. }\end{array}$ & Replaced "Usability" by "Accessibility" \\
\hline 672 & & ed & These are conclusions. & $\begin{array}{l}\text { You might rename the } \\
\text { chapter in conclusions. }\end{array}$ & $\begin{array}{l}\text { Chapter renamed to "Summary and } \\
\text { Conclusions". }\end{array}$ \\
\hline 1054 & & te & $\begin{array}{l}\text { Are perspective and dimensions } \\
\text { synonymous? }\end{array}$ & $\begin{array}{l}\text { The term perspective is used } \\
\text { in the title of appendix C but } \\
\text { is never defined. The single } \\
\text { time is seems to be defined is } \\
\text { on line } 405 . \text { Please, define } \\
\text { what perspective is and check } \\
\text { carefully this term throughout } \\
\text { the text. Perspective is a } \\
\text { synonymous of stakeholder } \\
\text { (see line 1045). }\end{array}$ & $\begin{array}{l}\text { "perspective" is replaced by "aspect" to } \\
\text { be consistent with that of Ramapriyan et } \\
\text { al. (2017). }\end{array}$ \\
\hline 1097 & table & te & $\begin{array}{l}\text { In table } \mathrm{C} 1 \text {, links are not working or } \\
\text { hyperlinks are missing }\end{array}$ & $\begin{array}{l}\text { We suggest to provide a } \\
\text { working web link example for } \\
\text { each single document type. }\end{array}$ & The links available work. \\
\hline
\end{tabular}




\begin{tabular}{|c|c|c|c|c|c|}
\hline $\begin{array}{l}1167- \\
1173\end{array}$ & & & $\begin{array}{l}\text { We fully agree on that and see a } \\
\text { strong relation to our } \\
\text { ideas/recommendations on future } \\
\text { DMPs and related tools (Henzen et } \\
\text { al. 2021). Thus, we suggest to } \\
\text { slightly modify the sentence and } \\
\text { reference our paper. }\end{array}$ & $\begin{array}{l}\text { We suggest modifying the } \\
\text { sentence of line } 1167-1169 \text { as } \\
\text { follows: "The dataset quality } \\
\text { assessment activities can be } \\
\text { greatly improved by adopting } \\
\text { state of the art DMP tools } \\
\text { (Henzen et al. 2021) } \\
\text { implementing the relevant } \\
\text { and appropriate standards, } \\
\text { tools,..." }\end{array}$ & Reference added. \\
\hline 1252 & & te & The weblink is not working & $\begin{array}{l}\text { Remove the Link. Reference } \\
\text { is enough }\end{array}$ & $\begin{array}{l}\text { Link works for us, but removed because } \\
\text { indeed reference is enough. }\end{array}$ \\
\hline \multirow[t]{2}{*}{1254} & & ge & Weblink is unnecessary & $\begin{array}{l}\text { Remove the Link. Reference } \\
\text { is enough }\end{array}$ & $\begin{array}{l}\text { Link works, but removed because indeed } \\
\text { reference is enough. }\end{array}$ \\
\hline & & ge & $\begin{array}{l}\text { What I highly appreciate is an } \\
\text { increased emphasis on open science: } \\
\text { it is regularly referenced, and } \\
\text { extends as well to software and } \\
\text { methodology. In that sense, a good } \\
\text { step forward is being made. } \\
\text { Scientists and applications of spatial } \\
\text { data will need more tools and } \\
\text { information to explore the quality of } \\
\text { the data. I further notice that you use } \\
\text { the terms accuracy, precision and } \\
\text { fitness for use. But I am missing the } \\
\text { error (or uncertainty) propagation. } \\
\text { That is for me always the key issue } \\
\text { of SDQ: how to quantify the quality } \\
\text { of the product that is obtained with } \\
\text { publicly available data, modeling } \\
\text { and software, that possibly was } \\
\text { collected/created with other } \\
\text { intentions than those for which it } \\
\text { will be used. I could imagine that } \\
\text { here open science can make a huge } \\
\text { step. An interesting and somewhat } \\
\text { unexplored component in open } \\
\text { science are its dangers and } \\
\text { restrictions - maybe that leads to a } \\
\text { nice and interesting new quality } \\
\text { criterion: the risk of abuse, i.e. } \\
\text { second use or unethical use, of data } \\
\text { (and models and software). }\end{array}$ & & $\begin{array}{l}\text { Appreciate the positive comments and } \\
\text { the great points on i) uncertainty } \\
\text { propagation and ii) how to ensure the } \\
\text { data, software, and information are } \\
\text { being used correctly and ethically, i.e., } \\
\text { the risk of abuse. Both are big } \\
\text { challenges for the community to } \\
\text { address, which may be beyond the } \\
\text { scope of this document. However, } \\
\text { providing quality information } \\
\text { including uncertainty in various } \\
\text { stages/aspects should support efforts } \\
\text { aiming to address either one of those } \\
\text { challenges - whether and how useful } \\
\text { will be a great use case for the } \\
\text { community to develop. We could } \\
\text { include this further research in the } \\
\text { next version of the guidelines. }\end{array}$ \\
\hline 142 & Phrase & ge & $\begin{array}{l}\text { "starts at the planning and designing } \\
\text { stage of a data product after data } \\
\text { collection" is not full data lifecycle }\end{array}$ & $\begin{array}{l}\text { Good QI has to be planned } \\
\text { for, starting before data } \\
\text { collection, e.g. capturing } \\
\text { sensor calibration information }\end{array}$ & $\begin{array}{l}\text { We will not treat this part specifically, } \\
\text { but we expanded further this sentence to } \\
\text { highlight this limitation of the guidelines } \\
\text { and the importance of the pre-data } \\
\text { collection stage for QI. }\end{array}$ \\
\hline 470 & $\begin{array}{l}\text { Section } \\
\text { Heading }\end{array}$ & ge & Section $4 \mathrm{f}$ not in ToC & & Added in ToC. \\
\hline
\end{tabular}




\begin{tabular}{|c|c|c|c|c|c|}
\hline 479 & Phrase & ge & Guideline 1 & $\begin{array}{l}\text { This is simply an elaboration } \\
\text { on FAIR principles, which } \\
\text { are already specified in } \\
\text { several FAIR implementation } \\
\text { guidelines/metrics }\end{array}$ & $\begin{array}{l}\text { Yes, this guideline is about how to } \\
\text { make a dataset findable, accessible } \\
\text { and potentially reusable based on the } \\
\text { existing FAIR implementation } \\
\text { guidelines. }\end{array}$ \\
\hline 503 & Phrase & $\mathrm{Ge}$ & Guideline 2 & $\begin{array}{l}\text { At a high level it should be } \\
\text { possible to create "a } \\
\text { structured quality assessment } \\
\text { model" that is domain } \\
\text { agnostic. It seems like that } \\
\text { should be a goal of this } \\
\text { publication }\end{array}$ & $\begin{array}{l}\text { This guideline recommends using a } \\
\text { structured quality assessment model } \\
\text { and what can be done to ensure the } \\
\text { assessment is searchable and } \\
\text { retrievable. The goal of this document } \\
\text { is not about how to create a quality } \\
\text { assessment model. }\end{array}$ \\
\hline 512 & Phrase & ge & Examples & $\begin{array}{l}\text { If these are good examples, } \\
\text { they should have a DOI }\end{array}$ & $\begin{array}{l}\text { Yes they all have a DOI, as reported in } \\
\text { the reference section. }\end{array}$ \\
\hline 609 & Notes & ge & Guideline 5 & $\begin{array}{l}\text { More should be done to } \\
\text { summarize/synthesize the } \\
\text { best practices for Guideline } 5\end{array}$ & Revised and improved. \\
\hline 637 & Phrase & te & $19115(2014)$ & $19115-1(2014)$ & Fixed. \\
\hline 687 & Phrase & gr & $\begin{array}{l}\text { Community guidelines ... is one step } \\
\text { closer }\end{array}$ & $\begin{array}{l}\text { Community guidelines ... are } \\
\text { one step closer }\end{array}$ & $\begin{array}{l}\text { Implemented in the sentence which is } \\
\text { also rephrased. }\end{array}$ \\
\hline 305 & Phrase & ge & $\begin{array}{l}\text { "Journal editors and reviewers may } \\
\text { refer to the guidelines when } \\
\text { assessing data that are associated } \\
\text { with manuscripts under evaluation } \\
\text { for potential publication" }\end{array}$ & $\begin{array}{l}\text { They would not refer to these } \\
\text { guidelines, but rather to a } \\
\text { community-specific } \\
\text { implementation of DQI as } \\
\text { guided by this doc. }\end{array}$ & $\begin{array}{l}\text { There is no reason why journal editors } \\
\text { and reviewers could not refer to the } \\
\text { guidelines, hence we keep this option on } \\
\text { the list. We also believe that editors and } \\
\text { reviewers would refer to the guidelines } \\
\text { first and then, for more context, to any } \\
\text { available community implementation of } \\
\text { these }\end{array}$ \\
\hline 0 & $\begin{array}{l}\text { Filenam } \\
\mathrm{e}\end{array}$ & ed & "FARI_": Tyро & Change it to "FAIR_". & $\begin{array}{l}\text { Agreed. Filename modified and } \\
\text { uploaded to OSF }(4 / 22 / 2021)\end{array}$ \\
\hline 0 & & ge & $\begin{array}{l}\text { Are you recommending people } \\
\text { should use ISO 19157, or ISO } \\
\text { 19115-1, as the structure for } \\
\text { documenting the data quality? }\end{array}$ & & $\begin{array}{l}\text { ISO } 19157 \text { (soon to be superseded by } \\
19115-1 \text { ) is one of the methods that } \\
\text { people can use to report quality } \\
\text { assessment reports but we are not } \\
\text { endorsing any particular method. }\end{array}$ \\
\hline 0 & & ge & $\begin{array}{l}\text { Are the guidelines only pertaining to } \\
\text { Earth science datasets? }\end{array}$ & & $\begin{array}{l}\text { The guidelines are primarily } \\
\text { developed for the Earth science } \\
\text { community. However, they are } \\
\text { general enough to be readily adopted } \\
\text { to other disciplines. }\end{array}$ \\
\hline 53 & TOC & te & $\begin{array}{l}\text { Missing subsections } 4 \mathrm{f}-\mathrm{h} \text { in the table } \\
\text { of contents }\end{array}$ & $\begin{array}{l}\text { Include subsections } 4 \mathrm{f}-\mathrm{h} \text { in } \\
\text { TOC }\end{array}$ & $\begin{array}{l}\text { Agreed. They are added to the TOC in } \\
\text { the revised version. }\end{array}$ \\
\hline
\end{tabular}




\begin{tabular}{|c|c|c|c|c|c|}
\hline 294 & $\begin{array}{l}\text { Subsecti } \\
\text { on Title }\end{array}$ & ge & Subsection title indent not consistent & $\begin{array}{l}\text { Adjust indent of subsection } \\
\text { title } 3 \mathrm{e} \text {. }\end{array}$ & Agreed. Implemented. \\
\hline 399 & Sentence & ed & possible typo? & $\begin{array}{l}\text { Replace "document" with } \\
\text { "documented". }\end{array}$ & $\begin{array}{l}\text { "document" is the object of } \\
\text { "captured". Added " } a \text { " in front of } \\
\text { "document" to be clear }\end{array}$ \\
\hline 453 & Phase & ed & $\begin{array}{l}\text { should this be referring to } \\
\text { Appendix F (rather than } \\
\text { Appendix E)? }\end{array}$ & $\begin{array}{l}\text { Replace "Appendix E" by } \\
\text { "Appendix F" }\end{array}$ & $\begin{array}{l}\text { Agreed. Implemented in the revised } \\
\text { version. }\end{array}$ \\
\hline 464 & Phase & ge & $\begin{array}{l}\text { "Appendix C" } \\
\text { Text highlighted in red. }\end{array}$ & Change "C" to "C". & $\begin{array}{l}\text { Agreed. Implemented in the revised } \\
\text { version. }\end{array}$ \\
\hline 562 & & te & $\begin{array}{l}\text { reference to "schema.com". Looks } \\
\text { like the wrong link? Or this domain } \\
\text { has been taken over at least because } \\
\text { this redirects to a private company. I } \\
\text { wondered if this was supposed to } \\
\text { reference schema.org but that } \\
\text { doesn't seem right within this } \\
\text { context since you can't mint PIDs } \\
\text { with them. }\end{array}$ & & $\begin{array}{l}\text { Good catch. It should be } \\
\text { "schema.org". Implemented in the } \\
\text { revised version. }\end{array}$ \\
\hline 630 & $\begin{array}{l}\text { Subsecti } \\
\text { on Title }\end{array}$ & ge & Inconsistent subsection title & Bold subsection title $4 \mathrm{~g}$. & Agreed. Implemented. \\
\hline 681 & Sentence & ed & "which in turns": grammar error & Replace "turns" by “turn" & $\begin{array}{l}\text { Agreed. Implemented in the revised } \\
\text { version. }\end{array}$ \\
\hline 715 & Sentence & ed & "helping laying ...": grammar error & Replace "laying" by "lay" & $\begin{array}{l}\text { Agreed. Implemented in the revised } \\
\text { version. }\end{array}$ \\
\hline 716 & Sentence & ed & $\begin{array}{l}\text { "We thanks .." } \\
\text { Grammar error. }\end{array}$ & Replace "thanks" by "thank". & $\begin{array}{l}\text { Agreed. Implemented in the revised } \\
\text { version. }\end{array}$ \\
\hline $\begin{array}{l}459 \\
475\end{array}$ & Word & ed & & $\begin{array}{l}\text { replace "exhausted" with } \\
\text { "exhaustive" }\end{array}$ & $\begin{array}{l}\text { Agreed. Implemented in the revised } \\
\text { version. }\end{array}$ \\
\hline 1258 & $\begin{array}{l}\text { Appendix } \\
\text { F }\end{array}$ & ge & $\begin{array}{l}\text { NVS would be a worthy mention. It } \\
\text { is a large collection of vocabularies } \\
\text { that we use for marine science and } \\
\text { other applications. } \\
\text { http://vocab.nerc.ac.uk/collection/ } \\
\text { (side note: many of these } \\
\text { vocabularies are related and } \\
\text { combined to for complex } \\
\text { descriptions: https://github.com/nvs- } \\
\text { vocabs/P01/blob/master/P01_wheel. } \\
\text { pdf) }\end{array}$ & & $\begin{array}{l}\text { Thanks for the suggestion. It has been } \\
\text { included in the revised version. }\end{array}$ \\
\hline
\end{tabular}




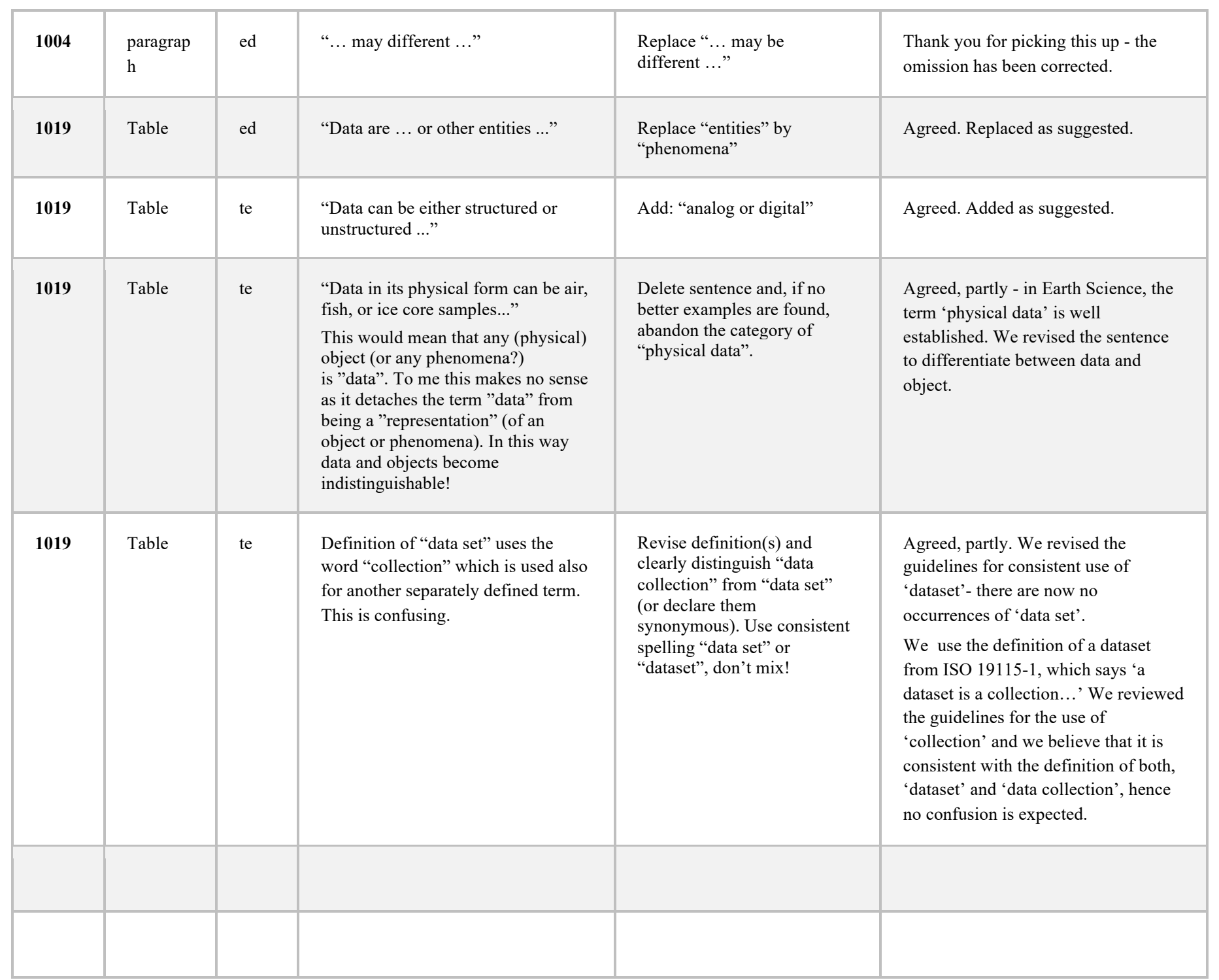

